\title{
4 Übersetzung und Rezeptionslinien
}

\subsection{Kommentierter Überblick: Erstausgaben in Frankreich}

Die internationale Rezeption von Clarice Lispectors Werk intensivierte sich in den Jahren nach ihrem Tod im Winter 1977 insbesondere dadurch, dass in Paris Éditions des femmes ab 1978 die Übersetzung und Publikation fast des gesamten Werks verantwortete, wodurch dem französischen Sprachraum eine besondere Bedeutung für die Übersetzungsgeschichte ihres Werkes zufiel. In den 1980er Jahren wurde ihr Werk durch die französischen Publikationen auch weit über den französischen Kontext hinaus rezipiert, es folgten vermehrt Übersetzungen auch in andere Sprachen.

Die Übersetzungsgeschichte Clarice Lispectors in Frankreich beginnt allerdings sehr viel früher: Bereits im Jahr 1954 war ihr Debutroman ins Französische übersetzt worden - eine Übersetzung, der ebenfalls eine besondere Bedeutung zukommt, weil es sich um die erste Übersetzung einer ihrer Monografien überhaupt handelte. Aus der Phase, als der französische Verlag Plon diese Übersetzung vorbereitete, liegen einige Briefe Clarice Lispectors vor. Insbesondere ein Briefwechsel mit ihren Schwestern sowie mit ihrem Verleger bei Plon zeugen von der großen Frustration, die für Clarice Lispector mit dieser Übersetzung verbunden war. Als sie die französischen Druckfahnen erhielt, die voller Fehler waren, versuchte sie zwar in mehreren Nachtschichten, die Übersetzung zu retten, gelungen ist es ihr nicht: Der Text erschien in einer für sie nicht akzeptablen Form. Diese auch aus heutiger Perspektive verfehlte frühe Übersetzung enthielt in extremer Form Tendenzen, zu denen auch spätere Übersetzer (wenn auch nicht in diesem Ausmaß), mitunter neigten, daher lohnt sich der nähere Blick darauf (vgl. Kapitel 4.1.2). Benjamin Moser nennt eine dieser Tendenzen unter Bezug auf einen Ausspruch Claire Varins „[to] pluck the spines from the cactus“ (Moser 2011: 80): Es geht um eine Tendenz, sehr umfassend zu glätten, auch frei hinzuzufügen und zu ersetzen, wo Clarice Lispectors Sätze von unkonventioneller Grammatik oder Syntax, von ungewohnten Wortschöpfungen geprägt waren. Diese erste Übersetzung bei Plon ist zum einen von Übersetzungsfehlern geprägt, zum anderen von einem sehr weitreichenden Bemühen, den Text in den Kontext der Zielsprache und in die Erzählkonventionen einzufügen, die die französischen Leserinnen und Leser gewöhnt waren:

1954 Près du cœur sauvage. Übersetzt von Denise-Teresa Moutonnier. Paris: Plon.

1970 erscheint, 3 Jahre nach der englischsprachigen Ausgabe desselben Romans bei Alfred A. Knopf, A maçã no escuro in französischer Übersetzung:

Ә Open Access. (c) 2021 Leonie Meyer-Krentler, publiziert von De Gruyter. (c) BY-NC-ND Dieses Werk ist lizenziert unter einer Creative Commons Namensnennung - Nicht-kommerziell - Keine Bearbeitung 4.0 International Lizenz. 
1970. Le bâtisseur de ruines (A maçã no escuro). Übersetzt von Violante do Canto. Paris: Gallimard.

Auch diese Übersetzung ist von Versuchen des Glättens nicht normgerechter Syntax und von Hinzufügungen geprägt (Marting 1993: 98). Es bleibt der einzige Titel Lispectors bei Gallimard. Einige Jahre später bringt der femististische Verlag Éditions des femmes den Roman A paixão segundo G. H. in französischer Übersetzung. Die Übersetzerin ist eine Studentin von Hélène Cixous, der Professorin, die Lispectors Werk im Kontext ihrer Arbeiten zu einer feministischen Literaturwissenschaft bearbeitet. Für viele spätere Lispector-Experten wird dies der erste Text sein, den sie von der Autorin kennenlernen. Im Unterschied zu der GallimardPublikation ist hier eine gewisse Resonanz in Intellektuellenkreisen zu verzeichnen:

1978 La passion selon G.H. Übersetzt von Regina Helena de Oliveira Machado. Paris: Éditions des femmes (Réédition 2014).

Nach Lispectors Tod 1977 kauft Éditions des femmes die Rechte an ihrem Werk. Zum ersten Mal in Lispectors Publikationsgeschichte widmet sich ein Verlag der Herausgabe ihres Werkes in seinem Zusammenhang, in den folgenden Jahren erscheinen zahlreiche Lispector-Texte. Zunächst erscheint der in Frankreich ebenfalls recht bekannt gewordene Text Agua viva:

1980 Agua Viva. Übersetzt von Regina Helena de Oliveira Machado. Paris: Éditions des femmes (Édition bilingue brésilien-français).

Zu Beginn der 1980er Jahre rückt Brasilien in der literarischen Welt Frankreichs erstmals stärker in den Fokus, etwa im Kontext der Buchmesse 1982 in Paris. ${ }^{28}$ Es erscheinen Sondernummern verschiedener Zeitschriften: Magazine Littéraire, Bicéphale, Europe. In dieser Zeit erscheint bei Éditions des femmes eine Neuübersetzung des Debutromans, der 1954 in so katastrophaler Übersetzung bei Plon publiziert worden war.

1982 Près du cœur sauvage. Übersetzt von Regina Helena de Oliveira Machado. Paris: Éditions des femmes (Réédition 1998).

Bei der Arbeit an diesem Text in den Jahren 1981/82 war die Übersetzerin Regina Helena de Oliveira Machado nach Meinung einzelner Expert/innen (insbesondere Claire Varin, vgl. Kapitel 4.1.3) gewissermaßen in das gegenteilige Extrem einer allzu wortgetreuen Übersetzung verfallen, die zwar nicht so erschreckend war wie die Plon-Übersetzung, aber doch zentrale Charakteristika, das ,Irrationale dieses Textes ein weiteres Mal nicht zu transportieren vermochte. Andere - etwa Lúcia Peixoto Cherem (2013) - heben eher die Leistung hervor, in einem französischen Kontext der langen Tradition ethnozentrischer Übersetzungen zu einer deutlich charakteristischeren Übersetzung des Romans gekommen zu sein.

28 Vgl. einen Messebericht von Michi Strausfeld aus Paris: „Paris steht im Zeichen der Entdeckung brasilianischer Literatur“, Messebericht Michi Strausfeld, Oktober 1982, SUA, zitiert nach Einert 2018: 124. 
An den bei Éditions des femmes publizierten Lispector-Übersetzungen lässt sich über einige Jahre hinweg ein regelrechtes Ringen um eine angemessene Übersetzung dieser Autorin ablesen, eine Entwicklung, die mit einer fortlaufenden Übersetzersuche von Seiten des Verlags einherging. In dieser ersten Phase der Übersetzungen bei des femmes wechseln die Übersetzer/innen von Text zu Text:

1984 La Belle et La Bête. Übersetzt von Claude Farny und Sylvie Durastanti. Paris: Éditions des femmes (Réédition 2012).

1985 Où étais-tu pendant la nuit. Übersetzt von Geneviève Leibrich und Nicole Biros. Paris: Éditions des femmes.

1985 L'heure de l'étoile. Übersetzt von Marguerite Wünscher. Paris: Éditions des femmes.

In Frankreich erreichte Clarice Lispector inzwischen bereits ein etwas größeres Publikum beispielsweise wurden neue Lispector-Publikationen seit der Neuübersetzung des Debutromans 1982 regelmäßig in Le Monde besprochen (allerdings mit Ausnahmen, z. B. Le lustre 1990). Man beauftragte nun den erfahrenen Literaturübersetzer Jacques Thiériot, der unter anderem Guimarães Rosa erfolgreich ins Französische übersetzt hatte, mit der Übersetzung eines Lispector-Erzählungsbandes. Er übersetzte die Autorin zusammen mit seiner Frau Teresa Thiériot, u. a. auch einige ihrer Crônicas - journalistische Arbeiten, die hier aber analog zu den anderen Sprachen nicht aufgeführt sind.

1989 Liens de famille. Übersetzt von Teresa und Jacques Thiériot. Paris: Éditions des femmes.

Ab 1989 übersetzt das Übersetzerpaar Thiériot sehr kontinuierlich literarische Texte Lispectors, darunter mehrere Erzählbände:

1990 Le lustre. Übersetzt von Teresa und Jacques Thiériot. Paris: Éditions des femmes.

1991 La ville assiégée. Übersetzt von Teresa und Jacques Thiériot. Paris: Éditions des femmes.

1992 Un apprentissage ou Le livre des plaisirs. Übersetzt von Teresa und Jacques Thiériot. Paris: Éditions des femmes.

1993 Corps séparés. Übersetzt von Teresa und Jacques Thiériot. Paris: Éditions des femmes.

1998 Un souffle de vie. Übersetzt von Teresa und Jacques Thiériot. Paris: Éditions des femmes.

Damit lag ein Großteil des Gesamtwerkes vor. 1990 sowie 2004/5 erschienen jeweils Bände mit Kindergeschichten, 2015/2016 zwei Bände mit Briefwechseln. Ein Band mit 
Briefen (Le Seul Moyen de vivre, 2012) erschien auch in einem anderen französischen Verlag, bei Rivages in Paris.

Analog zur englischsprachigen Gesamtausgabe der Erzählungen, die Benjamin Moser zusammengestellt und in kommentierter Form herausgegeben hat, folgt 2017 auch bei Éditions des femmes eine Gesamtausgabe der Erzählungen auf Französisch, an der acht verschiedene Übersetzer/innen beteiligt sind:

2017. Nouvelles. Hg. Benjamin Moser. Paris: Éditions des femmes.

Zum 100. Geburtstag der Autorin im Jahr 2020 erscheint ein Coffret anniversaire, das neben ihren beiden meistbeachteten Romanen mit einigen Bildern und unveröffentlichten Faksimiles ihrer Manuskripte versehen ist.

2020. La Passion selon G.H., L'Heure de l'étoile. Übersetzt von Paulina Roitman und Didier Lamaison (La Passion selon G.H.), sowie Marguerite Wünscher und Sylvie Durastanti (L'Heure de l'étoile). Paris: Éditions des femmes.

\subsubsection{Wie Lispector übersetzen? Près du cœur sauvage}

Bei seinem Erscheinen 1943 hatte das Debut Perto do coração selvagem der damals 23-jährigen Clarice Lispector in der literarischen Welt Brasiliens für eine Sensation gesorgt. Jurema Finamour schrieb im Rückblick im Jornal de letras im September 1960: „Wir entsinnen uns an kein sensationelleres Debut, das einen Namen, der kurz vorher noch völlig unbekannt war, zu solcher Prominenz erhob“ (zitiert nach Moser 2013a: 164). Die „Sensation“ hing nicht nur mit der Qualität des Textes und dem Alter der Autorin zusammen, sondern auch damit, dass diese Art der Literatur und der tabulosen Schilderung weiblicher Innenwelten völlig neu war, man in Brasilien nichts Vergleichbares kannte. Sérgio Milliet, einer der, wenn nicht der einflussreichste brasilianische Literaturkritiker zum Zeitpunkt des Erscheinens von Lispectors Debutroman, kommentierte das Buch im brasilianischen Kontext als „ernsthaftesten Versuch, den introspektiven Roman zu schreiben“ [...]. Zum ersten Mal dringe ein brasilianischer Autor in die Tiefen der psychologischen Vielschichtigkeit der modernen Seele vor (zitiert nach Moser 2013a: 165).

Was war das Ungewohnte an diesem Debut, das so sehr missverstanden wurde, als Anfang der 1950er Jahre ein französischer Verlag erstmals eine Übersetzung in Auftrag gab? Leserinnen und Leser des Originals haben diesen Text offenbar nicht nur als erfrischend kraftvoll, sondern in manchen Passagen auch als sehr schwer verständlich erlebt, weil er an keinem äußeren Handlungsverlauf orientiert ist, bzw. nur sehr grob. Ihn durchziehen und strukturieren 
Reflexionen über das Gefühlsleben, das Werden eines Mädchens bzw. einer jungen Frau: Joana. Diese Joana, die sich - und andere - zu ergründen sucht, hat eine Gegenspielerin, Lídia, ehemalige Kindheits- und Jugendgefährtin von Joanas Ehemann Otavio. Der Leser erfährt: Otavio verließ Lídia für Joana, fasziniert von der Freiheit, die er mit Joana empfand. „Als hätte er Joana erzählt, was er nur im Dunkeln fühlte. Und das Überraschendste an allem war: als hätte sie zugehört und danach verzeihend gelacht - nicht wie Gott, sondern wie der Teufel - und ihm weit die Tore geöffnet, durch die er gehen konnte." (Lispector 2016: 123). Otavios neu gewonnene Freiheit ist in diesen Passagen sehr präsent. Bald aber beginnt Otavio, in Joanas Gegenwart zu vereinsamen und trifft sich wieder mit Lídia. Als er Ehebruch begeht und seine Jugendfreundin schwängert, plagt Otávio ein starkes Gefühl von Sünde. Joana hingegen verhält sich ganz anders, als er es erwartet und befürchtet hatte. Sie macht ihm keine Vorwürfe, registriert recht nüchtern, was geschieht, und gibt Otavio frei, damit er Lídia heiraten und mit ihr und dem Kind leben kann. Otavio erträgt ihre Reaktion nicht, er wird wütend, beschimpft sie: „Natter!“ Das Schimpfwort hatte ihre Tante bereits für sie geprägt, weil sie sie für bösartig, für nicht richtig zu greifen und zu erziehen hielt. Joanas ,Amoralität‘ hatte sie erschüttert, das, was im Roman als Nähe zum „wilden Herzen“ immer wieder aufgerufen und mit Elementen aus dem Tierreich in Verbindung gebracht wird. Joana wird im Roman mit einer Natter, aber auch mit einem Hund, einem Pferd, einer Wildkatze und einem Vogel verglichen. Wie ein Tier ist sie gewissermaßen jenseits von Gut und Böse.

Sehr markant an diesem Debut ist die Tatsache, dass sich Lispector erzählerisch schon so stark auf einen eigenen Stil konzentrierte und so wenig auf Vorbilder, dass die eigene, in der Selbsterkundung entwickelte Sprache schon so reif war in diesem Debut, und insbesondere, dass sie das Ungeschliffene nicht fürchtete, sondern damit arbeitete. So hält sie sich nicht an die geläufigen Regeln der Grammatik und der Interpunktion, arbeitet sehr fragmentarisch. Ein Vorbild aber ist bei all dem deutlich, das Lispector selbst hinsichtlich ihrer frühen Einflüsse einmal genannt hat: Hesses Steppenwolf (Moser 2013a: 163). Bemerkenswert ist in diesem Kontext, dass von Kritikern nicht Hesse, sondern Joyce als Einfluss sehr häufig ausgemacht worden ist - was wohl einzig daran liegt, dass dessen Portrait des Künstlers als junger Mann das Titelzitat entlehnt ist: „Er war allein. Er war verlassen, glücklich, nahe dem wilden Herzen des Lebens.“ (vgl. Moser 2013a: 163). Clarice hatte Joyce gar nicht gelesen, der diesbezügliche Vorschlag kam von ihrem Freund Lúcio Cardoso - wegen des Titels jedenfalls und wegen der Erzähltechnik der Bewusstseinsströme, die es bei Lispector ebenfalls gibt, ist wohl Joyce so oft für einen entscheidenden Einfluss gehalten worden, auch Virginia Woolf. Gleichzeitig lässt sich mit einigem Recht sagen, dass es nicht viel Literatur gab, die eine Übersetzerin auf die Aufgabe, 
Clarice Lispector zu übersetzen, hätte vorbereiten können. Was für eine solche Übersetzung stattdessen absolut notwendig gewesen wäre, wäre die Einsicht und das Einarbeiten in die Tatsache, dass es hier um eine Autorin mit einer neuen, ganz eigenen, ganz und gar eigenwilligen Sprache ging. Am Beispiel der Übersetzung des Debutromans ins Französische und auch der weiteren Übersetzungsgeschichte der Autorin in Frankreich lässt sich ein Eindruck davon vermitteln, was für einen langen und aufwändigen Prozess es erforderte, bis erste Übersetzungen gelangen, die der Autorin auch nur annähernd gerecht wurden.

\section{Katastrophale Erstübersetzung ins Französische: Plon}

Ein Brief von Clarice Lispector an ihre Schwestern Elisa und Tania vom 10. Mai 1954 erzählt von dem Übersetzungs-Desaster, das sie erlebte, als ihr Debutroman Perto do coraçao selvagem 1954 für den Verlag Plon ins Französische übersetzt wurde. Übersetzerin war Denise-Teresa Moutonnier. Clarice Lispector erzählt ihren Schwestern davon in einem Brief vom 10. Mai 1954, einem Montag. Sie lebt zu dieser Zeit mit ihrem Mann und ihren beiden Söhnen in Washington und ist mit den Vorbereitungen für eine Reise nach Rio de Janeiro beschäftigt. Sie entschuldigt sich bei ihren Schwestern in Rio, dass sie sich wegen des großen Überarbeitungsaufwandes der Übersetzung nicht früher gemeldet habe, und schreibt:

Estou muito atrasada com a correspondência com vocês porque estive muito ocupada. Recebi as provas da traduçao de P.C.S., já em certo tipo de papel que Érico reconheceu como sendo papel definitivo: isto quer dizer, minhas correçoes devem ter ido tarde demais. E foram tantas correçoes que eles teriam que refazer toda a paginaçao etc. etc. Se já chegaram tarde demais, é melhor eu esquecer o caso, se não quiser me aborrecer seriamente. A conselho de Érico, mandei uma carta dizendo que a "tradução era escandalosamente má" etc. que preferia que o livro nunca fosse publicado na França a sair como está, sem correções.

(Lispector 2007: 254)

Érico Verissimo, mit dem sie sich in dieser Sache beraten hatte, war ein brasilianischer Romancier und Essayist, der von 1953 bis 1956 in Washington arbeitete und mit Clarice Lispector in regelmäßigem Kontakt stand. Clarice Lispector schreibt im gleichen Brief, sie habe dem Verleger Beispiele für Übersetzungsfehler geschickt und habe dafür fast zehn Tage gebraucht, „trabalhando muitas vezes até duas e tanto da madrugada, pois fui obrigada até a escrever em francês." (Lispector 2007: 254). Man kann sich vorstellen, wie sehr diese Erfahrung der letztlich nicht zu rettenden, ersten Übersetzung ihrer Arbeit sie beschäftigt haben muss. Sie versucht, ihren Schwestern etwas davon zu vermitteln, indem sie in ihrem Brief einige Beispiele zitiert und kommentiert: 
Para vocês terem uma idéia da traduçao, eis alguns exemplos: em português: "ao fim de alguns instantes, as chamas subitamente reanimadas", foi traduzido: "ao fim de alguns instantes, tudo o que nela o chavama, se acordou" (com certeza a tradutora vendo "chamas" achou que se tratava do verbo chamar). Onde ponho: "o pai estava despenteado", a tradutora põe: "o pai estava sem fôlego". Onde ponho: "ela temia continuar ao lado de Fulana”, a tradutora pôs: "repugnava-lhe estar" etc. Eu escrevi no original: "Fiquei tonta, disse ela". A tradutora traduziu: "Fiquei estúpida, disse ela". (A tradutora deve conhecer melhor o espanhol e tonto em espanhol quer dizer mais ou menos estúpido).

(Lispector 2007: 254)

Die Übersetzung ist, das vermittelt sich hier, voller Übersetzungsfehler, die teils ganz einfach mangelnder Sprachkenntnis der Übersetzerin zuzuschreiben sind. Dass Übersetzerinnen und Übersetzer viel Erfahrung in der Übersetzung spanischsprachiger Texte hatten und dann - oft erstmals - mit einer Lispector-Übersetzung zum Portugiesischen überwechselten, ist in ihrer Übersetzungsgeschichte kein Einzelfall, allerdings ist es später nicht mehr zu so weitreichenden Problemen auf dieser Ebene gekommen. Lispector fährt im Brief an ihre Schwestern mit ihrer Schilderung fort:

Escrevi: com suas olheiras negras ... Ela traduziu: com seus óculos escuros ... O livro está todo assim, e em muitos trechos perde totalmente o sentido.

(Lispector 2007: 254)

Mit diesem letzten Kommentar spricht sie etwas sehr Bedeutungsvolles an: Wenn die Übersetzung gegenüber dem Original bereits auf der Satzebene zu einem Verlust von „sentido”, von Sinn führt, dann ist das besonders gravierend, wenn es sich um Literatur handelt, die aufgrund ihres experimentellen Charakters ohnehin immer wieder dem pauschalen Vorwurf ausgesetzt ist, wenig verständlich zu sein. Ein ähnlicher Effekt, wenn auch nicht so stark, ergibt sich Jahre später bei der Übersetzung eines Lispector-Werkes ins Deutsche durch Christiane Schrübbers für den Lilith-Verlag in Berlin (vgl. Kapitel 4.2.2): Manche Textstellen sind kaum verständlich, die Dramatik ganzer Passagen ist dem Text vollkommen entzogen - aber die für die Publikation zuständigen Verlegerinnen scheinen dies gar nicht bemerkt zu haben. Angesichts der Schilderung innerer Zustände und ohne Kenntnis der Originalsprache ist eine Einschätzung selbstverständlich auch schwieriger als bei fehlerhaften Übersetzungen von Schilderungen äußerer Handlungsverläufe und auch natürlich dann, wenn Verlagsmitarbeiter/innen die Originalsprache beherrschen, was in Lispectors Übersetzungsgeschichte, vom spanischsprachigen Raum einmal abgesehen, so gut wie nie der Fall war. Daraus ergab sich eine Tendenz, die unzureichende Qualität von Übersetzungen, in denen Sinnzusammenhänge verstellt waren, nicht zu bemerken und negative Effekte wie Unverständlichkeit der Autorin selbst zuzuschreiben. 
Clarice Lispector entwickelte bei ihrer mühevollen Arbeit einen regelrecht verzweifelten Humor dem gegenüber, was ihr da widerfahren war:

Uma noite, à meia-noite mais ou menos, eu estava tentando ler e corrigir, quando deparei com uma brutalidade de traduçao, tão forte, tão inesperada, que, sozinha, mesmo, ri a ponto de chorar. Imaginem que escrevi, em má hora, no original: "a boca em forma de muchocho". E sabem como ela, toda emgraçadinha, traduziu? Assim: "la bouche em cul-de-poule”. Que tal? Quando escrevo a palavra "porcaria”, ela traduz por "excrementos”, mesmo quando não é o caso. Sem falar em liberdades engraçadas que ela tomou. Eu escrevo: "a criada" e ela traduz: "a criada preta" - sendo que em nenhum pedaço do livro se fala em nenhum criado negro.

(Lispector 2007: 254-255)

Der letztgenannte Fehler wirft den Verdacht auf, dass die Übersetzerin ganz einfach auch schnell und oberflächlich gearbeitet hat, dass sie sich gewissermaßen mehr in ihrer eigenen Vorstellungswelt bewegt hat als in der von der Autorin entworfenen. In dieses Verhalten mögen auch die mangelnde internationale Reputation der Autorin (in Brasilien war sie ja schon sehr bekannt, aber eben nur dort) gepaart mit schlechten Bezahlungen für Übersetzungen hineingespielt haben. Der Schluss, den Lispector aus all dem zieht:

Emfim, estou procurando passar por cima desse aborrecimento e esquecer. Parece que é tarde demais, que não vão poder fazer nada. Então vou procurar esquecer que o livro foi traduzido.

(Lispector 2007: 255)

Bereits am 6. Mai 1954, also vier Tage, bevor sie den Schwestern von dem Desaster mit der französischen Übersetzung ihres Debuts berichtete, hatte sie den erwähnten Brief an den Verleger Pierre de Lescure bei Plon geschrieben, um ihren Ärger mitzuteilen und ihre eigene Überarbeitung anzukündigen:

Cher Monsieur,

Je viens de lire les épreuves de la traduction de mon livre „Près du Cœur Sauvage” et je m’empresse de vous faire savoir que je ne peux pas consentir que le live soit publié comme il est maintenant. La traduction est scandaleusement mauvaise. Il y a des morceaux qui ne font pas sens du tout. En d'autres, le traducteur interprète mal la pensée de l'auteur. En beaucoup d'autres points, la chose devient même ridicule ...

Je suis en train de faire des corrections qui semblent indispensables, et je vous assure que je veux réellement dire: indispensables."

(zitiert nach einem Abdruck des Briefes im Anhang des Bandes Peixoto Cherem 2013: 287)

Sie schreibt, sie ziehe es vor, dass das Buch nicht in Frankreich publiziert werde, als dass es so erscheine, wie es ihr vorliege. Damit es publizierbar sei, korrigiere sie das, was unverzichtbar dafür sei. Die 26 Textstellen, die Clarice Lispector kurz darauf dann als vollkommen unumgängliche Änderungsnotwendigkeit an Pierre de Lescure schickte, um diese Übersetzung irgendwie zu „retten“, hat die Kanadierin 
Claire Varin in ihrer Doktorarbeit zusammengestellt (Universität Montréal 1986). Varin vergleicht in ihrer Arbeit jeweils (1.) die Originaltextstelle, (2.) die Übersetzung, die Clarice Lispector von Plon 1954 zugeschickt wurde, (3.) die Korrektur, die die Autorin zurück an Plon gesandt hat, (4.) die 1954 von Plon veröffentlichte Version, (5.) die neue Übersetzung im Verlag Éditions des femmes 1982 und (6.) eine 1977 auf Spanisch erschienene Übersetzung (Varin 1986).

In vielen Fällen, so hat Varin gezeigt, wurde die Überarbeitung durch Clarice Lispector bei Plon nicht übernommen, manche Fehler wirkten auch noch auf spätere Übersetzungen, sodass das von Lispector gefürchtete Szenario eintrat: die erste Übersetzung ihres Werkes in eine fremde Sprache verfälschte ihre Arbeit in nachhaltiger Weise.

\section{Vergleich der Übersetzungen Plon/Éditions des femmes: 2 Extreme?}

Nach dem Übersetzungsdesaster bei Plon brauchte es mehr als 30 Jahre, bis der französische Verlag Éditions des femmes eine Neuübersetzung des Debuts publizierte. Diese 1982 in Paris erschienene Übersetzung wurde dem Lispector-Text nach der Meinung mancher Experten wie der Kanadierin Claire Varin wieder nicht gerecht, allerdings mit der entgegengesetzten Tendenz einer allzu wörtlichen Übersetzung, eines allzu sehr dem Brasilianischen verhaftet Bleibens. Sieht man sich Claire Varins Übersetzungskritiken zu diesen beiden Übersetzungen von 1954 und 1982 an, hat man in etwa die Bandbreite dessen vor Augen, womit Clarice Lispectors Texte in der französischen Übersetzung konfrontiert waren. $\mathrm{Zu}$ fragen ist aber auch: Wie ist Varins Kritik an der Neuübersetzung bei des femmes zu sehen, wenn man sie in den Kontext der Konventionen ethnozentrischer Übersetzungen der Zeit in Frankreich stellt? Zu der ersten Übersetzung des Debuts von 1954 schreibt Varin in dem Band Clarice Lispector. A Bio-Bibliography:

This was the first translation in the world of a complete text by CL. It practically annexes the original text and lapses into excessive Frenchness. The ethnocentrism of the translation shows its tendency to neutralize the style and syntax of the author, opting for hyperbole in its choice of words and level of language, and adding many more elements of linguistic precision than even French, a tongue with a taste for clarity, demands. One could underline innumerable cases of subjectivism in this translation, which the author herself judged "scandalously bad". Undeniably this is the least faithful of the French versions of Clarice.

(Marting 1993: 137)

Ethnozentristische Vereinnahmung des Textes, Neutralisierung von Stil und Syntax, Hinzufügen von Elementen zur linguistischen Präzisierung - all dies sind Verfahrensweisen, mit denen auch spätere Übersetzer gearbeitet haben. 2013 hat der Übersetzer Luis Ruby in seinem Nachwort zu Clarice Lispectors zweitem Roman 
Der Lüster eindringlich auf die Notwendigkeit hingewiesen, „das nicht zu glätten, was ,seltsam“ ist und bleiben soll“, was bedeutet, dass im Übersetzungsprozess forlaufend sehr feinsinnig zwischen gewollten, im Text angelegten „Seltsamkeiten“ und ungewollten Effekten des Seltsamen unterschieden werden muss, die erst beim Übersetzen entstehen (Ruby 2013: 364). Ein solches Bewusstsein war jedoch nicht von Beginn an vorhanden. Das französische Beispiel zeigt, welch langer Weg es war, bis Übersetzer/innen Möglichkeiten fanden, über die Versuche des Glättens und Anpassens an etwas, das Clarice Lispector nicht mehr entsprach, hinauszukommen und zu angemesseneren Übersetzungen zu finden.

Die Übersetzerin Regina Helena de Oliveira Machado verfiel zunächst in das andere Extrem einer allzu großen Nähe zum Originaltext, als sie das in der ersten Übersetzung 1954 erschienene Debut Clarice Lispectors 1981/82 neu ins Französische übersetzte - zu einem Zeitpunkt, als Brasilien in der literarischen Welt Frankreichs langsam in den Fokus rückte, insbesondere im Kontext der Buchmesse 1982 in Paris. Claire Varin schreibt über diese Übersetzung: „It demonstrates an excessive faithfulness to the original text, more reasonably so because french does not appear to be the native language of the translator" (Marting 1993: 137).

In Frankreich, das spricht aus diesen Worten, war es nicht leicht, überhaupt fähige Literaturübersetzer/innen aus dem Portugiesischen zu finden, was die Möglichkeiten für gute Übersetzungen zu dieser Zeit eines aufflammenden Interesses an brasilianischen Autor/innen natürlich massiv erschwerte. Ähnlich war die Situation in Deutschland, wo die schwierige Übersetzersuche für Autor/ innen aus Lateinamerika und noch einmal mehr aus Brasilien im Deutschen Literaturarchiv in Marbach vergleichsweise gut rekonstruierbar ist. Die Suhrkamp-Lektorin Maria Dessauer schrieb in diesem Zusammenhang 1979 an Michi Strausfeld, die den Verlag hinsichtlich lateinamerikanischer Literatur beriet: „Bei einer Übersetzung aus Lateinamerika oder Katalanien, jedenfalls einer uns recht fremden Fremdsprache, muß gelten: So genau wie möglich, so frei wie nötig, während es ja bei Übersetzungen aus dem Englischen und Französischen gewöhnlich umgekehrt ist: So frei wie möglich, so genau wie - leider - nötig. “29 Diesem Ansatz entspricht in etwa die Neuübersetzung von 1982 ins Französische: „So genau wie möglich“. Auch wenn man die Beschränkungen bedauern mag, die lateinamerikanischen Autoren durch eine solche Verlagspolitik auferlegt wurden, zeigt sich hier doch auch ein gewisses Problembewusstsein, das durchaus nicht selbstverständlich war. Julio Cortázar, dessen Literatur - wenngleich aus anderen Gründen - für

29 Maria Dessauer in einem Brief an Michi Strausfeld, 15.05.1979, SUA, zitiert nach Einert 2018: 111. 
die französische Übersetzung in diesen Jahren ähnlich herausfordernd war wie Clarice Lispectors, vermisste ein Problembewusstsein bei seinen französischen Verlegern, wie seine Briefe aus dieser Zeit bezeugen. Cortázar arbeitete in mehreren Sprachen (Französisch, Englisch, Italienisch) sehr eng mit seinen Übersetzern zusammen, um ein Verständnis für seine Literatur auch in anderen Sprachräumen zu erreichen, und beklagte sich in einem Brief an seinen ersten französischen Übersetzer Jean Bernabé vom 8. Mai 1957 über ein entmutigendes Erlebnis mit dem französischen Verlag Gallimard, wo er versuchte, dessen Übersetzung von Bestiario zu veröffentlichen:

Creo haberle dicho en mi carta anterior [...] que le llevé Bestiaire a Caillois. Me lo devolvió diciéndome que las traducciones le parecían, demasiado apegadas al original' (sic). Cuando le pedí que me aclarara lo que quería decir, sostuvo que usted había sido ,demasiado fiel' en algunas cosas, alejándose del francés para mantenerse más cerca del giro español, del ritmo de la frase, etc. [...]; evidentemente la gente como Caillois considera que el autor no interesa gran cosa: lo único que cuenta es salvar a toda costa el GRRRAANNN estilo francés, la manera francesa de decir las cosas ... aun a riesgo de cualquier traición.

(Cortázar 2012b: 125)

Die von Varin so genannte „excessive faithfulness“, die man lateinamerikanischen Autoren bei Suhrkamp offenbar häufiger entgegenbrachte als Autoren aus „bekannteren“ Sprachräumen, wurde von mehreren französischen Verlagen in diesen Jahren bewusst abgelehnt. Insofern kann man es auch ein Stück weit als Verdienst sehen, wenn die Arbeit der Übersetzerin Regina Helena de Oliveira Machado an der Übertragung von Lispectors Debut ins Französische sehr am Original orientiert bleibt, allerdings gelingt die ,nötige Freiheit' laut Varin nicht recht: „If this version completely respects the author's images and unusual syntax, it shows a certain lack of understanding of the subtleties of the target language, manifesting as calques, grammatical errors, dissonances, etc.“ (Marting 1993: 137).

Der Fall der fehlerhaften Übersetzung des Debutromans für Plon, die sich in ihrem Charakter völlig vom Original unterscheidet und ohne Rücksicht auf die Ästhetik der Autorin für das Französische zurechtgestutzt wurde, und der nachfolgenden, in ihrer Problematik ins andere Extrem gehenden Neuübersetzung bei Éditions des femmes - dieser Fall ist sicherlich besonders extrem, aber auch richtungsweisend für Übersetzungsprobleme, mit denen Clarice Lispectors Werk immer wieder konfrontiert sein sollte.

\section{Übersetzungs-Extrem 1: ,Freier als möglich“}

Über die 1954 bei Plon erschienene Übersetzung Près du cœur sauvage urteilt Lúcia Peixoto Cherem zusammenfassend wie folgt: 
Temos a sensação de que a originalidade da escritora brasileira perde-se para estar conforme a um estilo corrente, limpio, confortável. A tradutora transforma Clarice em uma autora convencional e sua escrita aparece varias veces banalizada pelo emprego de clichês, imagens prontas da língua francesa, quando não era o caso no texto em português.

(Peixoto Cherem 2013: 158)

Die Übersetzerin hat dabei nicht nur klischeehafte Bilder eingefügt, sondern auch wichtige Passagen einfach herausgenommen (Peixoto Cherem 2013: 157). Das Bemühen der Übersetzerin, das darin gelegen haben mag, den Text ,literarischer klingen zu lassen, ihn an Konventionen anzupassen, die sie für gültig hielt, hat das Gegenteil bewirkt: Durch diesen Text konnte keine Leserin, kein Leser einen Zugang zu der Literatur, der ganz eigenen Stimme Clarice Lispectors finden. Dementsprechend blieb die Resonanz auf diese Publikation sehr gering. Lispector schickte man zwar zwei Besprechungen, die in Frankreich erschienen waren. Offenbar verkaufte sich der Text aber kaum und wurde in Frankreich auch von Experten nicht wahrgenommen, wie es später mit der Veröffentlichung der neuerlichen Übersetzung bei Éditions des femmes der Fall sein sollte: „Aparentemente, a primeira tradução do romance passa despercebida pela crítica na França“ (Marting 1993: 167).

Wie muss man sich diese erste, so misslungene wie richtungsweisende Übersetzung nun genau vorstellen? Lúcia Peixoto Cherem hat sich im Detail damit auseinandergesetzt, wie das Unverständliche und Fehlerhafte der Plon-Übersetzung zustande kommt. Um einen Eindruck der Fehler zu vermitteln, deren Korrektur Lispector verlangte, ohne dass ihre Bitte für die Plon-Publikation berücksichtigt wurde, seien einzelne Beispiele herausgegriffen. Einmal wird „um monte“ als „une bosse“ übersetzt (vgl. Peixoto Cherem 2013: 155) - ein Übersetzungsfehler, der an die von Clarice Lispector bemängelte Fehlübersetzung erinnert, bei der die Bedeutung des Substantivs „as chamas“ mit dem Verb „chamar“ verwechselt wurde. Es handelt sich um Fehler, die die Aussage völlig verändern.

In ihrer Analyse der französischen Übersetzungen verweist Peixoto Cherem weiterhin auf ein nicht weniger gewichtiges Problemfeld für die Übersetzung, das entsteht, wenn Übersetzer/innen Lispectors ästhetische Eigenheiten nicht respektieren. Man meint mitunter: Sie kennen die Schreibweise von Lispector nicht, es gibt keinen produktiven Umgang mit den Besonderheiten ihres Stils. Hier mag man trotz der großen Unterschiede, was das Verhältnis der Autor/innen zu ihren Texten und zu Übersetzungen derselben angeht, erneut an Julio Cortázar erinnert sein, der sich mit diesem Phänomen in dem Text „Musicalidad y humor en la literatura“ seiner Clases de literatura, Berkeley 1980 befasste und schrieb, es könne sogar eine inhaltlich völlig korrekte Übersetzung geben, die einem Text nicht gerecht werde (Cortázar 2016: 154). Cortázars Bild der „pulsación“, des Pulsschlags, scheint hier besonders hilfreich zu sein, um Übersetzungsprobleme auch 
bei Lispector besser zu verstehen. Cortázar hatte geschrieben, eine Übersetzung könne zwar korrekt sein („exactamente lo mismo en el plano de la prosa, como transmisión de un mensaje“), aber dennoch unzulänglich: „pero le falta esa aura, esa luz, ese sonido profundo que no es un sonido auditivo sino un sonido interior que viene con ciertas maneras de escribir prosa en español“ (Cortázar 2016: 154). Wenn man nun dieses Bild überträgt, so gibt es bei der Lispector-Übersetzung Probleme auf beiden Ebenen: die „transmisión de un mensaje“ funktioniert nicht gut, aber auch der sonido, o som, der Sound des Textes vermittelt sich nicht. Peixoto Cherem schreibt dementsprechend über die Übersetzung von Denise-Teresa Moutonnier für Plon: „Em primeiro lugar, a tradutora não respeita o ritmo da autora brasileira, não está atenta à respiração desse seu primeiro texto. $\mathrm{O}$ texto frances perde em fluidez: a tradutora modifica várias vezes a pontuação de Clarice [...]“ (Peixoto Cherem 2013: 156).

Im Original heißt es an einer Stelle:

Eu estava então sozinha? E essa alegria de dor, o aço franzindo minha pele, esse frio que é ciúme, não, esse frio que é assim: ah, andaste tudo isso? pois tens que voltar.

(Lispector 1980a: 156)

Im Französischen geht das Subtile an Joanas Gedankengang völlig verloren:

J'étais donc seule alors? Et ce plaisir de la douleur, cet acier qui fait frémir ma peau, ce froid de la jalousie, ah, ce froid! Ah! tu es allé si loin! Mais il te faut revenir.

(Lispector 1954: 179, vgl. Peixoto Cherem 2013: 156)

Eine weitere Tendenz, auf die Peixoto Cherem ebenfalls verweist, ist der Umgang mit Wiederholungen im Originaltext - ein wichtiges Stilmittel, das die Übersetzerin immer wieder eliminiert:

Os labios grandes de Lídia, de linhas vagarosas, tão bem pintados de claro, enquanto eu de batom escuro, sempre escarlate, escarlate, escarlate, o rostro branco e magro.

(Lispector 1980a: 153)

Diese Textstelle wird in der Übersetzung zu:

Les grandes lèvres de Lidia, aux formes douces, maquillées de clair, alors que moi j'emploie un rouge sombre, éclarate.

(Lispector 1954: 175; vgl. Peixoto Cherem 2013: 156)

Lúcia Peixoto Cherem schreibt, durch solche Eingriffe wirkten viele Textpassagen, die einen Einblick in Joanas Perspektive bieten, im Französischen weniger intuitiv, rationaler. Eine weitere ihrer Beobachtungen an den konkreten Textstellen ist in diesem Kontext erwähnenswert. Sie schreibt: „Se as reflexões de Joana precisam das reticências para guardar o sensação de vagueza em que a 
personagem se encontra, a Joana do texto francês tem um pensamento mais acabado, menos ambíguo“ (Peixoto Cherem 1993: 157).

Ein Beispiel illustiert diese Tendenz: ${ }^{30}$

Vejam os olhos daquela mulher ... redondos, transparentes, tremem, tremem, de um instante para outro podem cair numa gota d‘água ...

(Lispector 1980a: 155)

Regardez les yeux de cette femme, tout ronds et transparents, ils tremblotent, d'un instant à l'autre ils peuvent tomber comme une goutte d'eau.

(Lispector 1954: 177)

Sicher ist es hilfreich, mit Lúcia Peixoto Cherem nicht nur die Plon-Übersetzung, sondern auch Regina Helena de Oliveira Machados Übersetzungsleistung vor dem Hintergrund der Konventionen der französischen Übersetzungspraxis der Zeit zu sehen. In seinem 1995 erschienenen Werk Traduction et culture beschreibt Jean-Luis Coordonier die seit dem 15./16. Jahrhundert tradierte Übersetzungskunst in Frankreich als stark und auch zu Zeiten der Republik ungebrochen ethnozentrisch. Er verweist dabei auf Antoine Bermans Essays zur Übersetzung in Frankreich: „En France, le mode de traduir qui est traditionellement ethnocentrique et qui est toujours vivace aujourd'hui, a des origines dans ces événements qui montrent l'imbrication du politique et du culturel. La langue française a été «langue royale, langue régie» (Berman 1985: 211). Et la traduction aussi: commande du prince“ (Coordonier 1995: 9). Auch Claire Varin kommentiert diese französische Übersetzungstradition kritisch, gerade im Hinblick auf lateinamerikanische Literaturen:

A l'instar d'une part importante des traductions d'œuvres sud-américaines réalisées en France, on tend à expliquer le texte par des périphrases; à éclaircir par l'ajout de marques de précision (démonstratifs, adverbes, etc.) en nombre bien plus élevé que ne l'exige la langue française friande de netteté; à y mettre de l'ordre, en effaçant les répétitions, ellipses et inversions ou en découpant phrases et paragraphes; à les embellir par des expressions littéraires [...].

(Varin 1990: 41)

Bei Übersetzungen Clarice Lispectors, so lässt sich zusammenfassend sagen, hatte dieser Ethnozentrismus, diese Eingenommenheit von der eigenen Kultur und Sprache bei wenig Beschäftigung mit den Eigenheiten ,fremder` Autoren und ihrer Texte besonders gravierende Auswirkungen.

30 Eine ähnliche Praxis lässt sich auch in der deutschen Erstübersetzung Die Passion nach G.H. für den Frauenbuchverlag Lilith in Berlin nachweisen, vgl. Kapitel 4.2.2. 


\section{Übersetzungs-Extrem 2: Zu nah am Originaltext}

Auch die Neuübersetzung des Romans ins Französische für Éditions des femmes von 1982 ist so wegweisend für spätere Übersetzungen, dass ein genauerer Blick darauf lohnt. Von einzelnen Experten ist auch diese Übersetzung stark kritisiert worden. Wichtige Eigenheiten des Textes seien nicht in den Zielkontext überführt worden, es gäbe - um noch einmal mit der Bemerkung von Maria Dessauer zu sprechen - keine Freiheit der Übersetzung, sie füge sich nicht ins Französische ein. Es ist sehr aufschlussreich, die kontroversen Einschätzungen dazu einmal zusammenzubringen:

Claire Varin bewertet die neue Übersetzung bei Éditions des femmes zwar positiver als die Plon-Übersetzung, sieht sie aber ebenfalls problematisch. Sie sieht in ihr das andere Extrem: Hier habe sich jemand, so kann man ihren bereits zitierten Kommentar verstehen, fast sklavisch an das Original gehalten, hier sei eine Brasilianerin am Werk, die wiederum im Französischen vergleichsweise wenig zu Hause sei, wenngleich sie die Charakteristiken von Lispectors Sprache zunächst einmal respektiere: „If this version completely respects the author's images and unusual syntax, it shows a certain lack of understanding of the subtleties of the target language, manifesting as calques, grammatical errors, dissonances, etc.“ (Marting 1993: 137). Die Übersetzerin, die die Übersetzung für Éditions des femmes erstellte, war Studentin von Hélène Cixous, eine Brasilianerin, die zunächst Texte für Cixous' Seminare übersetzt hatte - damit Hélène Cixous sie lesen konnte, und auch die anderen Student/innen, die in der Regel kein Portugiesisch sprachen. Bedenkt man die Wirkungsmacht von Cixous' Rezeption, dann muss immer auch darauf verwiesen werden, dass zunächst Übersetzungen die Grundlage für ihre Rezeption lieferten, keine Originaltexte.

Peixoto Cherem bewertet die Übersetzung des Debutromans durch Regina Helena de Oliveira Machado positiver als Varin, vor allem, weil sie sie in den Kontext ethnozentrischer Übersetzungen in Frankreich stellt und gewissermaßen die Abweichungen Oliveira Machados von dieser gängigen Praxis wertschätzt. Tatsächlich tritt das Mündliche, das oftmal als ,unfertig' Wahrgenommene, das, so weit sich das so allgemein sagen lässt, für Lispectors Stil Charakteristische beider des femmes- Übersetzung wieder stärker hervor, der Text ist näher am ,sonido intimo' des Originals. Insgesamt beschreibt Peixoto Cherem in ihrer Arbeit ein Bemühen im Verlag des femmes um angemessene, von Publikation zu Publikation besser werdende Lispector-Übersetzungen, das gleichzeitig von den Schwierigkeiten eines solchen Unterfangens erzählt. Eine Studentin, die ganz aus dem akademischen Milieu kam, mit einer Literaturübersetzung für einen Publikumsverlag zu beauftragen, sei zunächst einmal ungewöhnlich, so Peixoto Cherems Einschätzung, aber man habe bei des femmes das Potential dieser Übersetzerin 
erkannt, das insbesondere darin lag, dem Leser etwas von dem ganz Eigenen, Charakteristischen an Lispectors Stil und Sprache nahezubringen, das in der ersten Übersetzung bei Plon verlorengegangen war. Im Kontext der Übersetzungskonventionen zu dieser Zeit in Frankreich und unter Einbezug von Detailanalysen $z u$ konkreten Übersetzungen wird deutlich, dass es ein einfaches Urteil zu der neuerlichen Übersetzung des Debutromans von 1982 nicht gibt. Vielmehr muss er als Element in einem langen Prozess des Ringens um eine angemessene Übersetzung für Clarice Lispector in Frankreich verstanden werden. $\mathrm{Zu}$ Recht hebt Peixoto Cherem also auch die Leistung von Regina Helena de Oliveira Machado heraus, die sich einiger in Frankreich sehr üblichen, sehr gut eingespielten Tendenzen entzog, indem sie sehr nah am brasilianischen Text übersetzte. ${ }^{31}$ Sie umgeht damit Tendenzen der Vermeidung von Wiederholungen, sie findet Entsprechungen für das von Lispector viel eingesetzte brasilianische Gerundium (vgl. Peixoto Cherem 1993: 167), sie passt Lispectors Sprache nicht, wie einige der anderen französischen Übersetzerinnen und Übersetzer, einem gehobenen französischen Register an, sie erklärt oder füllt keine Ellipsen des Originaltextes, sie ist näher an der gesprochenen Sprache, die Lispector in ihrem Debut einsetzt, um Gedanken oder innere Zustände wiederzugeben. Auch wenn sie manchmal, dies räumt auch Peixoto Cherem ein, über das Ziel hinausschießt in ihrem Bemühen, Lispectors Text, seine spezifische Grammatik und Syntax, seinen - manchmal fließenden, dann wieder stolpernden - Rhythmus ,intakt‘ zu halten: „exagera em alguns momentos ao apresentar um francês às veces muito aportuguesado, dificultando a compreensão do público-leitor“ (Peixoto Cherem 2013: 169).

\subsubsection{Das lange Ringen um eine angemessene Übersetzung}

Lúcia Peixoto Cherem kommt zu dem Schluss, dass sich der französische Verlag über einige Jahre hinweg bemüht hat, zu angemessenen Übersetzungen $\mathrm{zu}$ kommen und den Problemen der jeweiligen Neuerscheinungen in der darauffolgenden Übersetzung, mit der nächsten Übersetzerwahl entgegenzusteuern. Als Lispector bereits einen größeren Leserkreis erreichte, beauftragte man nicht mehr Regina de Oliveira Machado, sondern den Literaturübersetzer Jacques Thiériot und seine brasilianische Frau Teresa Thiériot mit der Übersetzung weiterer Werke von Lispector bei des femmes. Teilweise hätten diese Übersetzungen eine neue Qualität in das ,Lispector'sche Französisch` gebracht, so Peixoto Cherem. Andererseits bewertet

31 Éditions des femmes publizierte zwei Übersetzungen aus der Feder von Regina Helena de Oliveira Machado: ihre Übersetzungen von Perto do coração selvagem und Água viva. 
sie in einem Textvergleich zweier Übersetzungen einer der Crônicas Clarice Lispectors - ein Vergleich einer nicht publizierten Übersetzung von Regina Helena de Oliveira Machado mit einer publizierten Übersetzung von Jaques und Teresa Thiériot - manche Entscheidungen de Oliveira Machados als treffender (vgl. Peixoto Cherem 2013: 183-190). Man ,testete‘ gewissermaßen im Verlag als Übersetzer sowohl französische als auch brasilianische Muttersprachler/innen, um zu einer gangbaren Übersetzungspraxis für Clarice Lispector zu kommen: Es war nicht einfach, eine angemessene Übersetzung aus dem brasilianischen Portugiesisch ins Französische zu finden, zumal für eine Autorin, die die Suche nach dem Selbst als mäandernde Suche nach dem sprachlichen Ausdruck inszeniert, der es darum geht, hinter sprachlichen Konventionen und ungeachtet grammatikalischer Regeln, jenseits auch vorgeprägter literarischer Genres zu etwas anderem, ,Eigentlichen' vorzudringen. Gerade durch die Arbeit von Regina de Oliveira Machado war deutlich geworden, dass der Respekt vor den Eigenheiten der Sprache Lispectors unverzichtbar war, was auch bedeutete, mit Regeln der französischen Syntax zu brechen, ohne - wie es Regina de Oliveira Machado unterlaufen war - ein im Französischen allzu sperriges Resultat zu erzielen.

Eine Detailanalyse der späteren französischen Übersetzung von Clarice Lispectors Text $A$ hora da estrela der Übersetzerin Marguerite Wünscher hat gezeigt, dass diese zwar viele der vorgenannten Übersetzungsfehler nicht mehr begeht, allerdings eine starke Tendenz zeigt, Paraphrasen zu Textstellen einzufügen, die Lispector im brasilianischen Original im Ambivalenten verortet, die Lispector nicht erklärt, im Dunkeln lässt (vgl. Peixoto Cherem 2013: 176-183). Über solche Passagen hinaus gibt es Textstellen, deren Aussage komplett verändert wurde in der Übersetzung. Peixoto Cherem spricht bei Wünscher von ,casos de reformulação“ (Peixoto Cherem 2013: 182). Sehr relevant sind auch die Übersetzungen des genannten französisch-brasilianischen Übersetzerpaars Jacques und Teresa Thiériot, die vom Verlag Éditions des femmes zu einem Zeitpunkt engagiert wurden, als Lispector bereits eine breitere Leserschicht in Frankreich hatte, gerade im feministischen Umfeld, und es vor allem auch darum ging, ihre Texte einem breiteren Publikum zu vermitteln (nicht nur dem akademischen, so wie es Regina Machados Zielgruppe zunächst ja gewesen war). Jacques Thiériot war bereits ein erfahrener Übersetzer, er hatte für Éditions du Seuil bereits Guimarães Rosas Tutaméia übersetzt (1994), mit sehr guter Resonanz. 1995 erschien in der Übersetzung des Paars eine Sammlung von Crônicas: La découverte du monde, die Clarice Lispector zwischen 1967 und 1973 für das Jornal do Brasil geschrieben hatte und die teilweise Querverbindungen zu Themen und Arbeitsprozessen an den Romanen und Erzählungen aufweisen, mit denen Lispector zeitgleich beschäftigt war. In einem Vergleich einer frühen, nicht publizierten Übersetzung einer der Crônicas von Regina de Oliveira Machado für Cixous' Seminar mit der 
bei Éditions des femmes 1995 publizierten Version von J. und T. Thiériot lässt sich sehr eindrucksvoll ein weiterer Mosaikstein zu diesem Übersetzungsprozess hinzufügen (Peixoto Cherem 2013: 183-190). Es handelt sich bei der Übersetzung von J. und T. Thiériot um eine sehr sorgfältige Übersetzung, bei der sich allerdings bestimmte Tendenzen weiterhin nachweisen lassen:

(1) Die Tendenz, Gerundium-Konstruktionen zu eliminieren, wobei sie teilweise auch umgesetzt werden, etwa mit „en train de“-Konstruktionen.

(2) Herausnahme von Wiederholungen, die im Originaltext stilprägend sind, durch Variationen, teilweise insbesondere durch Begrifflichkeiten aus höheren Sprachregistern (der bereits angesprochene, vermeintliche Literarisierungs-Effekt).

(3) Etwas Sinnliches, vergleichsweise Konkretes wird in der Übersetzung abstrakter $^{32}$, wie das Beispiel der Übersetzung des Begriffs „carinho“33 im Sinne von Lispectors „carinho por Deus“ in der Crônica „Perdoando Deus“ (Pour pardonner à Dieu) zeigt: Die „tendresse“ ${ }^{\text {34 }}$ im Text der Thiériots hat viel von dem konkreten, im religiösen Kontext erst einmal ungewohnten Charakter der „caresses“35 Regina Machados eingebüßt (vgl. Peixoto Cherem 2013: 188). Die Thiériots distanzieren Lispector von Gott, so kommentiert Peixoto Cherem, sie machen das „fazer carinho“, etwas durchaus Konkretes, Körperliches, zu einem „testimoniar minha ternura“ - gerade die Rückübersetzung zeigt den Verfremdungseffekt (vgl. Peixoto Cherem 2013: 188-189).

(4) Noch immer sind hier die erklärenden Paraphrasen zu finden, die für viele französische Lispector-Übersetzer/innen offenbar unverzichtbar waren.

Über die Grunderfahrung anhand der französischen Übersetzungen zu Clarice Lispectors Werk der 1950er bis 1980er Jahre resümmiert Claire Varin:

On francise le texte brésilien. On dédaigne d'inscrire la motion de la langue portugaise en français et les aspérités de C.L., rude dans sa propre langue d'écriture. On lisse, on aplanit, plus ou moins gravement. Et ce, à la dérobée, car le lecteur ne sait souvent rien de cette operation, puisque la majorité des traductions semblent composées en «bon français».

(Varin 1990: 41)

32 Dieser Effekt spielte auch für Übersetzungen ins Deutsche eine wesentliche Rolle, wie der Vergleich der Übersetzungen für die Verlage Lilith und Suhrkamp zeigt bzw. die Bearbeitung der Übersetzung Die Passion nach G.H. durch Sarita Brandt, die solche Stellen oftmals wieder konkretisiert hat. Vgl. Kapitel 4.2.2.

33 „Ser-Lhe-ia aceitável a intimidade com que eu fazia carinho.“

34 „Il jugerait acceptable l'intimité dans laquelle je luis témoignais ma tendresse.“

35 „Lui serait acceptable l’intimité avec laquelle je faisais des caresses.“ 
Es kann nicht oft genug betont werden, welche Rolle es spielte, dass das Portugiesische in den neuen Rezeptionskontexten von Übersetzungen so wenig verbreitet war. Das ungewohnt Klingende fiel in den Verlagen schnell unangenehm auf, während Anpassungsversuche an französische Konventionen der Zielsprache, etwa an den von Cortázar so verhassten „GRRRAANNN estilo francés“ (Cortázar 2012b: 125) von Lesern unbemerkt blieben. Dabei mag es nicht überraschen, dass für eine Autorin, die sich im Verlauf ihres literarischen Werks so sehr der Suche nach einer Sprache verschrieb und dabei Neuerungen schuf, die Irritation provozierten, die ihr Werk in ein Reibungsverhältnis zum Bestehenden und Regelhaften versetzten, dass für eine solche Autorin auch eine angemessene Übersetzung erst gesucht werden musste. Man könnte auch anders sagen: die sprachlichen Elemente, die dieses zentrale Lispector'sche Thema der Suche transportieren, haben im Prozess der erstmaligen Übersetzung in eine fremde Sprache nur mittels einer letztlich jahrzehntelangen Suche geeignete Entsprechungen gefunden. So wenig überraschend dies sein mag, wenn man länger darüber nachdenkt, so eindrucksvoll ist es doch auch, wie deutlich sich diese Suche in die französische Übersetzungsgeschichte eingeschrieben hat. Eine Suche, die sich anhand der verschiedenen Übersetzungen, anhand der Arbeit verschiedener Übersetzerinnen und Übersetzer als Prozess dokumentieren lässt. Der französischen Übersetzungspraxis kommt damit als Mittlerkontext von Lispectors Werk nach Europa und US-Amerika und mit der frühen Übersetzung ihres Debuts in Frankreich eine herausragende Rolle zu.

\subsubsection{Netzwerkbildung in Frankreich}

Sowohl Hélène Cixous als auch Claire Varin haben die spezifische „pesquisa da linguagem interior“ (Peixoto Cherem 2013: 43) bei Clarice Lispector als deren großen Beitrag zur Weltliteratur gesehen. So kann man aus den Recherchen von Lúcia Peixoto Cherem schließen, die sich insbesondere auf die Zeit Ende der 1970er Jahre beziehen, als die brasilianische Autorin erstmals international breiter wahrgenommen wurde. Sie macht eine im Kontext dieser Arbeit sehr wertvolle Beobachtung:

Não se tratou apenas de uma descoberta intelectual instigadora para acadêmicos: parecenos que as duas sucumbiram a uma linguagem movediça, capaz de carregá-las para um espaço que já lhes era familiar. Porém, era a primeira vez que viam esse espaço transformado em palavras. As experiências vividas eram semelhantes, mas a experiência com a linguagem que Clarice apresentava, pareceu-lhes única.

(Peixoto Cherem 2013: 43) 
Wie kam es zu dieser Entdeckung, diesem Erweckungserlebnis? Die Verlegerin Antoinette Fouque (Éditions des femmes), die Lispector in Frankreich und auch international zu einem Durchbruch verhalf, erzählte 2012 in einem Interview, wie sie überhaupt auf Clarice Lispector gestoßen sei. Sie habe eine Möglichkeit schaffen wollen, militante Texte zu veröffentlichen, Zeugnisse eines weltweiten Kampfes. Sie habe daher eine Reihe geschaffen („mulheres em luta em todos os países“, vgl. Peixoto Cherem 2013: 267), um politische und verlegerische Aktivitäten zu verzahnen. Sie sei in diesen Jahren - sie spricht von der Zeit seit 1974 regelrecht um die ganze Welt gereist, um die in diesem Kampf befindlichen Frauen, die teilweise auch inhaftiert waren oder mit sonstigen Beschränkungen ihrer Reisefreiheit zu tun hatten, zu treffen. Im Mai 1974 habe sie zum ersten Mal von Clarice Lispector gehört, als sie bei einer Eröffnungsfeier Ruth Escobar getroffen habe, eine in der Theaterszene in São Paulo sehr einflussreiche Figur, die für die Widerstandsbewegung gegen die brasilanische Diktatur zentral war. Zur gleichen Zeit habe eine der Lektorinnen im Verlag die französische Ausgabe von A Maçã no Escuro gelesen - der Text war ja in Folge der Knopf-Publikation in den USA 1970 ebenfalls bei Gallimard erschienen - den sie ganz hervorragend gefunden habe.

Kurz darauf sei der Verlag als einziger französischer Verlag zum ersten Festival Internacional do Livro nach São Paulo gereist, der Stand habe sich zu einem Ort des politischen und literarischen Austauschs im Sinne des Widerstands entwickelt, man sei etwa zu geheimen Treffen von Frauen-Widerstandsgruppen eingeladen worden. Für sie selbst sei es gleichzeitig eine Gelegenheit gewesen, eine innovative literarische Stimme kennenzulernen. $\mathrm{Zu}$ einem Treffen mit Clarice Lispector kam es trotz der Initiative der Verlegerin 1974 in Brasilien allerdings nicht, weil zeitgleich Clarice Lispector nach Europa gereist war, wo man sich erneut verpasste, als Lispector früher abreisen musste als geplant.

$\mathrm{Zu}$ einem Vertragsabschluss mit Éditions des femmes kam es durch Vermittlung der Autorin Nélida Piñon, die nicht nur selbst dort publizierte, sondern Clarice Lispector auch ihre Agentin Carmen Balcells empfahl, die Lispector fortan vertrat. 1977, in dem Jahr, als Clarice Lispector starb, kaufte Éditions des femmes erstmals Rechte an der Veröffentlichung ihres Werks in Frankreich. Antoinette Fouque hat „ihre“ Entdeckung und Publikation Lispectors in einem Interview kommentiert:

Foi uma corrente de solidariedade e aliança entre mulheres, de Ruth Escobar a Nélida Piñon (que com uma grande generosidade permitiu que passássemos a obra de Clarice na frente da sua propia), de Carmen Balcells a Clelia Pisa, que resoltou na divulgação desta imensa escritora e eu fico orgulhosa de ter podido lhe ofrecer uma casa onde publicar.

(Moser 2012: 267) 
Fouque erklärt ihr besonderes Interesse an Lispectors Literatur mit der Tatsache, dass sie nicht nur Verlegerin, sondern auch Psychoanalytikerin sei: „Da lama do inconsciente, Clarice Lispector fue um diamante. Não existe, aliás, dentro de toda a literatura psicanalítica, uma análise tão rigorosa de um caso de loucura feminina como aquela que ela descreve em Laços de família“ (Moser 2012: 268). Auch wenn der Begriff „,caso de loucura feminina“ aus dem Munde einer Spezialistin etwas unspezifisch bleiben mag, erhellt sie doch mit diesem Kommentar ihren ganz eigenen Zugang zu Lispector, auch im Kontext der von ihr vertretenen feministischen Perspektive auf Literatur. Sie kommentiert weiter: „Encontro em A Paixão segundo G.H., inscrito lá, o eco da minha propia pesquisa, nossa paixão em carne viva: neste livro, como em Água viva, ela evoca o útero, a função matricial, o vivo, o que é muito raro em um texto." (Moser 2012: 268). Später macht sie noch eine sehr weitreichende Aussage zu der Rolle Lispectors für ihre Arbeit: „Eu fundei esta casa para que esta escrita específica pudesse se expresar; em sua homenagem, eu poderia tê-la batizado des femmes - Clarice Lispector, do tanto que esta casa foi impregnada por sua obra.“ Es ist also nicht nur so, dass Éditions des femmes als erster Verlag außerhalb Lateinamerikas, der das gesamte Werk Lispectors vertrat, mit seiner feministischen Programmatik die Rezeptions- und auch Übersetzungsgeschichte von Clarice Lispector sehr geprägt hat, sondern umgekehrt hat offenbar Clarice Lispector auch eine seltene Einzelstellung unter den Autorinnen des Verlags für die federführende Verlegerin eingenommen. Es ist bemerkenswert, wie eng die Verbindung empfunden wurde, ohne dass eine persönliche Beziehung der beiden Frauen entstanden war - zwei Versuche der Verlegerin, einen persönlichen Kontakt zu knüpfen, hatte Clarice Lispector ja verpasst. Auf die zitierte Aussage zu der Einzelstellung Lispectors fragt der Interviewer, wie die Verlegerin das Werk Clarice Lispectors im Zusammenhang des „projeto cultural“ des Verlags sehe. Auch hier wieder ist die Antwort sehr wegweisend: Man habe dem einen Ort geben wollen, was sie die Revolution des Symbolischen (,revolução do simbólico“, Moser 2012: 269) genannt habe, nach sechs Jahren Arbeit im Mouvement de Libération Féminine, das 1968 begründet worden war, „eu pensei que depois de ter liberado a palavra, era preciso retirar o recalque sobre a escrita das mulheres. A necessidade era política: precisávamos de um lugar para o não lugar, para dizer o que não se dizia, para que se escrevesse o que não se podia escrever em outro lugar“ (Moser 2012: 269).

Auf der einen Seite hat die einseitige Rezeption von Lispectors Literatur durch feministische Verlage und Multiplikatoren in den 1970er/1980er Jahren dem Werk insofern geschadet, als es zu ausschließlich in diesem Kontext verortet wurde und andere, sehr wichtige Aspekte unbeachtet blieben, die nicht mit einer feministischen Rezeption vereinbar waren. Man bedenke zum Beispiel das geringe Interesse an ihrem bis heute unterschätzten Roman A maçã no escuro, 
in dem eine männliche Hauptfigur agiert - ein Text, der später in kaum einer Sprache mehr neu aufgelegt wurde - während immer mehr dafür zu sprechen schien, dass sie zu einer Artikulation der Interessen und auch: der Nöte, der Seelenqualen, wie der Kommentar der Verlegerin nahelegt, von Frauen nahezu prädestiniert war.

Auf der anderen Seite nimmt der Verlag Éditions des Femmes eine sehr zentrale Rolle ein, die aus Clarice Lispectors Publikationsgeschichte nicht mehr wegzudenken ist. Antoinette Fouque machte dazu eine zutreffende Aussage: Es gab für Lispector in diesen Jahren keinen anderen Verlag, der sich so sehr um das Gesamtwerk bemühte, sie „hatte“ in der Verlagswelt keinen echten anderen Ort in Europa zu diesem Zeitpunkt, was einer Vereinnahmung durch einen einzelnen Verlag und dessen besondere Programmatik natürlich entgegenkam. Die Publikation von 13 Büchern aus ihrem Werk bei Éditions des femmes in französischer Sprache habe aus einer der größten brasilianischen Autorinnen, als die sie in ihren eigenen Land bereits anerkannt gewesen sei, eine internationale Autorin gemacht, so Fouque. Sie vergleicht den Fall mit James Joyce, der ebenfalls durch die französische Übersetzung weltbekannt geworden sei: „Nós nos empenhamos para que ela fosse conhecida no mundo inteiro; através de nós ela está viva“ (Moser 2012: 270). Ein Blick nach Deutschland und in die USA mag erhellen, wie dieses internationale literarische Leben sich konkret gestaltete.

\subsection{Von Frankreich nach Deutschland: Übersetzen und neu übersetzen}

\subsubsection{Kommentierter Überblick: Erstausgaben in Deutschland ${ }^{36}$}

Die ersten Übersetzungen ins Deutsche entstanden bereits Jahre vor den ersten Übersetzungen von $A$ maçã no escuro in den international renommierten Verlagshäusern Knopf und Gallimard. Dies hängt mit dem Engagement von Curt Meyer-Clason zusammen, der bereits Anfang der 1960er Jahre für einen kleinen deutschen Verlag begann, Texte von Clarice Lispector ins Deutsche zu übersetzen:

1964 Der Apfel im Dunkeln. Übersetzt von Curt Meyer-Clason. Hamburg: Claassen.

36 Dieses Kapitel konnte nur veröffentlicht werden, weil die aus unveröffentlichten Materialien zitierten Personen die Publikation genehmigt haben. Ich bedanke mich dafür bei allen Rechteinhaber/innen und dem Deutschen Literaturarchiv Marbach. 
1966 Die Nachahmung der Rose. Übersetzt von Curt Meyer-Clason. Hamburg: Claassen.

Als die Agentur Carmen Balcells 1973 erstmals ein Paket mit Werken Clarice Lispectors an das Lateinamerika-Lektorat des Suhrkamp-Verlags sandte, kam zunächst eine ablehnende Antwort: „[W]ir danken Ihnen für die Zusendung und bedauern, dass sich die genannten Titel nicht in unser Verlagsprogramm einfügen lassen.“37

1976 schrieb Michi Strausfeld ein Gutachten ${ }^{38}$ zu Die Nachahmung der Rose, einem Erzählband, und empfahl darin den Band dem Suhrkamp Verlag uneingeschränkt zur Publikation - diese allerdings ließ zunächst noch auf sich warten. 1980 begutachtete Strausfeld in ihrer Funktion als Beraterin Siegfried Unselds bezüglich lateinamerikanischer Autoren Lispectors Debutroman und empfahl ihn ebenfalls dringend zur Publikation in der Bibliothek Suhrkamp..$^{39}$ In diesem Gutachten nimmt sie auch noch einmal Bezug auf ihre frühere Empfehlung der Erzählungen und verleiht dieser mehr Nachdruck. 1981 erschien das Debut als Nahe dem wilden Herzen dann schließlich in der Bibliothek Suhrkamp, übersetzt von RayGüde Mertin.

1981 Nahe dem wilden Herzen. Übersetzt von Ray-Güde Mertin. Frankfurt am Main: Suhrkamp.

Die Unterlagen im Siegfried-Unseld-Nachlass lassen darauf schließen, dass das Interesse für Lispectors Romane bei Suhrkamp ab den 1980er Jahren durch die Publikationen Vivre L'Orange (1979) und später L'heure de Clarice Lispector (1989) von Hélène Cixous befördert worden sind. ${ }^{40}$ Für die darauffolgenden Lispector-Publikationen kaufte Suhrkamp die Rechte an den beiden in den 1960er Jahren zunächst bei Claassen erschienenen Titeln. Der Verkauf stand im Kontext einer Übersetzung von Curt Meyer-Clason, die 1982 massiv in die Kritik geraten war: Dieter E. Zimmer hatte in der ZEIT Meyer-Clasons Übersetzung von Chronik eines angekündigten Todes des Kolumbianers García Márquez verrissen (Zimmer 1981). Die zuständige Lektorin Bärbel Flad, damals bei Kiepenheuer\&Witsch, äußerte sich später zu der

37 Vgl. dazu eine Projekthomepage des Deutschen Literaturarchivs in Marbach zu „1968. Ideenkonflikte in globalen Archiven“: http://www.literaturarchiv1968.de/content/clarice-lis pector-als-unterstuetzerin-der-brasilianischen-studentenbewegung-in-brasilien/.

38 Strausfeld, Michi: Gutachten zu Lispector, Clarice: Die Nachahmung der Rose, 1976 (2 Seiten), DLA.

39 Strausfeld, Michi: Gutachten zu Lispector, Clarice: Perto do coração selvagem, 01.06.1980 (3 Seiten), DLA.

40 Vgl. Projekthomepage des Deutschen Literaturarchivs in Marbach zu „1968. Ideenkonflikte in globalen Archiven“: http://www.literaturarchiv1968.de/content/clarice-lispector-als-unter stuetzerin-der-brasilianischen-studentenbewegung-in-brasilien/. 
Tragweite des Vorfalls. ${ }^{41}$ Claassen gab nach Michi Strausfelds Vermutung ${ }^{42}$ im Zusammenhang mit diesem Vorfall die Rechte an der Meyer-Clason-Übersetzung der Lispector-Erzählungen und des Romans ab, Suhrkamp nahm sie in das eigene Lateinamerika-Programm auf:

1982 Die Nachahmung der Rose. Übersetzt von Curt Meyer-Clason. Frankfurt am Main: Suhrkamp.

1983 Der Apfel im Dunkeln. Übersetzt von Curt Meyer-Clason. Frankfurt am Main: Suhrkamp.

Die Resonanz auf Lispectors 1981 bei Suhrkamp erschienenes Debut blieb - trotz der im Verlag als sehr gelungen eingestuften Übersetzung Ray-Güde Mertins - in Deutschland relativ gering, nicht anders war es mit Meyer-Clasons Übersetzungen. „Sie sind eine Kostbarkeit, niemals für das große Publikum [...]“ hatte Michi Strausfeld in ihrem Gutachten über die Erzählungen geschrieben. ${ }^{43}$ Ray-Güde Mertin konnte als Übersetzerin nicht mehr gewonnen werden, sie lehnte eine spätere Anfrage aus Zeitgünden ab, obwohl sie Lispector nach eigenen Angaben sehr gern übersetzt habe. ${ }^{44}$

Nachdem 1978 La passion selon G.H. in Frankreich bei Éditions des femmes erschienen und gerade im Kontext des französischen Feminismus intensiv rezipiert worden war, kaufte ein deutscher Frauenbuchverlag die Rechte an zwei Texten Clarice Lispectors: der Berliner Verlag Lilith. In der ersten Übersetzung gelang es nicht, grundlegende Charakteristika der Lispector’schen Ästhetik zu transportieren (vgl. dazu Kapitel 4.2.2), auch Übersetzungsfehler prägen diesen Band:

1982 Eine Lehre; oder Das Buch der Lüste. Übersetzt von Christiane Schrübbers. Berlin: Lilith.

Für die zweite Publikation wurde kurz vor der Veröffentlichung die erfahrene Übersetzerin Sarita Brandt hinzugezogen, die einige der Probleme der Übersetzung lösen konnte:

41 „Das Buch ist in die Tonne gehauen worden, würde man heute sagen. Dieter E. Zimmer hat damals einen Verriss in der Zeit geschrieben. Wir waren alle ziemlich fertig. Es war die erste Übersetzung von Meyer-Clason, die ich ganz kritisch redigiert hatte ... Und ich hatte noch gesagt, da müsse noch einmal ein Hispanist ran. Man merkt ja, auch wenn man die Ausgangssprache nicht so gut kann, wenn die Übersetzung eines Textes wackelig ist. Das wurde jedoch abgelehnt, weil es wie immer schnell gehen musste. Und dann ging es ja auch schief. Beim nächsten Buch von García Márquez wurde überlegt, wen man jetzt als Übersetzer nehmen solle.“ So Bärbel Flad 2014 in einem Interview mit der Rezensionszeitschrift zur Literaturübersetzung: http://www.relueonline.de/2014/03/der-text-gehoert-dem-uebersetzer-und-ich-tue-weh/.

42 „Claassen hat offiziell die Rechte an den Texten zurückgegeben, verkauft also nur noch die Restexemplare (laut Anfrage von Balcells: 400 Stück) - sicher deshalb, weil in der ZEIT die Geschichte erschien“. Brief von Michi Strausfeld an Maria Dessauer, 2.9.81, SUA.

43 Strausfeld, Michi: Gutachten zu Lispector, Clarice: Die Nachahmung der Rose, 1976 (2 Seiten), DLA.

44 Vgl. Brief von Ray-Güde Mertin an Jürgen Dormagen, 10.8.1987, SUA. 
1984 Die Passion nach G.H. Übersetzt von Christiane Schrübbers bearbeitet von Sarita Brandt. Berlin: Lilith. ${ }^{45}$

Der Verleger des Suhrkamp Verlags, Siegfried Unseld, war darum bemüht, das Gesamtwerk der Autorin publizieren zu können, und verhandelte jahrelang mit Carmen Balcells, die als Agentin die Rechte der Autorin vertrat, um die zuvor an Lilith vergebenen Rechte, insbesondere für Die Passion nach G.H. In der Zwischenzeit erschienen weitere Bände in Curt Meyer-Clasons Übersetzung:

1985 Die Nachahmung der Rose. Übersetzt von Curt Meyer-Clason. Frankfurt am Main: Suhrkamp.

1985 Die Sternstunde. Übersetzt von Curt Meyer-Clason. Frankfurt am Main: Suhrkamp. (1991 als Hörfassung vertont für SFB/NDR/SWF, Regie: Marguerite Gateau, in dieser Fassung auch als Hörbuch im Suhrkamp Theater Verlag).

Auch der Rowohlt Verlag war am Werk der Autorin interessiert, und publizierte einen Band, der bei Lilith erschienen war und vorher in Frankreich eine gewisse Resonanz erfahren hatte, in einer neuen Übersetzung von Sarita Brandt:

1988 Eine Lehre; oder Das Buch der Lust. Übersetzt von Sarita Brandt. Reinbek bei Hamburg: Rowohlt.

Die Materialien des Suhrkamp Verlages im Nachlass von Siegfried Unseld geben Aufschluss darüber, wie schwer es zu dieser Zeit war, einen guten Literaturübersetzer, eine gute Literaturübersetzerin zu finden, die aus dem Portugiesischen ins Deutsche übersetzen konnte, und dazu noch Clarice Lispector. 1990 konnte endlich Lispectors Roman Die Passion nach G.H. bei Suhrkamp erscheinen.

1990 Die Passion nach G.H. Übersetzt von Sarita Brandt und Christiane Schrübbers. Frankfurt am Main: Suhrkamp.

Bei dieser Publikation Die Passion nach G.H. bei Suhrkamp handelt sich um eine sehr aufwändige, mehrmalige Überarbeitung der Übersetzung von Christiane Schrübbers durch Sarita Brandt. Im Band findet sich der Satz: „Die deutsche Übersetzung erschien zum ersten Mal 1984 im Lilith Verlag, Berlin. Sie wurde für diese Ausgabe mit Zustimmung der Übersetzerin Christiane Schrübbers und des Lilith Verlages von Sarita Brandt überarbeitet.“ Aus dem Archivmaterial des Suhrkamp Verlages geht hervor, dass eine Mitarbeiterin des Verlags bereits am 17.2.1983 zu geplanten Übersetzungen von Texten Clarice Lispectors notiert hatte, die Rechte für Die Passion nach G.H. habe bereits ein anderer Verlag erworben, für zwei andere Kurzromane könne man jetzt die Rechte kaufen. Dies versah wiederum Unseld mit einer handschriftlichen Notiz: „Keine Sammelsurien! Der ,Werk'-Charakter ist wichtig. Autoren sollen in der BS nur mit ihren besten Werken vertreten sein. Und die Autoren müssen

45 Auf die für diese Ausgabe erfolgte, erste Bearbeitung folgten mehrere Überarbeitungsgänge durch Sarita Brandt, bis der Band 1990 bei Suhrkamp erschien. 
als ,Klassiker der Moderne‘ gelten können.“46 Aus Briefwechseln des Lektorats mit der Lispector-Übersetzerin Sarita Brandt zwischen Januar 1989 und August 1994 lässt sich verfolgen, wie aufwändig es war, dieses Anliegen umzusetzen, vor allem durch die intensiven Überarbeitungen (vgl. dazu ausführlich Kapitel 4.2.2).

1990 Die Dame und das Ungeheuer. Übersetzt von Sarita Brandt. Reinbek bei Hamburg: Rowohlt.

1992 Von Traum zu Traum. Übersetzt von Sarita Brandt. Reinbek bei Hamburg: Rowohlt.

Mit der Übersetzung des Textes Agua Viva beauftragte der Suhrkamp Verlag erneut Curt MeyerClason. Diese Übersetzung wurde aber nicht publiziert, da im Verlag die Übersetzung auch nach einer Überarbeitung der ersten Fassung als nicht tragbar eingeschätzt wurde. ${ }^{47}$ An Magda Oliver in der Agentur Carmen Balcells schreibt der zuständige Lektor Jürgen Dormagen: „Ha surgido, una vez más, un problema con la traducción“. ${ }^{48}$ Er schreibt weiter, man könne die Übersetzungen A hora da estrela/Agua viva nicht wie geplant in einem Band bringen, den letztgenannten Text habe man nicht retten können, es sei so nicht publizierbar, sodass beide Texte nun einzeln in zwei schmalen Bänden erscheinen sollen, denn „arriesgar una versión alemana no perfecta nos pareció demasiado osadía con una autora que ya tuvo mala suerte en Alemania, y que requiere todavía un esfuerzo para introducirla del todo.“ Noch einmal konnte man Sarita Brandt gewinnen, die eine neue Übersetzung anfertigte. Zu dem Aufwand, den die erneute Übersetzung bedeutete, kam das Problem, dass Carmen Balcells nun einen neuen Vertrag schließen wollte, sodass Lektor Dormagen ihr schrieb, Unseld sei kurz davor, dieses so aufwändige Projekt nun ganz fallenzulassen. ${ }^{49}$ Es kam dann doch zu einer Publikation:

1994 Aqua viva. Ein Zwiegespräch. Übersetzt von Sarita Brandt. Frankfurt am Main: Suhrkamp.

1996 Wo warst du in der Nacht. Übersetzt von Sarita Brandt. Frankfurt am Main: Suhrkamp.

Hinderlich war für Suhrkamp in diesen Jahren noch ein weiterer Umstand: Dass das Werk Lispectors parallel bei Rowohlt und Suhrkamp verlegt wurde, geht auf eine Entscheidung von Paulo Gurgel Valente, des jüngeren Sohnes von Clarice Lispector zurück, die konträr zu Unselds Anliegen lag, nicht nur einzelne Bücher zu publizieren, sondern Autoren mit ihrem Gesamtwerk zu vertreten. ${ }^{50}$

46 Handschriftlicher Kommentar von Siegfried Unseld zu einer Notiz (Betreff: „Clarice Lispector/BS“) von Ulrike Langenbrinck, 17.2.1983, SUA.

47 Brief von Jürgen Dormagen an Curt Meyer-Clason, 29.01.1987, SUA; Brief von Jürgen Dormagen an Curt Meyer-Clason, 23.10.1987, SUA.

48 Brief von Jürgen Dormagen an Magda Oliver, 13.5.1985, SUA.

49 Brief von Jürgen Dormagen an Carmen Balcells, 30.4.1992, SUA.

50 Dies geht aus dem Archivmaterial im Deutschen Literaturarchiv in Marbach hervor, insbesondere aus der Durchsicht folgender Mappe: DLA, Mappe SUA/08 Lektorate/Lateinamerika/L (Stand: Februar 2016). 
Auf die genannten Publikationen in den 1990er Jahren folgte eine lange Publikationspause, in der viele Lispector-Ausgaben nicht wieder aufgelegt wurden. Clarice Lispector galt in Deutschland als eine vollkommen vergessene Autorin (vgl. Ingold 2011), kein einziger Titel von ihr war auf deutsch mehr lieferbar, als im Zuge des Länderschwerpunktes Brasilien der Frankfurter Buchmesse 2013 der Schöffling Verlag die im englischsprachigen Raum bereits sehr erfolgreiche Biographie Benjamin Mosers über Lispector auf deutsch publizierte, sowie ihre ersten beiden Romane in bearbeiteter Übersetzung beziehungsweise Erstübersetzung.

2013 Nahe dem wilden Herzen. Überarbeitete Übersetzung von Ray-Güde Mertin und Corinna Santa Cruz. Frankfurt am Main: Schöffling.

2013 Der Lüster. Übersetzt und mit einem Nachwort von Luis Ruby. Frankfurt am Main: Schöffling.

Mit den Übersetzungen von Luis Ruby ins Deutsche kommt eine herausragende Übersetzungsleistung hinzu, die später mit zu dem Erfolg insbesondere der Erzählungen in Deutschland beigetragen hat und aus einer tiefen Auseinandersetzung mit Lispectors Werk schöpft. Einen kurzen Einblick in diese Übersetzungsarbeit vermittelt das Nachwort zu Der Lüster. Ähnlich wie in den USA in den Jahren zuvor geschehen, plante der Schöffling Verlag in der Folge weitere Werke Lispectors in neuer Übersetzung herauszubringen, teils auch mit den Nachworten der englischsprachigen Ausgaben versehen:

2016 Der große Augenblick. Übersetzt von Luis Ruby. Nachwort von Colm Tóibín. Frankfurt am Main: Schöffling.

Im Jahr 2019 kommt ein weiteres Mal in der Publikationsgeschichte Clarice Lispectors einem Verlag, der ursprünglich am Gesamtwerk interessiert war, die Agentur der Autorin dazwischen, als die Rechte an den gesammelten Erzählungen - in den USA bereits ein großer Erfolg, gerade bei der Literaturkritik - für den deutschsprachigen Raum an einen anderen Verlag gehen:

2019 Tagtraum und Trunkenheit einer jungen Frau. Übersetzt von Luis Ruby. Hg. Benjamin Moser. München: C. Bertelsmann Verlag. [Band 1 der gesammelten Erzählungen]

Die Übersetzung der Erzählungen (Teil 1) wird 2020 für den Preis der Leipziger Buchmesse nominiert und sehr gut besprochen. Einige Rezensent/innen gehen darauf ein, dass der Erfolg der Erzählungen auch damit einhergehe, dass Lispector hier zugänglicher und leichter verständlich sei als im Romanwerk. Der zweite Band der gesammelten Erzählungen Clarice Lispectors erscheint ebenfalls 2020, in dem Jahr, in dem sich der Geburtstag der Autorin zum 100. Mal jährt:

2020 Aber es wird regnen. Übersetzt von Luis Ruby. Hg. Benjamin Moser. München: C. Bertelsmann Verlag. [Band 2 der gesammelten Erzählungen] 


\subsubsection{Die Passion nach G.H. - ein aufwändiger Überarbeitungsprozess}

Während die Übersetzungsgeschichte in Frankreich von einem langen Ringen um eine angemessene Übersetzung von Clarice Lispectors Sprache und Ästhetik in den Zielkontext geprägt ist, gab es in Deutschland sowohl ganz verfehlte, als auch recht früh schon einzelne, sehr annehmbare Übersetzungsarbeiten. Hier sind die Übersetzungen von Sarita Brandt zu nennen, die - wie in der Übersicht erkenntlich - insbesondere in den 1980er Jahren eine ganze Reihe von Lispector-Bänden für Rowohlt und Suhrkamp übersetzte und aus der Kontinuität ihrer Beschäftigung mit Lispectors Werk schöpfen konnte. Ihren Übersetzungen liegt eine Tiefe der Auseinandersetzung mit Lispectors Sprache, ihren Themen und ihrer Ästhetik zugrunde, die als beispielhaft gelten kann dafür, dass Übersetzungen ihrer Literatur durchaus gelingen konnten. Doch auch in Deutschland war der Weg insgesamt ein sehr mühsamer - wenn auch aus anderen Gründen als in Frankreich.

Die langwierigen Verhandlungen um den Rechteerwerb zu Die Passion nach G.H. wurden bereits thematisiert. Suhrkamp kaufte schließlich nach jahrelangen Verhandlungen mit Carmen Ballcells und dem Verlag Lilith in Berlin die Rechte an der deutschen Übersetzung bzw. an einer Überarbeitung der im Lilith Verlag erschienenen Version zu Die Passion nach G.H., einem Schlüsseltext in Lispectors Werk, der sicherlich in eine Reihe der „Klassiker der Moderne“ eingefügt werden kann. Diese Überarbeitung soll hier exemplarisch herausgegriffen werden, um nachvollziehbar zu machen, welche Hürden auch in Deutschland genommen werden mussten, um Lispector an ein breiteres Publikum zu vermitteln und ,Fehlversionen“ ihres Werkes zu überwinden, wie es sie in der Übersetzung immer wieder gegeben hat.

\section{A paixão segundo G.H. - ein Schlüsseltext für Lispectors Werk}

Bevor nun jedoch eingehender auf die Übersetzungen von A paixão segundo G.H. durch die beiden deutschen Übersetzerinnen Christiane Schrübbers und Sarita Brandt eingegangen wird, seien einige zentrale Punkte zusammengefasst, die die Bedeutung des Romans und die Kontexte für eine Übersetzung betreffen. Benedito Nunes hat in einer kritischen Edition von A paixão segundo G.H. von 1988 die herausragende Bedeutung dieses Textes als Schlüsseltext für Lispectors Werk herausgestellt: Hier finde sich im Kern alles, was zu den Charakteristika ihres Werkes zähle, etwa die typischen Innensichten, die Philosophie des Augenblicks, das erotische Moment, die Themen der Auflösung von Identitäten und der Krise der Repräsentation, sowie die spezifische Spannung zwischen erlebter und erzählter Erfahrung (Nunes 1988: xii). Benjamin Moser schreibt über den Text: „Mit 
einer raschen, skizzenhaften Handlung erreicht G.H. den Kulminationspunkt einer langen ureigenen Suche. Zum ersten Mal schreibt Clarice in der ersten Person. Und zum ersten Mal fängt sie die ganze Gewalt, den physischen Ekel ihrer Begegnung mit Gott ein.“ (Moser 2013a: 325).

Gerade wenn man an die Flut von Sekundärliteratur denkt, die heute zu dem Text vorliegt, überrascht die Tatsache, dass dieses Buch Clarice Lispectors zum Zeitpunkt seines Erscheinens überhaupt keine Resonanz hervorgerufen hat in Brasilien erschien im Publikationsjahr 1964 eine einzige Rezension von Walmir Ayala, einem engen Freund von Lúcio Cardoso, der wiederum Clarice Lispector sehr nahe stand und der zu einem der wichtigsten Förderer ihres literarischen Werkes gehörte. Ansonsten: nichts. Der Roman war als erster Roman seit langer Zeit ohne langwierige Verlagssuche erschienen, was Lispector dem Umstand zu verdanken hatte, dass zwei ihrer engsten Freunde, Fernando Sabino und Rubem Braga, einen eigenen Verlag gegründet hatten (Editora do Autor). Eines der wichtigsten Werke Clarice Lispectors wurde also lediglich von einigen führenden Intellektuellen unter ihren Freunden als solches erkannt, ansonsten aber nicht weiter beachtet diese Situation steht in krassem Kontrast zu der Bedeutung, die diesem Text von Seiten der Literaturkritik später zugesprochen wurde.

Das Buch erschien im Jahr des Militärputsches in Brasilien, wurde aber noch in der Phase davor verfasst, also in den politisch verhältnismäßig ruhigen Jahren der kulturellen Blüte vor dem Putsch, wobei der genaue Entstehungszeitraum lange nicht bekannt war und keine Manuskripte, Notizen o. ä. dazu vorliegen (vgl. die Schilderung von Luiza Lobo, in Marting 1993: 113). Luiza Lobo verweist auf eine Aussage von Benedito Nunes, der erwähnt habe, dass Lispector das Buch nach einer langen Schaffenskrise „ohne Unterbrechung“ geschrieben habe. Benjamin Moser schreibt, sie sei sieben Jahre nach Abfassung von A maçã no escuro zutiefst besorgt gewesen, ob sie überhaupt noch fähig sein würde zu schreiben, ,als sie Ende 1963 in raschen Energieschüben einen der großen Romane des zwanzigsten Jahrhunderts zu Papier brachte“ (Moser 2013a: 324). Im Vergleich zu dem sehr viel umfassenderen Roman A maçã no escuro, der 1961, knapp drei Jahre zuvor publiziert worden war und aus der Perspektive eines Mannes einen Identitätsfindungsprozess schildert, dabei ähnlich existenzielle Themen verhandelt, hat dieser neue Text eine relativ geschlossene Form, die das Buch leichter rezipierbar, ,lesbarer' macht. Zugleich ist die für Lispector so charakteristische Sprachskepsis präsent, die ein Ringen der zentralen Figur um eine selbst bestimmte Identität zum Ausdruck bringt. Auch hier trägt wieder der Innere Monolog den Text, diesmal die Introspektion der Frauenfigur G.H., die im Verlauf der Handlung gewissermaßen aus dem Zivilisatorischen heraustritt. Zur leichteren Verständlichkeit im Vergleich zu A maçã no escuro trägt neben der vergleichsweisen Kürze des Textes sicher auch die Tatsache 
bei, dass die äußere Handlung sehr begrenzt und von Beginn an eindeutig ist, dass der Roman an einem einzigen Ort spielt - im Dienstmädchenzimmer einer Wohnung in Rio de Janeiro - und die Ereignisse eines einzigen Tages erzählt. Es ist ein Text mit einem klaren, wenn auch knappen Handlungsaufbau, auf den die Erzählerin immer wieder zu sprechen kommt: Eines Tages betritt sie das Zimmer ihres Dienstmädchens, entdeckt dort eine Schabe, versucht, sie zu töten, und isst sie. Zwischen den einzelnen, teils minimalen Schilderungen zum Fortschreiten der äußeren Handlung finden sich lange und eingehende Reflexionen, die von einer existenziellen Auseinandersetzung, ja: einer schrittweisen Annäherung an eine Art Essenz des Lebens, an ,das Neutrale‘, an Gott erzählt. Die kürzestmögliche Zusammenfassung für die nicht einmal 200 Seiten, aus denen Die Passion nach G.H. besteht, für den inneren Prozess, der dort verhandelt wird, liefert die Autorin selbst in Aqua Viva. Zitiert wird hier die SuhrkampÜbersetzung von Sarita Brandt: „Manchmal elektrisiere ich mich, wenn ich ein Tier sehe. Jetzt höre ich den Urschrei in meinem Innern: es ist, als wüßte ich nicht, wer mehr Kreatur ist, ob ich oder das Tier. Dann fühle ich mich völlig verwirrt. Anscheinend bekomme ich Angst, unterdrückten Instinkten ins Auge zu sehen, die ich dem Tier gegenüber gezwungen bin, anzunehmen“ (Lispector 1994: 56).

Der Roman ist wegen der Begrenzung der Handlung auf einen Tag und wegen des Fokus auf die Innensicht der Figur mit Joyces Ulysses und vor allem mit Virginia Woolfs Mrs Dalloway verglichen worden. Luiza Lobo erweitert die Gruppe der Vergleichsautoren noch und schreibt, bei dem Text handle es sich um ,a modernist piece of writing in the sense that the author tries to break with the epic and the heroic to present her caracter's everyday acts on a single day, as did Joyce, Woolf, Kafka, Eliot, Pound, Gertrude Stein and other contemporary writers“ (Marting 1993: 115). Es gibt hier eine gewisse Folie für eine Rezeption auch außerhalb des brasilianischen Kontextes und im Kontext englischsprachiger Autoren, gerade deshalb ist es bemerkenswert, dass gerade dieser Roman in der englischsprachigen Welt weniger enthusiastisch aufgenommen wurde als später in Brasilien selbst oder von der feministisch orientierten Literaturkritik in Frankreich, zu deren Konzepten der Text offenbar gut passte. Festzuhalten ist bezüglich der Übersetzungsgeschichte des Romans, dass erst einmal gar nichts passierte, nachdem ja der vorige Roman in renommierten US-amerikanischen, deutschen und französischen Verlagen, in den zentralen Verlagen, wenn es um die internationale Förderung lateinamerikanischer Autoren ging, publiziert worden war: bei Knopf, Suhrkamp und Gallimard. Von 1964 bis zu Lispectors Tod blieb A paixão segundo G.H. - ein überaus zentraler Text innerhalb ihres Werkes - unübersetzt. 13 Jahre nach Erscheinen des Originals, in ihrem Todesjahr 1977, kommt dann bei Knopf eine Übersetzung, allerdings handelt es 
sich lediglich um einen kurzen, 13 Seiten langen Auszug aus dem in der portugiesischsprachigen Erstausgabe 182 Seiten langen Text in The Borzoi Anthology of Latin American Literature (Marting 1993: 117).

In den auf Clarice Lispectors Tod folgenden Jahren 1978/79 erscheinen dann französische und spanische Übersetzungen, 1984 eine deutsche und eine japanische Übersetzung, dann Ende der 1980er Jahre einzelne Ausgaben in Skandinavien: in Holland (1988, Auszüge in einer Zeitschrift) und Norwegen (1989). Die 1984 in Tokio publizierte Übersetzung ist ungewöhnlich, zu dieser Zeit eine der wenigen Übersetzungen lateinamerikanischer Autor/innen ins Japanische überhaupt (Marting 1993: 116). Erstmals zirkuliert ein Lispector-Text nach Skandinavien und nach Asien.

Viele der Übersetzungen sind allerdings ungenügend, transportieren die Charakteristika des Originals, seine Ausdruckskraft nicht. In den USA gelangt der Text nach dem besagten 13-seitigen Auszug erst 1988 in einer Übersetzung von Ronald W. Sousa (Minneapolis: University of Minnesota Press) an den englischsprachigen Leser. Es handelt sich um eine korrekte, aber weitgehend recht uninspirierte Übersetzung, so die Darstellung von Diane E. Marting: Sie stellt eine Tendenz zur „regularization of punctuation“ fest, ansonsten habe der Übersetzer sich bemüht, stilistische Anomalien und grammatische Unregelmäßigkeiten, etc. beizubehalten (Marting 1993: 117) - allerdings ohne ein wirkliches, mit Cortázar könnte man sagen: emotionales Verständnis für das ,Irrationale‘ dieses Textes jenseits der korrekten Übertragung.

In Brasilien ist dieser Text vielfach als der wichtigste der Autorin eingeschätzt und im Laufe seiner Rezeptionsgeschichte insgesamt sehr positiv bewertet worden, auch was seinen Einfluss auf andere Autorinnen und Autoren angeht. Nur wenige brasilianische Kritiker/innen haben im Rückblick die Werke $A$ hora da estrela oder auch Água viva als bedeutsamer bezeichnet, so Luiza Lobo (Marting 1993: 113). In Kritiken zu den englisch- und spanischsprachigen Übersetzungen ist dieses extrem positive Urteil so nicht wiederzufinden - in der englischsprachigen Rezeption erhält zum Beispiel $A$ hora da estrela oftmals einen sehr viel höheren Stellenwert, während A paixão segundo G.H. unter anderem wegen des predigthaften Tons kritisiert wurde. Ungeachtet der unterschiedlichen Reaktionen der Literaturkritik in verschiedenen Sprachräumen muss der Roman in jedem Fall zu den zentralen Werken der Autorin gezählt werden - wichtig, auch weil er sehr grundlegende Themen der Autorin transportiert, eine Art Brennpunkt ihres Schaffens darstellt. Dies hat auch Clarice Lispector selbst empfunden: Kurz vor ihrem Tod erzählte sie einer Reporterin, dieses sei von all ihren Büchern dasjenige, was ihrem Anspruch als Schriftstellerin am besten entspreche (Battella Gotlib 1995: 480). 


\section{Zur Bedeutung des Romans in Frankreich}

Während in Frankreich die Publikation der französischen Übersetzung von $A$ maçã no escuro bei Gallimard 1970 unter dem Titel Le bâtisseur de ruines von Violante do Canto ohne Resonanz beim französischen Lesepublikum geblieben war (Peixoto Cherem 2013: 152), erschien 1978 eine Übersetzung von A paixão segundo G.H. bei Éditions des femmes, die die Situation in der französischsprachigen Welt verändern sollte: Laut Lúcia Peixoto Cherem gaben alle Personen aus dem französischen und dem kanadischen Kontext, die sie für ihre Studie As duas Clarices entre a Europa e a América befragte, an, anhand dieses Textes erstmals mit Lispector in Berührung gekommen zu sein (Peixoto Cherem 2013: 151-152), es sei darüber hinaus der in Nordamerika und Europa meistgelesene Lispector-Text zum Zeitpunkt ihrer Wiederentdeckung Ende der 1970er Jahre (Peixoto Cherem 2013: 38). Lúcia Peixoto Cherem kommentiert zentrale Aspekte von Lispectors Ästhetik mit Bezug auf die Kanadierin Claire Varin, die Lispector ebenfalls anhand dieses Textes für sich entdeckt hatte:

Concordando com a ensaísta canadense, seria bom acrescentar ainda que até $A$ paixão segundo G.H., a memória ajuda a reconstituir o instante vivido no passado, mas como era impossivel presentificar a experiência através da palavra, Clarice foi tentando diminuir ao máximo a distância entre enunciação e enunciado. A paixão segundo G.H. representa ainda a construção literária, embora o sujeito-narrador despreze a narrativa ao narrar. Com Água viva, mais um passo é dado em direção à nudez que Clarice tanto buscava: tentar escrever sem fingir, escrever como se vive.

(Peixoto Cherem 2013: 52)

Diese Ästhetik des „tentar escrever sem fingir“ wendet sich in bestimmten Aspekten gerade gegen eine Unterscheidung zwischen feminin und maskulin, indem sie das Menschliche, die Conditio humana zum Thema macht:

Ah, será que nós originalmente não éramos humanos? E que, por necessidade prática,
nos tornamos humanos? Isso me horroriza, como a ti. Pois a barata me olhava com sua
carapaça de escaravelho, com seu corpo rebentado que é todo feito de canos e de antenas
e de mole cimento - e aquilo era inegavelmente uma verdade anterior a nossas palavras,
aquilo era inegavelmente a vida que até então eu não quisera.
(Lispector 1988: 77)

Gerade wegen der starken Rezeption in feministischen Kontexten ist dieser Aspekt einer Neutralisierung von Polarisierungen immer wieder kommentiert worden. Laut Benedito Nunes, der das Vorwort zur zitierten kritischen Ausgabe verfasst hat, „é patente que o despojamento pessoal em G.H. neutraliza a diferença entre o masculino e o femenino, absorvida numa condição humana geral em contraste com a animalidade e a vida orgânica“ (Nunes 1988: xxix). 
Auch Peixoto Cherem kommentiert den feministischen Kontext, in dem der Roman zirkulierte. Sie beschreibt die feministische Bewegung in Frankreich Ende der 1970er Jahre als bereits gereift und, anders als zu Beginn, zwischen sehr unterschiedlichen Autorinnen differenzierend. Lispector habe keine einfache Identifikationsmöglichkeit geboten, sei in ihrem Werk mit Aspekten der menschlichen Seele befasst, die weit über die Themen der feministischen Bewegung hinausreichten, habe aber für viele Autorinnen und Kritikerinnen so etwas wie einen Weg aufgezeigt: „É o alto nível das discussões que a obra de Clarice possui que vai seduzir muitas leitoras estrangeiras.“ Weiter schreibt sie: „Ao contrário de apresentar uma identidade feminina acabada e fortalecida, A paixão segundo G.H. é cenário de uma deconstrução, mostrando o avesso do que a sociedade havia reservado para a personagem“ (Peixoto Cherem 2013: 40). Sie bemerkt, dass die starke Identifikation mit dem Werk Lispectors, die sie immer wieder als Charakteristik für viele Kritiker/ innen und Rezipient/innen hervorhebt, mit einer Intimität zwischen der Erzählerin und einem „Du“ in diesem Text einhergeht, und dass die von ihr beschriebenen, identifikatorischen Tendenzen in der Rezeption keineswegs auf Frauen beschränkt sind. Es habe auch Männer gegeben, die sich geradezu obsessiv dem Werk Lispectors gewidmet haben und den beschriebenen Kriterien entsprächen. Als Beispiele nennt sie die Dissertation von Gilberto Figueiredo Martins, in dessen Vorwort der Autor von symbiotischen und identifikatorischen Erlebnissen berichtet, sowie den Autor Fernando de Abreu, der jahrelang obsessiv Lispector-Texte gelesen habe und nach eigenen Aussagen damit aufhören musste, weil er nicht mehr in der Lage gewesen sei, selbst zu schreiben (Peixoto Cherem 2013: 41-42).

Bedenkt man die Bedeutung, die dem Roman A paixão segundo G.H. in Frankreich zugesprochen wurde, ist es sicher besonders unglücklich, dass die Qualität der Übersetzung bei Éditions des femmes von 1978 nach Ansicht verschiedener Expert/innen als noch weit desaströser eingeschätzt werden muss als im Englischen: Claire Varin schreibt dazu:

One could place this translation of Lispector's fifth novel among the „annexationist“ versions. In it one finds a syntactical roughness erased and a frequent modification of the special cadence of her phrase. The attempt here is to make the translation into "literature" by employing a level of literary language, of recherché terms and turns of phrase; this does not conform either to the language of the original or to the project of the narrator, which was to disengage herself from estheticism.

(Marting 1993: 117)

Auch und gerade wenn in Frankreich eine vergleichsweise starke Rezeption beginnt - es gab bald eine Theateradaptation und ein Audiobuch - ist es natürlich hoch problematisch, dass hier der literarische Charakter stark verfälscht wurde. 


\section{Zur Überarbeitung der Übersetzung in Deutschland}

Einen Eindruck der Herausforderungen der Übersetzungsarbeit an diesem Roman gewinnt man, wenn man die Übersetzung von Sarita Brandt für den Suhrkamp Verlag einmal neben die frühere Fassung legt, die von Christiane Schrübbers für den Frauenbuchverlag Lilith in Berlin erstellt wurde. ${ }^{51}$ Beide Fassungen liegen in publizierter Form vor. Für den Suhrkamp-Verlag hatte Sarita Brandt die Übersetzung noch mehrmals überarbeitet, im Suhrkamp-Band findet sich der Hinweis: „Die deutsche Übersetzung erschien zum ersten Mal 1984 im Lilith Verlag, Berlin. Sie wurde für diese Ausgabe mit Zustimmung der Übersetzerin Christiane Schrübbers und des Lilith Verlages von Sarita Brandt überarbeitet“ (Lispector 1990). Wie aufwändig dieser Prozess war, lässt sich in Ansätzen anhand des im Deutschen Literaturarchiv in Marbach archivierten Materials aus dem Siegfried-Unseld-Nachlass nachvollziehen: vor allem anhand von jahrelangen Korrespondenzen zwischen Lilith, Suhrkamp und der Agentur Carmen Balcells, um die Rechtefrage zu klären bzw. die Rechte an einer neuen, überarbeiteten Übersetzung zu bekommen, sowie anhand von Korrespondenzen des zuständigen Suhrkamp-Lektors Jürgen Dormagen mit Sarita Brandt. ${ }^{52}$ Einige Aspekte der verschiedenen Übersetzungen können aufschlussreich sein, wenn es um die Frage geht, welchen Einfluss Übersetzungen auf die Rezeption von Clarice Lispector nehmen konnten. An dieser Stelle sei auch auf einen Aufsatz von Christiane Quandt (2015) zum Thema „(Un-)Sichtbare Übersetzungen? Übersetzungsstrategien bei Erzählungen von Clarice Lispector“ verwiesen. Quandt folgt darin der Argumentation der brasilianischen Translationswissenschaftlerin Rosemary Arrojo, dass mit der Übersetzung immer auch eine Interpretation erfolge, was sie an einem Vergleich der Übersetzungsstrategien bei Sarita Brandt und Curt Meyer-Clason festmacht, die beide die Erzählungen Amor und A bela e a fera ou a ferida grande demais ins Deutsche übersetzt haben. Dabei stellt sie fest, dass auch im deutschen Sprachraum der 1980er und 1990er Jahre die „zielsprachliche Lesbarkeit einer Übersetzung als höchstes Qualitätskriterium“ eine sehr prägende Rolle spielte (Quandt 2015: 123). Sie zeigt, wie jede übersetzerische Entscheidung auf der Detailebene - etwa, was Satzzeichen angeht - dazu beiträgt, die Interpretation des Textes zu prägen.

In Bezug auf Lispectors zentralen Roman Die Passion nach G.H. (1964) sei hier zunächst die Eingangspassage, in der sich Clarice Lispector „A possíveis leitores“/„An mögliche Leser“ wendet, noch einmal zitiert:

51 Bereits diese Ausgabe wurde von Sarita Brandt vor der Veröffentlichung ein erstes Mal überarbeitet.

52 Vgl. dazu die in dem kommentierten Überblick zur Publikationsgeschichte in Deutschland in diesem Band aufgeführten Materialien. 
Êste livro é como um livro qualquer. Mas eu ficaria contente se fôsse lido apenas por pessoas de alma já formada. Aquelas que sabem que a aproximação, do que quer que seja, se faz gradualmente e penosamente - atravessando inclusive o oposto daquilo de que se vai aproximar. Aqueles pessoas que, só elas, entenderão bem devagar que êste livro nada tira de ninguém. A mim, por exemplo, o personagem G.H. foi dando pouco a pouco uma alegria difícil; mas chama-se alegria. C.L.

(Lispector 1964: 5)

Die Suhrkamp-Übersetzung beginnt wie folgt:

Dieses Buch ist wie jedes andere auch. Trotzdem würde ich mich freuen, wenn es nur von denen gelesen würde, deren Seele bereits geformt ist. Von denen, die wissen, daß die Annäherung an etwas - was immer es auch sein möge - sich Schritt für Schritt und auf steinigem Weg vollzieht, indem man selbst das Gegenteil dessen durchlebt, dem man sich annähert [...].

(Lispector 1990: 5)

In der Lilith-Ausgabe heißt es noch:

Dieses Buch ist wie so viele andere auch. Aber ich würde mich freuen, wenn es nur von Menschen gelesen würde, deren Seele bereits geformt ist. Jene, die wissen, dass die Annäherung, an was auch immer, sich gradweise und schmerzlich vollzieht, indem man selbst das Gegenteil dessen durchquert, dem man sich annähern wird [...]. (Lispector 1984: 5)

In dieser kurzen Eingangssequenz fallen bereits zwei grundlegende Charakteristika auf, die die Überarbeitung der früheren Übersetzung durch Sarita Brandt kennzeichnen: Zum einen wird eine vage, rätselhaft bleibende Aussage durch einen eindeutigen Satz ersetzt: „Dieses Buch ist wie so viele andere auch“ wird zu „Dieses Buch ist wie jedes andere auch“. Zum anderen wird eine abstrakte Beschreibung durch ein konkretes Bild ersetzt: die Annäherung, die „sich gradweise und schmerzlich vollzieht“ wird zu einer Annäherung, die „sich Schritt für Schritt und auf steinigem Weg“ vollzieht. Der Leser verfolgt auf den nächsten Seiten den inneren Monolog einer Frau, deren Annäherungsversuch sich auf nichts weniger als auf das Leben, eine Essenz des Lebens richtet. In der Lilith-Übersetzung heißt es:

Auf den Schlaf zuzugehen, ähnelt sehr der Art, wie ich jetzt auf meine Freiheit zugehen muß. Mich dem hinzugeben, was ich nicht verstehe, bedeutet, mich an den Rand des Nichts zu stellen. Es bedeutet, immer nur weiterzugehen, wie eine Blinde, die auf einem Feld verloren ist. Dieses Übernatürliche, das leben bedeutet. Das Leben, das ich gezähmt hatte, um es mir vertraut zu machen. Diese mutige Tat, die darin besteht, mich hinzugeben, und die so ist, wie die schemenhafte Hand des Gottes zu ergreifen [...].

(Lispector 1984: 17)

Es handelt sich, dies ist sehr charakteristisch auch für viele andere LispectorTexte, um eine Textpassage, in der innere Zustände angenähert werden, suchend, mäandernd. Einer Übersetzerin stellt sich die Schwierigkeit, hier nichts $\mathrm{zu}$ begradigen und gleichzeitig einen verständlichen Text zu produzieren, vor 
allem auch die Dramatik zu transportieren, die Kraft, die sich hier im Rahmen sehr begrenzter äußerer Handlung entwickelt. Gelingt dies nicht, werden schnell Leseeindrücke von Belanglosigkeit oder Unverständnis provoziert. Es geht darum, so könnte man vielleicht allgemein formulieren, ein lebendiges, nachvollziehbares Bild innerer Dynamiken zu entwerfen. In der späteren Bearbeitung durch Sarita Brandt klingt diese Passage so:

Sich dem Schlaf hinzugeben ähnelt sehr der Art, wie ich jetzt auf meine Freiheit zugehen muß. Mich dem hinzugeben, was ich nicht verstehe, bedeutet, mich an den Rand des Nichts zu stellen. Es bedeutet, immer nur weiterzugehen, wie eine Blinde, verloren auf einem Feld. Dieses Übernatürliche, das zu leben bedeutet. Das Leben zu leben, das ich gezähmt hatte, um es mir vertraut zu machen. Diese mutige Tat, die darin besteht, mich hinzugeben, und die so ist, wie die schemenhafte Hand Gottes zu ergreifen [...]. (Lispector 1990: 13)

Auch hier wieder zwei Kommentare:

„Sich dem Schlaf hingeben“ als alltägliches Bild verschafft den dann folgenden Reflexionen gewissermaßen einen festen Boden, einen bekannten Bezugspunkt. Bei der ursprünglichen Formulierung „Auf den Schlaf zuzugehen“ geht es hingegen wieder um eine Abstraktion, um eine Umschreibung, die dem Text nichts Wesentliches hinzufügt, das Verständnis aber erschwert.

Die Formulierung „die schemenhafte Hand des Gottes zu ergreifen“ hat wiederum erneut etwas vages, uneindeutiges: des Gottes? welches Gottes? Gibt es andere Götter? Wird dieser Gott irgendwie in Frage gestellt, oder anderweitig kommentiert?

Nein, eine Kommentierung, einen Zusammenhang dafür gibt es nicht. In der Überarbeitung fehlt dann dieser Artikel: es geht nunmehr um eine Tat, „die so ist, wie die schemenhafte Hand Gottes zu ergreifen“: Hier erst vermittelt sich das Machtvolle, Intensive, Bahnbrechende dieser Tat - eine schöne Textstelle, um zu verstehen, wie der Zugang zu einem Lispector-Text mit kleinen Details verstellt werden kann, wie leicht ein solcher Text in der Übersetzung an erzählerischer Kraft einbüßt.

Die Erzählerin berichtet im Text von der Art ihrer Annäherungsversuche an das ,ungezähmte Leben“:

53 Im Original: „Ir para o sono se parece tanto com o modo como agora tenho de ir para a minha liberdade. Entregar-me ao que não entendo será pôr-me à beira do nada. Será ir apenas indo, e como uma cega perdida num campo. Essa coisa sobrenatural que é viver. $O$ viver que eu havia domesticado para torná-lo familiar. Essa coisa carajosa que será entregar-me, e que e como dar a mão à mão mal-assombrada do Deus, e entrar por essa coisa sem forma que é um paraíso.“ (Lispector 1964: 16). 
Kann, was ich gesehen habe, die Liebe gewesen sein? Aber was ist das für eine Liebe, die so blind ist wie die einer Keimzelle? war es das? Jener Schrecken, war das Liebe? Liebe, die so neutral ist, daß - nein, ich will noch nicht über mich sprechen, jetzt zu sprechen würde bedeuten, einen Sinn zu überstürzen, wie jemand, der schnell durch die lähmende Sicherheit eines dritten Beins die Bewegung verliert. Oder schiebe ich nur den Beginn des Sprechens auf? warum sage ich nichts und gewinne nur Zeit? Aus Angst. Es erfordert Mut, den Versuch einer Konkretisierung dessen, was ich spüre, zu wagen. Es ist, als hätte ich eine Münze und wüßte nicht, in welchem Land sie gültig ist.

(Lispector 1990: 14) $)^{54}$

Dieser Annäherungsversuch kulminiert in einer Szene, in der die Erzählerin sich über die Grenzen des bisherigen hinaus begibt, sich, dem hingibt ,was sie nicht versteht‘, ja, auch die ,schemenhafte Hand Gottes ergreift‘ und mit der lebendigen Materie gewissermaßen eins wird, ,sich dem Nichts annähert‘. Dies geschieht, als sie nach langer Zeit das Zimmer ihres Dienstmädchens betritt, das ihren Haushalt gerade verlassen hat, und in diesem ihr gänzlich fremd und leblos, ,trocken“ erscheinenden Zimmer einer Schabe begegnet, die sie zu töten versucht.

Aus den auf dieses Handlungselement folgenden Passagen soll nun abschließend eine Textstelle herausgegriffen werden, die zeigt, wie die an einzelnen Formulierungen bereits herausgearbeiteten Aspekte der Übersetzungsvarianten ganze Passagen, ganze Isotopien prägen. Immer wieder finden sich in der früheren Übersetzung für Lilith Textstellen, die im Abstrakten verortet sind und dem Gegenüber über Vergleiche mit dem Sinneserleben der Erzählerin vermittelt werden:

Versuche mich zu verstehen, das Neutrale ist unerklärbar und lebendig: so wie das Protoplasma, der Samen und das Protein lebendig und neutral sind. Und ich fühlte mich wie neugeboren, ich fühlte mich wie ein Mädchen, das vor kurzem initiiert wurde. Es war, als wäre mein Gaumen zuvor durch Salz und Zucker verdorben worden und meine Seele durch Freuden und Schmerzen - es war, als hätte ich niemals den ursprünglichen Geschmack gespürt. Und jetzt spüre ich den Geschmack des Nichts. Es war ein neuer Geschmack, wie der von Muttermilch, die nur dem Kind schmeckt, und sehr bald hatte ich mich von meinem verdorbenen Geschmack befreit. Durch den Zusammenbruch meiner Zivilisation und meiner Menschlichkeit - der mich mit schmerzlicher und wehmütiger Erinnerung erfüllte - durch diesen Verlust der Menschlichkeit gelang es mir, einer Orgie des Geschmacks beizuwohnen, in der die Identität der Dinge fühlbar wurde. ${ }^{55}$

(Lispector 1984: 109-110)

54 „Terá sido o amor o que vi? Mas que amor é esse tão cego como o de uma célula-ovo? foi isso? aquele horror, isso era amor? amor tão neutro que - não, não quero ainda me falar, falar agora seria precipitar um sentido como quem depressa se imobiliza na segurança paralisadora de uma terceira perna. Ou estarei apenas adiando o começar a falar? por que não digo nada e apenas ganho tempo? Por medo. É preciso coragem para me aventurar numa tentativa de concretização do que sinto. É como se eu tivesse uma moeda e não soubesse em que país ela vale.“ (Lispector 1964: 18).

55 „O neutro é inexplicável e vivo, procura me entender: assim como o protoplasma e ô sêmen e a proteína são de um neutro vivo. E eu estava toda nova, como uma recém-iniciada. Era como se 
„Einer Orgie des Geschmacks beizuwohnen, in der die Identität der Dinge fühlbar wurde“ - solche Formulierungen erzeugen eine Fülle von Assoziationen, während ihnen zugleich etwas Vages anhaftet, etwas Uneindeutiges. Weite Assoziationsräume entstehen: Was kann man sich unter einer „Orgie des Geschmacks“ vorstellen? Wie ist es, wenn die „Identität der Dinge fühlbar" wird? In der Suhrkamp-Ausgabe wird die ganze Passage konkreter und in ihrem Bezug auf das Sinnesleben kohärenter:

Versuche mich zu verstehen, das Neutrale ist unerklärbar und lebendig: so wie Protoplasma, Samen oder Protein lebendig und neutral sind. Ich fühlte mich wie neugeboren, wie eine Eingeweihte. Es war, als wäre mein Gaumen zuvor von Salz und Zucker und meine Seele von Freude und Schmerz verdorben worden - es war, als wäre ich niemals in den Genuß des ursprünglichen Geschmacks gekommen [Entworfen wird zunächst ein kohärentes Bild des Geschmacks-Erlebnisses, des Genusses - dass sich das Geschmackserlebnis auf den ganzen Körper ausweitet, spürbar wird in einem weiteren Sinne, folgt hier erst im nächsten Satz, Anm. LMK]. Und jetzt spüre ich den Geschmack des Nichts. Es war ein neuer Geschmack, wie der von Muttermilch, die nur dem Kind schmeckt, schnell hatte ich mich von meiner Geschmacksverirrung befreit. Mit der Zerstörung meiner Zivilisation und meiner Menschlichkeit - die eine große schmerzliche Sehnsucht in mir hervorrief - [hier wird die innere Dramatik deutlich, da es sich nicht nur um eine „Erinnerung“ handelt, Anm. $L M K]$ mit dem Verlust der Menschlichkeit erwachte eine Leidenschaft: ich begann, Geschmack an der Identität der Dinge zu finden.

(Lispector 1990: 85)

„Geschmack an der Identität der Dinge finden“ funktioniert als poetische Metapher eines im Sinneseindruck verankerten, verbildlichten Abstrakten. Die Formulierung „einer Orgie des Geschmacks beizuwohnen, in der die Identität der Dinge fühlbar wurde“ ist im Vergleich dazu eine Umschreibung, in der zwar die gesamte zitierte Passage mündet und auf der rhetorisch dementsprechendes Gewicht lastet, die aber auf nichts Greifbares, Sinnliches hinausläuft und als Metapher so nicht funktioniert. Solche Schwierigkeiten der Übersetzung sind es, die dem Text in der ersten deutschen Übersetzung in ihrer Häufung und ihrem Zusammenspiel seine Kraft entziehen. Gleichzeitig mag an den zitierten Textstellen deutlich geworden sein, welche Herausforderung er für die Übersetzung darstellt.

antes eu estivesse estado com o paladar viciado por sal e açúcar, e com a alma viciada por alegrias e dores - e nunca tivesse sentido o gosto primeiro. E agora sentia o gosto do nada. Velozmente eu me desviciava, e o gosto era novo como o do leite materno que só tem gosto para boca de criança. Com o desmoronamento de minha civilização e de minha humanidade - o que me era um sofrimento de grande saudade - com a perda da humanidade, eu passava orgiacamente a sentir o gosto da identidade das coisas.“ (Lispector 1964: 101-102) . 


\subsection{3 Übersetzungen und Literaturkritik in Deutschland}

Welche Rolle spielte es für die Zirkulation und Rezeption im deutschsprachigen Raum - um eine Frage wieder aufzugreifen, die eingangs aufgeworfen wurde welche Rolle spielte es, dass Lispector eine Frau war? Zum einen waren da die Schwierigkeiten, die es dem Suhrkamp Verlag auf einer ganz pragmatischen Ebene bereitete, die Rechte an diesem Roman zu erwerben, nachdem der Frauenbuchverlag Lilith sie innehatte und eine unzulängliche Übersetzung erschienen war. Man kann nur darüber spekulieren, wie anders das Engagement des Verlags für diese Autorin ausgesehen hätte, wäre nicht jedes Buchprojekt aufs Neue mit hohen Kosten und zeitlichen Verzögerungen einhergegangen. Dass es noch eine andere Ebene gab, auf der es eine prägende Rolle spielte, dass Lispector eine weibliche Autorin war, zeigen die Rezensionen in der deutschsprachigen Presse der Zeit: Liest man Literaturkritiken aus der ersten Phase ihrer „Entdeckung“ in Deutschland, einer - zunächst ja sehr zögerlichen - Entdeckung durch die Verlage Suhrkamp und Rowohlt in den 1980er und 1990er Jahren, liegt der Bezug zu diesem Thema immer wieder auf der Hand.

Mehrere Rezensionen zu Der Apfel im Dunkeln (zunächst 1964 bei Claassen erschienen, dann 1983 bei Suhrkamp neu herausgebracht, in der bestehenden Übersetzung von Curt Meyer-Clason) kreisen um die Überlegung, dass es sich hier offenbar nicht um „Frauenliteratur“ handeln könne, obwohl man Clarice Lispector eigentlich in diesem Kontext verorten möchte, das wird zumindest implizit immer wieder deutlich. Christoph Neidhart (1984) schreibt in der Frankfurter Rundschau:

Der Apfel im Dunkeln indes ist keine „Frauenliteratur“ im marktgängigen Sinne, kein Text, der ein weibliches Schicksal beispielhaft fortführt, auch kein Beispiel typisch weiblicher Problematik, mit vielen Identifikationsangeboten für „Ich auch“-Leserinnen. Im Gegenteil, unter solchen Gesichtspunkten müßte der Roman als „Männerliteratur“ kategorisiert werden. Lispector fühlt sich so genau und umfassend in die Einsamkeit und den Schmerz, in die Größenphantasien und die Großmut ihres männlichen Protagonisten ein; kaum vorstellbar, daß der Text von einer Frau verfaßt wurde.

Problematisch ist nicht allein die wenig zu Lispectors Literatur passende Fixierung auf diese Frage, sondern dass das eigentlich Innovative an diesem Roman, sein experimenteller Charakter, sein Umgang mit Sprache, nicht ins Zentrum gerückt wird, oftmals nicht einmal kommentiert wird. Bemerkenswert ist auch, dass der Roman Der Apfel im Dunkeln im Deutschen, aber auch in den anderen hier verhandelten Sprachen nie neu übersetzt worden ist - ein Text, der leider allzusehr im Kontext der Diskussionen um Frauen- und Männerliteratur verhaftet geblieben ist. Das Debut Clarice Lispectors, 1981 erstmals auf Deutsch erschienen, wurde übrigens bei Suhrkamp 1987 im so genannten „Damenprogramm“ 
neu aufgelegt: Einer Reihe, in der unter dem Motto „Weißes Programm: Im Jahrhundert der Frau“ 22 Suhrkamp-Autorinnen aus der Backlist des Verlags in einer etwas aufwändigeren Leinen-Variante zusammengestellt und als Frauenliteratur vermarktet wurden. ${ }^{56}$

Die Literaturkritikerin Iris Radisch bezeichnete 1995, als Aqua viva ins Deutsche übersetzt erschienen war (Lispector 1994), diesen Roman Clarice Lispectors in der ZEIT als „Gründungsmanifest der Frauenliteratur“ (Radisch 1995). Hélène Cixous, so geht aus diesem Artikel hervor, spezialisiert im Fach „Études feminines“, habe die „écriture feminine“ in Frankreich erfunden und Água viva zum Gründungsmanifest erklärt, ohne dass der Text selbst auf französisch oder deutsch überhaupt publiziert worden sei. Clarice Lispector fungierte also schon als Patronin des französischen Feminismus, bevor überhaupt das dazugehörige Werk ins Französische übersetzt wurde, und auch in Deutschland eilte ihr dieser Ruf voraus. Iris Radisch legt diese Zusammenhänge offen, um dann selbst ganz in diesem interpretatorischen Kontext verhaftet zu bleiben. Die Lektüre von Aqua viva im Kontext von Clarice Lispectors Gesamtwerk gäbe eine solche Lesart hingegen nicht her. „Zum ersten Mal gibt es eine deutsche Übersetzung dieser 1973 verfaßten Bibel der weiblichen Literatur“ schreibt Radisch, „eher ein Dokument als ein Buch, ein beinahe schon historischer Text, die ferne Stimme einer Toten, die wie auf alten Schallplatten ein wenig blechern und geisterhaft zu uns herüberschallt“. Ihr Urteil: „Unvorstellbar, heute so zu schreiben“. Dies ist ganz aus der Verortung in einem französisch-femististischen Kontext heraus gedacht, den Clarice Lispector für diesen Text nie gesucht hat.

Eine andere Rezensentin greift dieses Thema ebenfalls auf, um diese Verortung Lispectors viel konsequenter zu problematisieren. Ellen Spielmann (1994) schreibt im Freitag: „Vielleicht ist Clarice Lispector heute, was die Erneuerung der Erzählprosa und die Auseinandersetzung mit weiblichem Schreiben betrifft, mit Virginia Woolf die bedeutendste Schriftstellerin der Moderne. Sicherlich ist sie - wie Jorge Luis Borges, Gabriel García Márquez und Julio Cortázar - eine der Stimmen Lateinamerikas, die eine tragende Rolle in der Weltliteratur und als Vermittlerin zwischen den Kulturen spielt. In Europa, Kanada und den USA wurde Clarice Lispector Ende der siebziger Jahre von der Frauenbewegung entdeckt, mehr oder weniger erfolgreich lanciert und teilweise auch vereinnahmt.“ Auch sie kommt auf die Rolle der Theoretikerin Hélène Cixous zu sprechen: „Für Hélène Cixous war die Entdeckung der Texte Clarice Lispectors der entscheidende Anstoß, um eine Theorie der weiblichen Schrift $\mathrm{zu}$ formulieren. Aqua

56 Ohne feministischen Impuls, kommentierte damals die NZZ („Im Jahrhundert der Frau“, 16.7.1987), anders als vergleichbare Reihen bei Fischer und Rowohlt. 
Viva wurde für sie zu einer Metapher für die Weiblichkeit in der Schrift schlechthin.“ Tatsächlich wurde der Text damit zu einem „historischen Text“, wie Iris Radisch geschrieben hatte - unglücklicherweise. In keinem der hier näher betrachteten Sprachräume wurde auch dieser Text - ähnlich wie Der Apfel im Dunkeln - jemals aus der Festlegung auf die „weibliche Schrift“, auf die „Bibel der weiblichen Literatur“ herausgelöst und wieder neu herausgebracht, nachdem die Hochphase der feministischen Literatur vorbei war. Nachdem auch der Übersetzungsprozess an Aqua Viva, wie bereits der Überblick über die Übersetzungen ins Deutsche gezeigt hat, wieder so enorm aufwändig und teuer gewesen war, läutete das Projekt das Ende der Suhrkamp-Bemühungen um ihr Werk ein. In gewisser Weise wandte man sich damit auch von einem Thema ab, das übermäßig mit ihrem Werk in Verbindung gebracht worden war. Ellen Spielmann (1994) schreibt weiterhin: „Doch die Claricewege sind weder als eine Strategie der Umkehrung der Geschlechterrollen oder Entwurf eines Gegenmodells mißzuverstehen, denn es geht nicht um ein Schreiben für weibliche Stimmen und Helden oder das Schaffen einer weiblichen Schrift." Spielmann verortet Lispectors Auseinandersetzung mit dem Schreiben in einer Tradition der modernen Literatur und der Auseinandersetzung mit dem Schreiben: „Schreiben wird in Aqua viva zu einem Experimentierfeld, das weder darauf abzielt, die Welt abzubilden, noch das Innere des Menschen auszudrücken.“

Zusammenfassend lässt sich sagen: Vielen deutschsprachigen Rezensionen der 1980er und 1990er Jahre ist gemein, dass sie - ob nun kritisch oder unkritisch gegenüber der Zuordnung Lispectors zu einer ,weiblichen Schreibweise ${ }^{\text {‘ }}$ - sehr auf dieses Thema fokussiert sind. Dabei besteht, das kann man an manchen solcher Texte nachvollziehen, auch eine besondere Gefahr, dass sich solche Perspektiven mit Eindrücken mischen, die durch Übersetzungsfehler und -Unzulänglichkeiten entstanden sind, wie sie für die Arbeit an Die Passion nach G.H. gezeigt worden sind. Meinungen wie die folgende von Georg Sütterlin konnten unter solchen Umständen besonders Raum greifen: „Romane, deren Thematik dermassen reduziert ist, drohen an mangelndem Inhalt zu ersticken. Es scheint einfach nicht möglich, die eigene Person zu thematisieren, ohne dies mit einem zündenden Stoff anzureichern und mit prägnantem Stilwillen darzustellen. Lispectors Methode kommt daher bestenfalls im beschränkten Rahmen einer Erzählung zum Tragen.“ Dies schreibt Georg Sütterlin (1983) in der Neuen Zürcher Zeitung zu dem Roman Eine Lehre oder das Buch der Lüste, 1982 bei Lilith erschienen ein Roman, der ebenfalls neu übersetzt werden musste (die Übersetzung erschien bei Suhrkamp: Lispector 1988), bevor er in seinen ästhetischen Eigenheiten überhaupt rezipierbar war. Solche Meinungen verbreiteten sich in mehreren Fällen - ähnlich dem Bild von der „Bibel der Weiblichkeit“ in Bezug auf Aqua viva - ohne dass der dazugehörige Text interessierten Leser/innen 
(in angemessener Form) zugänglich gewesen wäre. Das deutsche Beispiel belegt dies gut. Hinsichtlich auch der neueren Rezeptionswelle durch die Übersetzungen bei Schöffling \& Co im 21. Jahrhundert ist auch noch ein weiterer Punkt wegweisend: Bereits in den 1980er Jahren kritisierten Rezensent/innen wiederholt, dass den Suhrkamp-Ausgaben erläuternde Begleittexte fehlen. Zu der Neuausgabe von Der Apfel im Dunkeln 1983 etwa schreibt Hanspeter Brode (1984) in der FAZ:

Die Neuausgabe darf als schöner Beleg gelten für das zähe Bemühen des Verlages, lateinamerikanische Literatur in unseren Breiten durchzusetzen. Aber der hiesige Leser leidet ein weiteres Mal: kein Nachwort, keine Erläuterung, nicht einmal eine biographische Notiz. Da spart man nicht an Druck- und Bindekosten, bringt endlich ein stattliches Buch zuwege, aber die unentbehrlichen zehn Seiten Hilfestellung fehlen.

Dass eine solche „Hilfestellung“ in den vielen Neuausgaben, die im 21. Jahrhundert erschienen sind, oftmals vorhanden ist, spricht dafür, wie dringend etwa europäische und US-amerikanische Leser/innen eine solche Erläuterung, einen Kontext tatsächlich benötigen, um Clarice Lispector mit Gewinn rezipieren zu können. Ein gutes Beispiel für eine solche, gelingende Kontextualisierung ist der bei New Directions in New York erschienene Band The Hour of the Star, der mit Vor- und Nachwort versehen ist. Hinsichtlich des Leser/innen-Bedürfnisses der Verortung des Werkes, aber auch der Person Clarice Lispectors ist weiterhin ein Aspekt von Bedeutung, auf den Ellen Spielmann (1994) hinweist: „Diese sehr intime Stimme eines weiblichen Ich, die Bekenntnis ablegt, verführte die Kritik oft dazu, sich in die Fallstricke einer biographischen Lektüre zu begeben. Dieses gerade im Umgang mit weiblichen Texten übliche Verfahren trägt meist nur zur Legendenbildung über die Schriftstellerin bei. Die Erklärung vom Werk durch die Biographie und umgekehrt läßt wesentliche Fragen und Antworten, die Clarice Lispectors Texte liefern, außer acht.“ Als 2013 Benjamin Mosers Lispector-Biographie in Deutschland erscheint, erfüllt sich diese Sehnsucht nach dem Biographischen in umfassender Weise. Es lässt sich beobachten, dass sich in der deutschen Presse in der Folge ein Festschreiben auf bestimmte biographische Narrative einstellt, die die Rezensionen $\mathrm{zu}$ ihrem Werk fortan durchziehen und die sicher - mit Spielmann - kritisch gesehen werden müssen, gerade in der verkürzten Darstellung. ${ }^{57}$

Nachdem das auf deutsch erschienene Werk Lispectors bei Suhrkamp und Rowohlt nun also jahrelang vergriffen war und auch in Intellektuellenkreisen

$57 \mathrm{Zu}$ nennen wäre etwa eine häufig anzutreffende, einseitige Fixierung von Rezensent/innen auf die Prägung Clarice Lispectors durch Erfahrungen von Krankheit und Verlust, für die ausschließlich die Biographie der früh verstorbenen Mutter herangezogen wird. 
offenbar völlig in Vergessenheit geriet, hat der deutschsprachige Verlag Schöffling \& Co im Kontext eines Gastlandauftritts Brasiliens bei der Frankfurter Buchmesse 2013 eine Übersetzung der in den USA bereits erfolgreichen Biographie Benjamin Mosers sowie der beiden ersten Romane Lispectors gewagt. Es folgte 2016 der Roman Der große Augenblick, ein Erfolg ebenfalls in den USA, der in Deutschland zwar von Kritikern gut besprochen wurde, das breitere Publikum aber nicht erreichte. Im Herbst 2019 erschien dann ein Band mit den Erzählungen der Autorin: Tagtraum und Trunkenheit einer jungen Frau, der erste Band einer 2-bändigen Gesamtausgabe. Interessant ist, dass fast noch mehr als in den 1980er Jahren, als Lispector stark im Kontext von Fragen um „Frauenliteratur“ wahrgenommen wurde, im beginnenden 21. Jahrhundert in Deutschland ein recht enges, festgelegtes Spektrum an Themen die Rezensionen prägen. Der Verweis auf die Person Clarice Lispector erfolgt in Deutschland immer wieder über den Kommentar von Gregory Rabassa, sie habe ausgesehen wie Marlene Dietrich und geschrieben wie Virginia Woolf (Rabassa 2005: 70). Die gesamte Rezeption ist sehr spürbar an den in den USA erschienenen Kritiken sowie an Mosers Perspektive orientiert. Aus dem überstrapazierten Vergleich mit Virginia Woolf, der inhaltlich nicht sehr weit reicht, spricht die in der deutschen Literaturkritik nach wie vor sehr ausgeprägte Tendenz, nicht-westliche Autoren mit den bekannten Größen der westlichen Welt zu vergleichen (vgl. Meyer-Krentler 2019: 7-15; 43). Die übergroße Bedeutung, die in fast allen deutschsprachigen Rezensionen darüber hinaus dem Vergleich mit dem Bekannten beigemessen wird - auf literarischer Ebene sind es neben Woolf immer wieder Vergleiche mit Kafka und Joyce, die sie als Weltliteratin ausweisen sollen - kontrastiert mit dem Eindruck, dass die Person Lispector über ihre außergewöhnliche und vielbeschworene Schönheit hinaus dem internationalen Lesepublikum kaum greifbar war. „Wer war diese Frau, von der es hieß, sie habe ausgesehen wie Marlene Dietrich und geschrieben wie Virginia Woolf?" fragt Carmen Stephan in einem Artikel zu Lispectors Werk noch Anfang des Jahres 2014, und weiter: „Bis heute lässt sich diese Frage nicht beantworten. Das Geheimnis zählt zu ihrem tiefsten Wesen, das Geheimnis macht sie lebendig“ (Stephan 2014). Erst der „hingebungsvollen Arbeit ihres Biographen Benjamin Moser“ schreibt ein anderer Rezensent, sei es „zu verdanken, dass sich hier endlich ein zusammenhängendes Bild ergibt“ (Müller 2013).

Zugänglich wird Lispectors Werk den deutschsprachigen Rezensentinnen und Rezensenten offenbar über ein solches Bild von ihrer Person und - auch wieder sehr deutschlandspezifisch - ganz besonders über die von mehreren Kritikerinnen und Kritikern so genannte „doppelte Tragödie“ ihres Lebens, die darauf anspielt, dass Clarice Lispector als Kind habe erleben müssen, wie ihre Mutter starb und dann als Erwachsene einen der Söhne nicht vor einer Schizophrenieerkrankung habe retten können - auf diese doppelte Ohnmachtserfahrung wird 
mitunter ihr literarisches Werk sehr weitgehend zurückgeführt. Eine Rezension in der Frankfurter Allgemeinen Zeitung zu den Publikationen bei Schöffling (im Zusammenhang des Gastlandauftritts Brasilien bei der Frankfurter Buchmesse 2013 sind das: Nahe dem wilden Herzen, Der Lüster und die Biographie von Benjamin Moser) formuliert diese Perspektive auf ihr Leben und Werk besonders nachdrücklich:

Und tatsächlich ist der Tod das lebensbeherrschende Thema dieser Autorin. Clarice wie sie von ihren Anhängern bald nur noch genannt wurde - hieß ursprünglich Chaja Pinchassowna und wurde 1920 in Tschetschelnik, einem kleinen Ort im ukrainischen Polodien, geboren, mitten hinein in die furchtbarsten Greuel des Bürgerkriegs, kurz bevor es den Eltern gelang, mit den Töchtern nach Brasilien zu emigrieren. Über ihre Herkunft hat Lispector sich selten geäußert, umso mehr hat sich das schreckliche Schicksal ihrer Mutter Mania direkt und indirekt in ihren Texten und öffentlichen Äußerungen niedergeschlagen: Sie war eine der zahllosen Frauen, die von russischen Soldaten vergewaltigt wurden, und trug nicht nur die psychischen Leiden davon, sondern litt in der Folge auch an einer schweren Syphilis-Erkrankung, die so weit auf das Nervensystem übergriff, dass sie am Ende ihres Lebens fast vollständig gelähmt war. Die Mutter starb wenige Monate vor Clarice Lispectors zehntem Geburtstag. ,Ich wurde für meine Geburt so schön vorbereitet", notiert Lispector 1944, halb selbst dem Volksglauben erliegend, halb sich einen fatalen Fluch auferlegend:,Meine Mutter war damals schon krank, und einem recht verbreiteten Aberglauben folgend, dachte man, ein Kind zu bekommen, kann eine Frau von einer Krankheit heilen ... Nur habe ich meine Mutter nicht geheilt. Und ich spüre bis heute ,wie diese Schuld auf mir lastet.' Der Wunsch, Erlöserin zu sein, und sein permanentes Scheitern ist eines der traurigen Motive, die sich durch die Romane ziehen.

(Porombka 2013)

Nachdem sie über dieses Motiv einen Zugang zu verschiedenen Texten der Autorin sucht, schließt Porombka dann am Ende der Besprechung den Kreis zur „doppelten Tragödie“ der Lispector:

Das doppelt Tragische am Leben dieser eigenwilligen Schriftstellerin, deren Werk so eng verflochten ist mit ihrer Biographie, kann man bei Benjamin Moser aufs eindrücklichste nachlesen: Auch ihren ältesten Sohn Pedro, der an Schizophrenie erkrankte, hat Lispector nicht retten können. Ihr Wunsch nach Erlösung sollte nicht erfüllt werden. Postum immerhin erfolgte die Anerkennung als Schriftstellerin.

(Porombka 2013)

Auch wenn die Biographie der Autorin wichtige Kontexte bietet, um sich dem für viele Leser lange offenbar so schwer verständlichen Werk zu nähern, müssen solche Interpretationsversuche in ihrer Ausschließlichkeit dennoch sehr kritisch gesehen werden: Ist das Tragische, das Leben und Werk Lispectors verbindet, wenn man schon danach fragt, nicht viel stärker als bisher geschehen auch in der jüdischen Geschichte zu suchen? Warum wird das ,doppelte Trauma' ihrer privaten Verlusterfahrungen in der deutschen Literaturkritik so ausbuchstabiert, während, um dieses Beispiel herauszugreifen, die traumatische Entlassung jüdischer Mitarbeiter beim Jornal do Brasil unter der brasilianischen Diktatur meist gänzlich 
unerwähnt bleibt, die Lispector im Januar 1974 ereilte und die ihr ihr Publikum, ihre Leser nahm? Nicht abschließend geklärt ist auch, ob die Syphilis-Erkrankung der Mutter, über die Moser so eindrucksvoll schreibt, als zweifelsfrei erwiesen gelten kann und wie die Mischung aus Fiktionalem und faktisch Recherchierbarem bei Moser insgesamt zu bewerten ist. Eine kritische Anmerkung in diese Richtung, die Mosers herausragende Leistung als Biograph gleichzeitig würdigt, findet sich bei Felix Philipp Ingold (2013) in der Neuen Zürcher Zeitung:

In einem fast 600-seitigen Band unternimmt es Benjamin Moser, die bisher kaum erhellte osteuropäische Herkunft wie auch den internationalen Lebens- und Schaffensweg der Autorin faktografisch nachzuzeichnen. [...] Dass sich die sehr persönlich intonierte biographische Erzählung über weite Strecken an den Leitfaden des Romanwerks hält, mithin fiktive Texte als Lebensdokumente nutzt, ist problematisch - zu vermeiden war das bei der prekären Quellenlage wohl nicht.

Eindrucksvoll bleibt ungeachtet solcher Fragen, in welchem Maße das Werk von Clarice Lispector offenbar eines biographischen Zugangs bedurfte, um überhaupt eingehender rezipiert zu werden. Nun endlich muss es auch um die englischsprachigen Ausgaben gehen, die in Europa den Weg für solche Rezeptionsperspektiven erst geebnet haben.

\section{3 Übersetzung und Rezeption in der englischsprachigen Welt}

Die Rezeption in der englischsprachigen Welt ist aus verschiedenen Gründen sehr zentral, um Clarice Lispectors weltweite Rezeption zu verstehen: Zum einen, weil insbesondere die USA eine so entscheidende Rezeptionsstufe für Übersetzungen in andere Sprachen markieren, zum anderen aber auch, weil sie ganz eigene Brüche und Misserfolge sichtbar macht, die Clarice Lispectors Übersetzungs- und Rezeptionsgeschichte nachhaltig geprägt haben.

\subsubsection{Kommentierter Überblick: Erstausgaben in den USA/England ${ }^{58}$}

$\mathrm{Zu}$ Clarice Lispectors Lebzeiten, vor ihrem Tod 1977, erschienen auf Englisch nur zwei Monographien: ein Roman und ein Erzählband. Und das, obwohl in den 1960er Jahren durchaus vielversprechende Kontakte in die englischsprachige

58 Aufgelistet sind auch hier ausschließlich Kommentare zu zentralen Erst- bzw. Neuübersetzungen des literarischen Werkes, nicht etwa die - oftmals leichter lesbaren und thematisch mit dem literarischen Werk manchmal verwobenen - journalistischen Arbeiten (vgl. dazu den Sammelband Discovering the World, in der Übersetzung von Giovanni Pontiero erstmals 1992 
Verlagswelt entstanden. Der Übersetzer Gregory Rabassa hatte den 1961 in Brasilien erschienenen Roman A maçã no escuro zur Kenntnis genommen und empfahl seine Autorin dem amerikanischen Verleger Alfred A. Knopf. Im Zuge einer eigenen Brasilien-Reise Anfang der 1960er Jahre wurde Knopf zudem bewusst, wie angesehen Clarice Lispector in Intellektuellenkreisen zu dieser Zeit war, mit Guimarães Rosa zusammen gelte sie als die Autorin der Stunde, sagten ihm verschiedene Gesprächspartner im Kontext dieser Reise. Tatsächlich kaufte er die Rechte am Roman. Zeitgleich bemühte sich die Dichterin Elisabeth Bishop um eine Übersetzung von Kurzgeschichten Lispectors ins Englische - angesichts der häufigen Probleme mit Übersetzungen Lispectors beispielsweise in Frankreich ein Glücksfall, war sie doch als muttersprachlich Englisch sprechende, in Brasilien lebende Dichterin und Übersetzerin prädestiniert für diese hoch anspruchsvolle Arbeit an einem Werk mit so eigener Ästhetik. Bishop bekannte sich zudem als glühende Verehrerin von Clarice Lispectors Kurzgeschichten: Sie finde sie sogar besser als Borges, schrieb sie 1962 an Ilse und Kit Barker (Moser 2013a: 319). All dies hätte einiges Potential entfalten können.

Allerdings verzweifelte Bishop im Zuge ihrer Übersetzungsarbeit geradezu an der Tatsache, dass sich Clarice Lispector dem Kontakt entzog, über Wochen für sie nicht erreichbar war. Im Januar 1963 schrieb Elisabeth Bishop aus Rio de Janeiro an Robert Lowell:

I have translated five of Clarice's stories, all the short ones \& one longer one. The New Yorker is interested - I think she needs money, so that would be good, the \$ being what it is ... But at the moment, just when I was ready to send off the batch, except for one, she has vanished on me - completely - and for about six weeks!

(Tóibín 2011: vii)

Im Juni 1964 brachte Bishop eine Lispector-Übersetzung im Kenyon Review unter: "Marmosets", ein Text, der später wiederholt in Anthologien erschien. 1967 erschien dann der erwähnte Roman bei Knopf:

1967 (USA)/1985 (England): The Apple in the Dark. Übersetzt von Gregory Rabassa. New York: Knopf/London: Virago.

Diese Publikation hatte durchaus Potential, auch wegen des namhaften Verlages und des erfolgreichen Übersetzers. Der Verleger Alfred A. Knopf verhalf in den 1960er Jahren mehreren Autoren insbesondere aus dem spanischsprachigen Amerika auf dem US-amerikanischen Buchmarkt zu weitreichender Bekanntheit. Als Clarice Lispectors Name in Knopfs Programm erschien, wurden ebenfalls Verlage wie Gallimard in Frankreich und

in England erschienen, in den USA 1996 bei New Directions in einer Auswahl erschienenen als Selected Crônicas). 
Suhrkamp in Deutschland aufmerksam, die den Roman sogleich übersetzen ließen und in ihr Programm aufnahmen.

In den USA lag der Text zudem in einer außergewöhnlich guten Übersetzung vor (vgl. Tanya T. Fayen, in: Marting 1993: 97-98). 1966 war in Rabassas Übersetzung Julio Cortázars Hopscotch erschienen, fast zeitgleich mit der Publikation von Lispectors Text in den USA wurde Gregory Rabassa für die Cortázar-Übersetzung mit dem National Book Award for Translation ausgezeichnet. Gabriel García Márquez wartete drei Jahre, um nach Julio Cortázars Erfolg mit Hopscotch ebenfalls von Gregory Rabassa übersetzt zu werden. Es ging um den Text Cien años de soledad. ${ }^{59}$ Bekanntlich ging Rabassas englische Übersetzung von García Márquez' Roman in einer beispiellosen Weise um die Welt. Der Text ist nicht nur der weltweit bekannteste der lateinamerikanischen Literaturen überhaupt, nach einer Recherche des Schriftstellers Ilija Trojanow (2017) ist es noch immer der einzige, mit dem ein Autor des ,Globalen Südens' in die Rankings der westlichen Medien zu einem Kanon der Weltliteratur Eingang gefunden hat.

In Lispectors Fall blieb die Resonanz auf Rabassas Übersetzung jedoch aus. Der Verleger hatte zwar zunächst Interesse an ihr, weil er nicht nur lateinamerikanische Literaturen aus den spanischsprachigen Ländern, sondern auch brasilianische Literatur publizieren wollte. Er hatte aber persönlich keinerlei Bezug, keinen Zugang zu Lispectors Text, der sich zudem nicht gut verkaufte, sodass Knopf Lispector nicht weiter vertrat und sich stattdessen, wie der Übersetzer selbst auch, neuen Entdeckungen zuwandte (Rabassa 2005).

Lispector erfuhr demnach keine kontinuierliche Förderung durch einen Verleger, wie sie bei vielen anderen lateinamerikanischen Autoren vonnöten war, bis sie in den USA erfolgreich wurden, wie etwa im Fall von Vargas Llosa oder Cortázar (vgl. Müller 2020). Dass der erste englischsprachige Roman eines spanisch- oder portugiesischsprachigen Autors am US-amerikanischen Markt nicht weiter erfolgreich war, war keine Seltenheit, eher die Regel. Allerdings hatte Clarice Lispector auch im Umfeld ihres amerikanischen Verlegers keine wichtigen Fürsprecher/innen, sie selbst pflegte bezüglich eines Gatekeeping in den USA keine engeren Kontakte (obwohl sie von 1952 bis 1959 in den USA lebte), kurz: Es waren keine Voraussetzungen dafür gegeben, dass sich ein ,langsamer Erfolg‘ hätte einstellen können. Eine Neuauflage von The Apple in the Dark in den USA brachte 1986 nicht mehr Knopf, stattdessen University of Texas Press.

1972, fünf Jahre nach der Publikation bei Knopf, erschien erstmals ein englischsprachiger Band mit Erzählungen Clarice Lispectors, auf den sich ihr Ansehen als „Short Story Writer” in den USA im Wesentlichen gründen sollte:

1972 (USA) Family ties. Übersetzt von Giovanni Pontiero. Austin: University of Texas Press.

59 Marling schreibt dazu: , [...] the assignment to translate Cien Años de Soledad landed in Gregory Rabassa's in-box on the basis of his translation of Julio Cortázar (symbolic capital), which came through friendship with Paul and Sara Blackburn (social capital), but there it remained for three years. Only García Márquez' sense of his potential earnings and audience in English persuaded him to wait“" (Marling 2016: 8-9). 
Auch wenn der Text zunächst ohne große Resonanz blieb, interessierten sich doch im Laufe der Jahre immer wieder Zeitschriftenredaktionen oder Herausgeber/innen englischsprachiger Anthologien für Clarice Lispectors Erzählungen. So erschien beispielsweise „Marmosets“, übersetzt von Elisabeth Bishop. ${ }^{60}$ Der der Sammlung Family ties zugrundeliegende, 1960 in Brasilien erschienene Band Laços de família hat Überschneidungen mit der früheren Publikation Alguns contos. Vor allem aus diesen beiden Kurzgeschichten-Sammlungen stammen viele Erzählungen Lispectors in englischsprachigen Anthologien (z. B. Short Stories of the Americas (1974), Longman Anthology of World Literature by Women, 1875-1975 (1989), oder auch: A Hammock beneath the Mongoes: Stories from Latin America (1991). Bezüglich der Erfahrungen mit Kurzgeschichten Clarice Lispectors auf dem US-amerikanischen Buchmarkt lässt sich eine weitere Parallele zu Julio Cortázar vermuten. William Marling schreibt: „The American poet Paul Blackburn, serving as US agent of his friend Julio Cortázar, discovered that he could charge higher prices for short stories than for longer works, because Americans just wanted a taste of Cortázar’s dizzying prose“ (Marling 2016: 16) - eine Einschätzung, die wohl auch für Clarice Lispectors Literatur zutrifft. Auch bei Lispector ging es lange lediglich, wenn überhaupt, um einen „taste“ ihrer Erzählweise als um eine Rezeption längerer Texte im Werkzusammenhang. Auch während der Rezeptionswelle in den USA nach der Publikation der Biographie von Benjamin Moser 2009 und der ersten Bände seines „retranslation project“ waren es wieder Erzählungen, diesmal die gesammelten Erzählungen der Autorin, denen die Aufmerksamkeit der Literaturkritik in ganz besonderer Weise galt.

Aber zurück zu der Erstpublikation ihres englischsprachigen Erzählbandes in den 1970er Jahren: Nach dieser Knopf-Publikation 1967 erschien nun also 19 Jahre lang kein weiterer ihrer Romane oder längeren Erzähltexte auf Englisch. Der Verlag, der bereits den Erzählungsband „Family Ties“ realisiert hatte, ließ dann Mitte der 1980er Jahre von einem neuen Übersetzer-Team einen Roman übersetzen, der im Rahmen der Feminismus-Debatten in Frankreich besprochen worden war: ${ }^{61}$

1986 (USA): An Apprenticeship; or, The Book of Delights. Übersetzt von Richard A. Mazzara and Lorri A. Parris. Austin: University of Texas Press.

Den letzten von Lispector selbst 1977 noch beendeten Roman übersetzte dann wieder Giovanni Pontiero, erstmals für New Directions, den Verlag also, der sich nach der Wende zum 21. Jahrhundert zu einer Neuübersetzung mehrerer Lispector-Bände unter der Herausgeberschaft von Lispectors Biograph und Förderer Benjamin Moser entschließen sollte. Moser äußerte in diesem Zusammenhang mehrfach die Meinung, Lispectors Reputation habe sehr unter einigen schlechten Übersetzungen ihrer Werke ins Englische gelitten, manche ihrer Texte seien auf Englisch so gut wie unlesbar (Morgan Teicher 2011), was ein wichtiger Grund dafür sei, dass sie in der englischsprachigen Öffentlichkeit so wenig beachtet worden sei. Unter anderem bezieht sich diese Kritik offenbar auf die Arbeit von Giovanni Pontiero, der erstmals in den 1980er Jahren The Hour of the Star übersetzte.

60 In: The Eye from the Heart. Short Stories from Latin America. Ed. Barbara Howes. New York: Bobbs-Merrill, 1973, S. 455-457.

61 Vgl. zu dem Text auch die Passagen zu Lispectors „Sprache des Körpers“ in Ette (2021). 
1986 (England)/1992 (USA): The Hour of the Star. Übersetzt von Giovanni Pontiero. Manchester: Carcanet/New York: New Directions.

Im gleichen Publikationsjahr erschien jeweils in England (1986) und in den USA (1992) eine Sammlung von Erzählungen und Crônicas in Pontieros Übersetzung:

1986 (England)/1992 (USA): The Foreign Legion: Stories and Chronicles. Übersetzt von Giovanni Pontiero. Manchester: Carcanet/New York: New Directions.

Während die Meinungen der Experten zur Erstübersetzung The Hour of the Star etwas auseinandergehen, sind die Mängel des letzteren Bandes offensichtlicher. Tanya T. Fayen schreibt dazu: „Although Pontiero is thoroughly familiar with Lispector's work, as his numerous translations of her work attest, this is an awkward translation. There are frequent changes from the original and misattribution of dialogue which may confuse readers. Pontiero regularly breaks Lispector's longer sentences, sometimes inexplicably. He also adds information to clarify her images“ (Marting 1993: 81). University of Minnesota Press lässt Ende der 1980er Jahre ebenfalls zwei zentrale Texte von verschiedenen Übersetzern Ins Englische übertragen:

1988 (USA): The Passion According to G.H. (1964). Übersetzt von Ronald W. Sousa. Minneapolis: University of Minnesota Press.

1989 (USA): The Stream of Life (1973). Übersetzt von Elisabeth Lowe und Earl Fitz. Minneapolis: University of Minnesota Press.

Diese letztgenannte Übersetzung von Elisabeth Lowe und Earl Fitz ist recht einhellig als sehr gelungen kommentiert worden und beinhaltet eine profunde Auseinandersetzung mit Lispectors Poetik (vgl. Marting 1993: 7). Bei New Directions erscheinen dann ein weiterer Erzählband sowie Lispectors Debut aus dem Jahr 1943:

1989 (USA): Soulstorm. Stories (29 Erzählungen, aus: Onde estivestes de noite, 1974/A via crucis do corpo 1974). Übersetzt von Alexis Levitin. New York: New Directions.

1990 (USA/England): Near to the Wild Heart. Übersetzt von Giovanni Pontiero. New York: New Directions 1990/Manchester: Carcanet 1990.

Es sind damit im Laufe des 20. Jahrhunderts seit Lispectors Debut 1943 in Brasilien im englischsprachigen Raum verschiedene zentrale Romane und Erzählbände erschienen, allerdings entstand dabei keine rechte Kontinuität bei Übersetzer/innen und/oder Verlagen. Anders gesagt: Es gab niemanden, der ihr Werk nachhaltig vertrat, wie es später dann der Biograph und Übersetzer Moser in Zusammenarbeit mit dem amerikanischen Verlag New Directions getan hat. Diese Geschichte vieler verschiedener Übersetzer, die nur sehr vereinzelt Übersetzungen geschaffen haben, die der Kritik standhalten bzw. die wichtigsten Charakteristika von Lispectors Schreiben in ihren Texten überhaupt transportieren konnten, ist in der angelsächsischen Welt lange nicht reflektiert worden. Dies mag 
etwa ein Eintrag in die Encyclopedia of Literary Translation Into English ${ }^{62}$ verdeutlichen („Clarice Lispector: Brazilian novelist, short-story-writer and journalist“). Über die Übersetzung und Zirkulation im englischsprachigen Raum heißt es dort in einer teils schlichtweg nicht korrekten, teils recht unreflektierten Formulierung: „Clarice Lispector’s writings have been consistently well translated into English, which unfortunately cannot be said of versions of her work in some other languages. Giovanni Pontiero has translated five of her nine extant volumes into British English, and Gregory Rabassa won the National Book Award for Translation in 1967 for The Apple in the Dark into American English."63 Diesem positiven Blick hält - dies ist in der Übersicht bereits deutlich geworden - ein genaueres Hinsehen auf die Übersetzungsgeschichte in den USA nicht stand. Einzig wird in der Encyclopedia Bedauern darüber ausgesprochen, dass nur die populärsten und bekanntesten Lispector-Texte auf Englisch vorlägen, während „her most experimental works have yet to appear in English“.

Dieser Situation wirkte im 21. Jahrhundert ein Stück weit dann der New Yorker Verlag New Directions entgegen: Zunächst erschien Benjamin Mosers Lispector-Biographie 2009. Das Buch bekam in den USA und mehreren europäischen Ländern hervorragende Besprechungen, ,a surprise hit“ (Morgan Teicher 2011), der zeigte, dass es für das Thema ein Publikum gab. Als Moser gehört habe, dass man bei New Directions plane, The Hour of The Star neu aufzulegen und mit einem Begleittext des Schriftstellers Colm Tóibín zu versehen, habe Moser sich dafür eingesetzt, dass der Roman neu übersetzt würde und schließlich eingewilligt, die Übersetzung selbst zu besorgen. Nicht nur Lispector wurde in dieser Zeit neu aufgelegt, man versah auch andere Autoren der Backlist mit neuen Covern und mit Kommentaren bekannter zeitgenössischer Autoren, um sie neu herauszubringen. Sehr wichtig für diese neue Publikation von The Hour of the Star ist neben Mosers Übersetzung in der Tat der Begleittext von Colm Tóibín, auf wenigen Seiten ein sehr zentraler, sehr pointierter Schlüsseltext zu Lispector.

2011 (USA) The Hour of the Star. Übersetzt von Benjamin Moser. Mit einem Vorwort von Colm Tóibín und einem Nachwort von Benjamin Moser. New York: New Directions.

2012 (USA) Near to the Wild Heart. Übersetzt von Alison Entrekin. Herausgegeben von Benjamin Moser. New York: New Directions.

2012 (USA) The Passion according to G.H. Übersetzt von Idra Novey. Herausgegeben von Benjamin Moser. New York: New Directions.

2012 (USA) Água Viva. Übersetzt von Stefan Tobler. Herausgegeben von Benjamin Moser. New York: New Directions.

62 Band A-L (Vol. 1), Hg. O. Classe, Routledge 2001, S. 856.

63 Dies ist so nicht richtig (wenn auch häufig kolportiert worden, vgl. auch Tanya T Fayen, in: Marting 1993, S. 97). Rabassa erhielt den Preis für Cortázars Hopscotch, Lispectors Buch war zu diesem Zeitpunkt seine aktuelle Übersetzungsarbeit. 
2012 (USA) A Breath of Life. Übersetzt von Johnny Lorenz. Herausgegeben von Benjamin Moser. New York: New Directions.

Die portugiesischsprachige Vorlage zu A Breath of Life wurde aus dem Nachlass publiziert von Olga Borelli - es handelt sich um Lispectors letzten, von ihr nicht mehr vollendeten längeren Prosatext.

2015 (USA) The Complete Stories. Übersetzt von Katrina Dodson. Herausgegeben von Benjamin Moser. New York: New Directions.

Das Erscheinen der 86 gesammelten Erzählungen Lispectors löste in den USA eine Welle der Begeisterung aus. Enthusiastische Besprechungen und/oder Kommentare zu ihren Short Stories erscheinen in so unterschiedlichen englischsprachigen Medien wie Art in America, The Boston Globe, The Times, The New York Times Book Review, Publishers Weekly, The Wall Street Journal, Vanity Fair, Vogue, Women's Review of Books, Newsday, The National, TIME, The New Republic und zahlreichen mehr. Der New York Times Book Review kommt, 38 Jahre nach ihrem Tod, zu dem Schluss: „Clarice Lispector is the premier Latin American woman prose writer of the century“. Die Übersetzerin Katrina Dodson erhielt für ihre Arbeit an dem Band den 2016 den PEN Translation Prize. Weiterhin erschien Lispectors zweiter Roman, der bisher allerdings in keinem der genannten Sprachräume übermäßig viel Resonanz erfuhr:

\section{8 (USA) The Chandelier. Übersetzt von Benjamin Moser und Magdalena} Edwards. New York: New Directions.

Noch weniger bekannt war der dritte Roman, den sie in der Schweiz geschrieben hatte. Ihr amerikanischer Verlag New Directions schreibt dazu auf der Verlags-Homepage ${ }^{64}$ : „Seven decades after its original publication, Clarice Lispector's third novel - the story of a girl and the city her gaze reveals - is in English at last.“ Nach dem großen Erfolg vor allem von The Hour of the Star und der gesammelten Erzählungen wurden nun auch die unbekannten, weniger verkäuflichen Texte ins Verlagsprogramm aufgenommen, sodass mehr und mehr tatsächlich das Gesamtwerk der Autorin auf englisch zugänglich wurde.

2019 (USA) The Besieged City. Übersetzt von Johnny Lorenz. Herausgegeben von Benjamin Moser. New York: New Directions.

Im Jubiläumsjahr 2020, in dem sich der Geburtstag Clarice Lispectors zum 100. Mal jährte, erschien zudem eine Hardcover-Ausgabe des Erfolgstitels The Hour of the Star, mit einem Nachwort eines der Söhne von Clarice Lispector, der zuvor ihre Rechte vertreten, sich aber nicht auf diese Weise zum Werk der Mutter geäußert hatte. Ihn für das Projekt zu gewinnen, passt zu der Strategie des Herausgebers, Werk und Person bzw. einen persönlichen Zugang zur Biographie der Autorin eng zu verknüpfen.

64 Stand: 27.7.2020. 
2020 (USA) The Hour of the Star. Übersetzt von Benjamin Moser. Mit einem Vorwort von Colm Tóibín und Nachworten von Paulo Gurgel Valente und Benjamin Moser. New York: New Directions.

Der Verlag bewirbt die Sonder-Edition wie folgt: „Clarice Lispector's best-selling masterpiece - ,her finest book' (The Nation) - now in a special hardcover edition to celebrate the centenary of her birth, with an illuminating new afterword by her son. ${ }^{* 65}$ In diesem Nachwort geht Paulo Gurgel Valente, der jüngere Sohn Clarice Lispectors, darauf ein, wie stark das Bedürfnis, soziale Veränderungen in Brasilien herbeizuführen, in ihrem Leben verankert gewesen sei. Er beschreibt die Suche nach einem Weg, dies in ihr Schreiben zu integrieren, bis es zur Publikation dieses Romans kam.

\subsubsection{The Apple in The Dark -„I didn't understand a word of it“}

Alfred A. Knopf publizierte in den für die internationale Zirkulation lateinamerikanischer Literaturen in den USA so wichtigen 1960er Jahren Lispectors Roman A maçã no escuro (1961; The Apple in the Dark, 1967) - übersetzt von Gregory Rabassa, eine Übersetzung, die von Experten immer wieder sehr gelobt worden ist. Warum geriet nun The Apple in the Dark, während die Romane zahlreicher lateinamerikanischer Autoren in den USA boomten, schon so bald wieder in Vergessenheit? Warum nahmen Verlage zu späteren Zeitpunkten, wenn sie sich neu dem Werk dieser Autorin zuwandten, gerade diesen Roman nicht in ihr Programm auf? Für wie viele Jahre, anders formuliert, bleibt es ein Hinderungsgrund, wenn eine vergleichsweise unbekannte Autorin die Chance bekommt, in einem sehr renommierten Verlag zu veröffentlichen, der Erfolg aber ausbleibt? Es ging ja nicht nur um die Erfahrungen mit der englischsprachigen Ausgabe, auch Gallimard veröffentlichte 1970 eine Übersetzung des Romans, der kein weiterer Titel der Autorin mehr folgen sollte. Es folgten außerdem Ausgaben bei Suhrkamp in Deutschland (1983) und Feltrinelli in Italien (1988), beides Verlage, die zum damaligen Zeitpunkt zu den gerade im Kontext der bekannter werdenden lateinamerikanischen Literaturen zu den interessantesten und renommiertesten des jeweiligen Landes zählten. In mehreren Sprachen - auf deutsch, auf italienisch - ist der Roman inzwischen vergriffen.

Wie ist nun der Kontext für diese erste Übersetzung einer Lispector-Monografie ins Englische zu sehen? Nach den Angaben von Earl Fitz (1977) verfügte Lispector bereits über Notizen zum Roman, als sie 1952 als Ehefrau eines Diplomaten in die USA kam, und sie überarbeitete das über 500 Seiten starke Manuskript insgesamt

65 https://www.ndbooks.com/book/the-hour-of-the-star-1/\#/. 
11 Mal. Die Zeit der Endkorrektur und Erstpublikation (1961) fällt zusammen mit entscheidenden Wendepunkten in ihrem Leben und ihrer Karriere: mit der Trennung von ihrem Ehemann, der Rückkehr nach Brasilien mit den beiden Söhnen und dem Entschluss, sich ganz dem Schreiben zu widmen. Rabassas Übersetzung wurde einige Jahre nach dem Erscheinen bei Alfred A. Knopf 1967 von zwei anderen englischsprachigen Verlagen erneut publiziert: Virago Press, 1985 und University of Texas Press, 1986, was für einen gewissen Erfolg der Übersetzung spricht, allerdings blieb es die einzige Publikation bei Knopf, auch die beiden anderen englischsprachigen Ausgaben blieben ohne nennenswerte Resonanz beim breiteren Lesepublikum. Nancy Gray Diaz verweist auf die sprachliche Innovationskraft des Romans, einer der Gründe, warum er im Kontext des Gesamtwerkes von besonderer Bedeutung ist: „Some of the best criticism of ME [A maçã no escuro, Anmerkung LMK] focuses on Clarice's innovative use of language and on her thematics of language. ME like PGH [The Passion according to G.H., Anmerkung LMK], problematizes the spoken - and, by extension, the written - word as that which coincides with cognition of otherness, but since that otherness is made dramatically unfamiliar by the caracter's existential crisis, the word is no longer adequate to express the sensation or the thing“ (Marting 1993: 95). Das ist sicher eines der ganz prägenden Themen in Lispectors Werk: die krisenhafte Erfahrung „the word is no longer adequate to express the sensation or thing“ - Lispectors Held Martim erlebt dies auf der Flucht nach einem Verbrechen, das er begangen zu haben glaubt.

Wie waren die Umstände der Lispector-Publikation bei Knopf nun genau? Wie kam Alfred Knopf dazu, den Text nicht nur zu publizieren, sondern ihn im gleichen Atemzug auch zu degradieren? „I didn’t understand a word of it“, soll er nach seiner Lektüre gesagt haben (Moser 2009: 259). Von Lispector-Gegnern wurde dieser so abwertende wie skurrile Ausspruch ihres eigenen Verlegers während der Rezeptionswelle in den USA nach 2009 vermehrt wieder aufgegriffen (Shakespeare 2014) und ist zu einem festen Bestandteil der Debatte um die literarische Qualität ihres Werkes geworden.

Der Übersetzer Gregory Rabassa schreibt, er selbst sei 1962 erstmals in Brasilien gewesen und dort auf den Roman gestoßen, neben Grande Sertão: Veredas von João Guimarães Rosa sei er das Gesprächsthema unter den „books people“ in Brasilien gewesen (Rabassa 2005: 70). Wirkungsmächtig wurde allerdings auch bei Rabassa nicht nur seine Übersetzungsarbeit, sondern auch ein Ausspruch in Reaktion auf ein Treffen mit der Autorin:

A few years later I met Clarice at a conference in Brasil in Texas where she was the featured speaker. I was flabbergasted to meet that rare person who looked like Marlene Dietrich and wrote like Virginia Woolf. She also had those Kyrgisenaugen that so fascinated Thomas Mann.

(Rabassa 2005: 70) 
Der Vergleich mit Marlene Dietrich und Virginia Woolf ist in der internationalen Literaturkritik inzwischen zu der von Rezensenten am häufigsten zitierten oder auch einfach übernommenen Charakterisierung Clarice Lispectors geworden ${ }^{66}$ und dabei natürlich längst zu einer Phrase erstarrt, was nicht gerade förderlich ist, wenn es darum geht, die Eigenheiten dieser Autorin zu vermitteln. Über die Motivation von Alfred Knopf, Rabassa mit der Übersetzung des Romans $A$ maçã no escuro zu beauftragen, von dem ihm der Übersetzer bei einem Mittagessen erzählte (Rabassa 2005: 70), schreibt Rabassa:

Back in New York I was invited to lunch by Alfred Knopf to talk about Brazilian books. He had recently been married in Rio de Janeiro and this had increased his warm feelings for the country and his interest in its writers. He had already published books by Gilberto Freyre and wanted to do some more things, including Clarice's book. (Rabassa 2005: 70)

Hier erklärt sich vielleicht ein wenig, wie es möglich war, dass Knopf trotz seiner Publikationsentscheidung offenbar keinerlei inhaltlichen Zugang zu Lispectors Schaffen hatte - er war wohl mehr an dem Roman als einem der brasilianischen Texte der Stunde interessiert als an dem eigenwilligen Werk Lispectors. Dazu kam, dass das Projekt für den damals schon sehr bekannten Rabassa recht passend kam: „Hopscotch was behind me and I was finishing Mulata, so I was ready to take on another job. The conditions were ideal because I was preparing to leave for Brazil on my Fulbright and Clarice would be available in case I needed any help.“ (Rabassa 2005: 70-71). So kam also Gregory Rabassa zu seiner ersten Übersetzung aus dem Portugiesischen, darüber hinaus beauftragte ihn Knopf, ein Vorwort zu schreiben, „because they felt it would be difficult to understand“ (...). „I disagreed, but I was glad to oblige“ (Rabassa 2005: 74). Später scheint Rabassa diese Zusage zu bereuen: „[...] my explication would probably only be one of many possible twists“ (Rabassa 2005: 74). Interessant an Rabassas Aussagen zu seiner Lispector-Übersetzung ist in jedem Fall, dass ihr brasilianisches Portugiesisch ihm zufolge nicht schwer ins Englische zu übersetzen gewesen sei - anders etwa als im Fall eines Guimarães Rosa, und dass er den Roman zudem in keiner Weise als schwer verständlich empfand, während im Verlag diese Einschätzung vorherrschte. Ungewöhnlicherweise setzte Knopf den Namen des Übersetzers auf den Umschlag des Buches, was sonst nicht üblich war - eine besondere Anerkennung für den Übersetzer und eine Praxis, die im Verlag später nicht mehr fortgesetzt wurde.

Rabassa macht auch eine Aussage dazu, warum er nur einen einzigen Lispector-Text übersetzte:

66 So die Beobachtung nach Durchsicht zahlreicher Literaturkritiken zu Lispectors Werk insbesondere aus Deutschland, Frankreich, den USA und England. 
Clarice subsequently turned out several more fine novels and stories but I didn't do them. Her story "The Crime of the Mathematics Professor" had appeared in Odyssey as we went about discovering new talent. There was no breakup of any kind, just the usual situation in which I was working on something else.

(Rabassa 2005: 73)

Er verweist darauf, dass sich eine besondere Situation ergeben habe, als zwei seiner besten Studenten an der CUNY Graduate School, Elisabeth Lowe and Earl Fitz „went on to translate Clarice with great success“ (Rabassa 2005: 73). Rabassas Kommentar zum Erfolg bezieht sich dabei weniger auf eine nachhaltige Steigerung des Bekanntheitsgrades der Autorin oder eine Intensivierung der Zirkulation ihres Werkes als auf die Qualität der Übersetzung. Das Übersetzen eines Textes von Clarice Lispector war für viele Übersetzer - wie für Rabassa und seine Schüler - ein einmaliges Experiment. Oftmals ein Experiment, bei dem erstmals brasilianisches Portugiesisch übersetzt wurde - insgesamt wirkt es mitunter, als habe das Übersetzen ähnlich experimentellen Charakter wie die Literatur Clarice Lispectors selbst. Während die Autorin selbst immer wieder neue Herausforderungen suchte - ihre Prosa-Publikationen sind ja auch formal sehr unterschiedlich - gingen die meisten Übersetzer nach dieser Erfahrung ebenfalls zu neuen Herausforderungen über, in ihrem Fall: zu neu zu entdeckenden Autor/innen. Dies mag immer wieder äußere Gründe gehabt haben - Rabassa verweist darauf, er sei danach eben immer mit etwas anderem beschäftigt gewesen - aber ganz offensichtlich geht die Tendenz zum Übersetzen eher vereinzelter Werke bei Lispectors Übersetzern auch mit der Art ihres Schreibens und dem ausbleibenden breiten internationalen Erfolg einher.

Die Übersetzungsgeschichte von A maçã no escuro ins Englische zeigt jedenfalls, wie eine ganz hervorragende Übersetzung durchaus mit großen Schwierigkeiten in der Rezeption einhergehen konnte. Gray Díaz resümiert diesbezüglich: „Initial reviews of ME indicate a certain perplexity with its difficulties, but in Brazil at least reviewers knew that they were dealing with a major work" (Marting 1993: 97).

Man meint, einer ähnlich positiven Rezeption wie letztlich in Brasilien könne eigentlich nichts im Wege gestanden haben, wenn man liest, was Tanya T. Fayen schreibt:

He [Rabassa, Anm. LMK] has sensitively reproduced Lispector's delicate prose, from the intimate rhythm of each character's internal monologue to the subtlety of the lyrical quality of her prose. Lispector's use of alliteration is creatively and tenderly reproduced; the flow of words and the unexpected quality of her character's inner lives is captured. The translator seldom alters Lispector's punctuation and then not to obey English grammar but to maintain the original's fluidity.

(Marting 1993: 97-98)

Den Qualitäten dieser Übersetzung zum Trotz ist man in den USA nicht über die „perplexity with its difficulties“ hinausgekommen. Anders als bei anderen 
Texten Lispectors und wohl auch mit Blick auf den Umfang des Romans wurde keine der frühen, oftmals vergriffenen Übersetzungen des Romans, die in verschiedenen europäischen Sprache in den 1960er/1970er Jahren publiziert wurden, wieder neu aufgelegt - wäre dem nicht so, hätte man an einer solchen Ausgabe in gewisser Weise „messen“ können, wie sehr die mäßigen oder ganz ausbleibenden Reaktionen auf den Roman in ihrer Zeit verankert waren, wie sehr sie auch von eingefahrenen genderspezifischen Wahrnehmungsweisen bestimmt waren. Hier hat es keine weiterreichende Auseinandersetzung gegeben, mehr ein kurzes Innehalten angesichts der „perplexity“ der Literaturkritik. Auch hier wäre wohl ein weiterreichender Prozess der Auseinandersetzung vonnöten gewesen, um diesem Text gerecht zu werden, sodass die „Leerstelle“, die stattdessen entstanden ist, heute ins Auge fällt, betrachtet man das Gesamtwerk von Clarice Lispector und die zentrale Stellung von The Apple in the Dark darin, die in keinem Verhältnis zu der geringen Beachtung und der Nichtverfügbarkeit des Textes in vielen Sprachen steht. ${ }^{67}$

\subsubsection{The Hour of the Star - Zur physischen Dramatik in der Neuübersetzung}

Auch in den USA gab es wie in Frankreich und Deutschland mehrfache Übersetzungen eines Textes durch verschiedene Übersetzer, sodass man diese verschiedenen Übersetzungen ins Englische gewissermaßen „nebeneinanderlegen“ kann, was in Clarice Lispectors Fall immer hoch interessant ist, weil dieses Nebeneinanderlegen Aufschluss gibt über das Verwobensein verschiedener Aspekte: ästhetische Konventionen im Umgang mit ihren Arbeiten treffen auf die Herausforderung, aus dem brasilianischen Portugiesisch zu übersetzen, und werden mitunter darüber hinaus von genderbedingten Perspektiven beeinflusst. Zu The Hour of the Star liegt zunächst einmal eine Übersetzung durch Giovanni Pontiero aus dem Jahr 1986 vor, daneben die Neu-Übersetzung durch Benjamin Moser aus dem Jahr 2011, die im Rahmen einer Sonderausgabe zum 100jährigen Geburtstag der Autorin 2020 wiederaufgelegt und zusätzlich mit einem Nachwort von Paulo Gurgel Valente versehen wurde, eines der Söhne von Clarice Lispector.

Craig Morgan Teicher (2011) erzählt in Publisher's Weekly, wie Lispectors Biograph Benjamin Moser nach dem Erfolg seiner Biographie in den USA die Verlegerin Barbara Epler (New Directions, New York) davon abhielt, die

67 Ins Schwedische ist der Text allerdings 2009 unter dem Titel Äpplet I Mörkret übersetzt worden, vgl. Kap. 5.1. 
bestehende Übersetzung von Pontiero, eine seiner Meinung nach schlechte Übersetzung von Lispectors letztem Roman The Hour of the Star, neu aufzulegen. Nach Mosers Meinung sollte der Text unbedingt neu übersetzt werden, letztendlich übernahm er diese Übersetzung selbst, um Epler zu überzeugen: „You can’t say no to this guy“, wird sie zitiert. „He finally just put a bag over my head and clubbed me and said he'd do the translation himself in two or three weeks“ (Morgan Teicher 2011). Die Verlegerin meint, auch die vorige Übersetzung von Giovanni Pontiero habe ihre Qualitäten, wenngleich sie sehr anders sei als Benjamin Mosers Arbeit. Moser hingegen vertritt die Meinung, die vor den Neuausgaben im Rahmen des von ihm herausgegebenen New Retranslation Project zu Clarice Lispector (gleichzeitig bei New Directions in den USA und Penguin Modern Classics in England) vorliegenden, englischsprachigen Ausgaben seien überwiegend kaum lesbar gewesen: „The problem was the books were so badly translated most of them, not all of them - were almost unreadable in English. I got all this attention for her. I had hoped that someone like Barbara would take it upon them to re-translate her, and that's what happened“ (Morgan Teicher 2011). Moser hat nicht nur die Rezeption Lispectors massiv angekurbelt, sondern sie auch inhaltlich weit über den englischsprachigen Raum hinaus stark geprägt - gerade auch im Zusammenspiel mit seiner Biographie Why this World.

Darüber hinaus hat der irische Autor Colm Tóibín mit seinem Vorwort ${ }^{68} \mathrm{zu}$ der neuen Übersetzung von The Hour of the Star einen prägnanten, viel rezipierten Text zu Clarice Lispectors Person und ihrem Schaffen vorgelegt. Der Roman, der in Brasilien 1977 erschien, wenige Monate bevor Clarice Lispector im Dezember starb, verschaffte ihr postum einen - bescheidenen - internationalen Durchbruch und ist im englischsprachigen Raum stärker wertgeschätzt worden als jeder andere Roman Lispectors. ${ }^{69}$ Der nur wenige Seiten umfassende Begleittext von Tóibín veranschaulicht, wie wichtig der begleitende Kommentar für die Rezeption des oft als hermetisch oder rätselhaft wahrgenommenen Werkes Lispectors sein kann. Bereits früher hatte es vereinzelt Ausgaben gegeben, die Vor- oder Nachworte enthielten, so auch Giovanni Pontieros englischsprachige Übersetzung des Romans von 1986, an die sich ein Nachwort des Übersetzers anschließt, das in erster Linie eine Interpretation des Romans versucht. Tóibín hingegen legt in seinem Kommentar weniger eine bestimmte Lesart des folgenden literarischen Textes nahe, als dass er mehrere zentrale Aspekte von Clarice Lispectors Leben, ihres

68 In die deutsche Ausgabe des Romans bei Schöffling \& Co von 2016 ist dieser Text als Nachwort übernommen worden.

69 Vgl. auch Adaptationen in Bildmedien, etwa die Verfilmung des Romans von Suzana Amaral auf portugiesisch mit englischen Untertiteln (Hour of the Star, New York: Kino on Video, 2005). 
Schaffens und der Rezeption ihres Werkes anspricht. Zum Beispiel diesen: „The idea of Lispector as fleeting, oddly unreliable, complicated, someone who could vanish, as Bishop would have it, is essential to her work and her reputation“ (Tóibín 2011: viii). Wenn es wirklich ein Schlüssel zu ihrem Werk und ihrer Legende ist, dass die brasilianische Autorin oft unzuverlässig und unzugänglich wirkte, sich zu entziehen schien, dann ist es nicht sehr verwunderlich, dass Neuausgaben ihres Werkes besondere Beachtung finden, die ihre Texte mit Vor- und Nachworten zum Kontext, auch zu der Person der Autorin versehen. Tóibín kommentiert Lispectors Wurzeln in der Ukraine und die Flucht der jüdischen Familie vor den dortigen Pogromen, die von Benjamin Moser erstmals umfassend aufgearbeitet und kontextualisiert worden seien und, wie Tóibín schreibt, in Mosers Biographie erstmals in ihren erschütternden Einzelheiten geschildert werden. Tóibín zitiert Mosers Charakterisierung einer „unbeugsamen Individualität“ Lispectors („her inflexible individuality“) und schreibt, durch diese habe Lispector auf ihre Umgebung und ihre Leser eine ungeheure Faszination ausgeübt, „but there was always a sense that she was deeply mystified by the world, and uncomfortable with life itself, as indeed with narrative“ (Tóibín 2011: viii). Zum Eindruck der von Moser herausgestellten „unbeugsamen Individualität“ trägt auch ein wiederholt von Experten so oder in ähnlichem Sinne geäußertes, literarisches Urteil bei: „Lispector had, in common with Borges in his fiction, an ability to write as though the work's originality and freshness arrived in the world quite unexpected“ (Tóibín 2011: viii). Anhand des Borges-Vergleiches lässt sich nachvollziehen, wie sehr nicht nur die Übersetzungsgeschichte einen langen Prozess erforderte, sondern auch in der Publikations- und Rezeptionsgeschichte Lispectors langjährige Prozesse der Auseinandersetzung abliefen, bis beispielsweise der zunächst von Elisabeth Bishop geäußerte Vergleich mit Borges ${ }^{70}$ von Tóibín aufgegriffen wurde. Von der Konstatierung einer tragischen Vereinzelung und Unvergleichlichkeit, die die ersten Jahrzehnte der Rezeption durchziehen, gelangt man hier zu einem extrem positiven Werturteil ihrer mit Borges vergleichbaren Einzigartigkeit, der ihr Werk in verkaufsfördernder Weise flankiert: Sich auf ein Lispector-Buch nach einer solchen Ankündigung einzulassen, ihre so eigene Ästhetik auf sich wirken zu lassen, ist mitunter sicher einfacher, als sich ,unvorbereitet' mit dem literarischen Text und all seinem Irritationspotential auseinanderzusetzen, wenngleich dann mehr Raum für eigene Lesarten bliebe.

Zusammenfassend lässt sich sagen: All dies zusammen, der Eindruck des völlig Neuartigen, den ihre Texte verströmen, zusammen mit der Unnahbarkeit

70 Vgl. das Kapitel „Better than Borges“, Moser 2009. 
der Autorin, ihrem Sich-Entziehen, ist offenbar nicht ohne Belang, was die internationale Rezeption, was das Verständnis ihres Werkes und den Zugang dazu betraf. Die englischsprachige Ausgabe bei New Directions, die in Kooperation mit einer britischen Ausgabe bei Penguin Modern Classics erschien, greift diese Erfahrung mit der Publikation von Tóibíns Begleittext explizit auf.

Giovanni Pontiero hatte über den Inhalt des Romans noch geschrieben: „The nucleus of the narrative centres on the misfortunes of Macabéa, a humble girl from a region plagued by drought and poverty, whose future is determined by her inexperience, her ugliness and her total anonymity“ (Pontiero 1986: 90). Häufig ist betont worden, dass Clarice Lispector als Kind in der gleichen Region lebte, nachdem ihre Familie nach Brasilien emigriert war und bevor der Vater mit den Töchtern 1935 nach Rio de Janeiro umzog. Zentral an dem Text ist neben dem sozialkritischen Thema in ungewohntem Gewand - Lispector lässt Macabéas „misfortunes“ von einem männlichen Erzähler schildern, der die Frau gnadenlos ausnutzt - insbesondere die Erzählweise, die Tóibín in seinem Vorwort für Lispectors potentielle Leser in ein Bild fasst:

The Hour of the Star is like being brought backstage during the performance of a play and allowed odd glimpses of the actors and the audience, and further and more intense glimpses of the mechanics of the theater - the scene and costume changes, the creation of artifice - with many interruptions by the backstage staff. It is to be told in ironic, maybe mocking, whispers by the box office on the way out that those glimpses were in fact the whole performance, plotted out with care and attention by a writer who is still nervously watching from somewhere close, or somewhere in the distance, who may or may not even exist.

(Toíbín 2011: x)

Die Neuübersetzung The Hour of the Star bei New Directions ist nicht nur mit Tóibíns Vorwort versehen, das über sehr prägnante Bilder Wertschätzung für Lispectors Schaffen vermittelt, sondern auch mit einem richtungsweisenden Nachwort des Übersetzers Benjamin Moser. Er zitiert den Kommentar, Lispectors Übersetzer hätten sich immer wieder dazu verleiten lassen, die „Stachel aus dem Kaktus zu ziehen“"71, und misst dieser Tendenz eine zentrale Bedeutung in der Übersetzungsgeschichte bei. Über seine eigene Erfahrung beim Übersetzen schreibt er relativierend aber auch:

The tendency is understandable. It may even, to some extent, be inevitable. Clarice Lispector's weird word choices, strange syntax, and lack of interest in conventional grammar produces sentences - often fragments of sentences - that veer toward abstraction without ever quite reaching it. Her goal, mystical as well as artistic, was to rearrange conventional language to find meaning, but never to discard it completely.

(Moser 2011: 80)

71 Eine Formulierung der kanadischen Literaturwissenschaftlerin und Schriftstellerin Claire Varin, zitiert nach Moser 2011: 80. 
Wenn man verschiedene Fassungen zu Übersetzungen ihrer Texte vergleicht, finden sich immer wieder Schlüsselstellen, an denen genau dies passiert: Eine abstrakte Formulierung, die sich auf einen - oft dramatischen - inneren Zustand einer Figur bezieht, wird nicht recht verständlich, bleibt in einer Weise abstrakt, die die Dramatik der Szene nicht auszudrücken vermag. Dieser Effekt ließ sich bereits an den deutschen Übersetzungsvarianten zu Die Passion nach G.H. zeigen. In der ersten Übersetzung von Christiane Schrübbers sind abstrakte Formulierungen mehrfach kaum zu verstehen, wohingegen es in der überarbeiteten Fassung, die bei Suhrkamp erschien, an eben solchen Stellen gelingt, „to find meaning“, ohne die Fremdheit und Eigenheit der Lispector'schen Suche nach Bedeutung ,hinter den Worten' aufzulösen.

Insofern ist auch Mosers folgende Aussage zutreffend und wichtig:

Yet her books are not untranslatable. They are not littered with regionalisms, slang, puns, or inside jokes. Her meaning is almost always perfectly clear. The translator must therefore resist the temptation to explain or rearrange her prose, which can only flatten it and remove from it that "foreign" aura that is its hallmark, and its glory.

(Moser 2011: 80)

Lassen sich solche Dynamiken auch im Englischen konkreter machen? Welche Möglichkeiten gibt es, die frühe Übersetzung mit der Neuübersetzung des Romans $\mathrm{zu}$ vergleichen und die verschiedenen Fassungen auf solche Effekte hin zu prüfen? Es geht hier selbstverständlich nicht um einen umfassenden Übersetzungsvergleich, sondern allein um einen konkreten Aspekt. Vergleicht man Mosers The Hour of the Star von 2011 mit der älteren Fassung des zum Zeitpunkt der Übersetzung bereits renommierten Literaturübersetzers Giovanni Pontiero ${ }^{72}$, so fällt zunächst der große Unterschied der Übersetzungen hinsichtlich der Erzählstimme auf. Moser wählt ein anderes, jüngeres Sprachregister, orientiert sich mehr an einer gesprochenen, klingenden Sprache, sodass sich im Vergleich zu der bei Pontiero gewählten ein ,verlebendigender Effekt‘ einstellt. Dies prägt bereits den ersten Satz des Textes in „The Autor's Dedication (alias Clarice Lispector)“. Bei Pontiero heißt es: „I dedicate this narrative to dear old Schumann and his beloved Clara who are now, alas, nothing but dust and ashes“ (Lispector 1992b: 7). Moser: „So I dedicate this thing here to old Schumann and his sweet Clara who today alas are bones. “73 Ungeachtet der Entstehungszeit in den 1970er Jahren bzw. des Erscheinens der Moser-Übersetzung 2011 spricht aus Mosers Einstieg eine grundlegend andere Haltung dem Text gegenüber als bei

72 Hier in der britischen Ausgabe von Carcanet, 1986 - Pontiero hat für Carcanet mehrere Lispector-Texte übersetzt, vgl. die Übersicht in Kap. 4.3.1.

73 „Pois que dedico esta coisa aí ao antigo Schumann e sua doce Clara que são hoje ossos, ai de nós.“ (Lispector 2002a [1977]: 9). 
Pontiero. Diese Übersetzungsvarianten werden so zu einem weiteren Beispiel dafür, dass Übersetzung auch Autorschaft bedeutet. Inwiefern Moser näher am Original ist, welche Übersetzung besser ist als die andere - solche Fragen sollen hier nicht näher erörtert werden. Vielmehr geht es darum, darauf aufmerksam zu machen, auf welche Weise solch grundverschiedene Zugänge zu einem Text durch verschiedene Übersetzer die Rezeption prägen.

Bezüglich der beiden Übersetzungen von Pontiero und Moser fällt erneut ein Thema ins Gewicht, das mit der Tatsache zu tun hat, dass die meisten Texte Lispectors innere Zustände erkunden, Unausgesprochenes zugänglich machen. Wie sich bereits an den deutschen Übersetzungen zu Die Passion nach G.H. gezeigt hat, ist es dabei von großer Bedeutung, ob ein Text sich in Abstraktionen ergeht, die nicht recht zugänglich werden, oder sich innere Dramatik auch physisch vermittelt. Man betrachte einmal einige der 13 Titelvarianten, die Lispector dem Text A Hora da Estrela voranstellt, in den verschiedenenen englischsprachigen Übersetzungen.

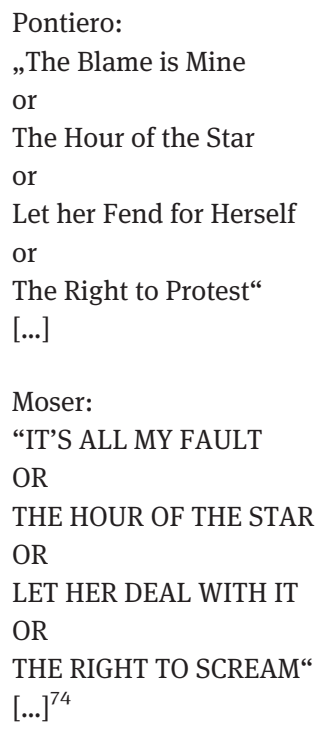

The right to scream. Dies erinnert wieder an einen Effekt, den man häufig findet in überarbeiteten oder neu übersetzten Lispector-Texten: Eine Tendenz weg von Abstraktionen und hin zu dramatischeren, physischeren Bildern. „The right to protest“ kann vieles sein, ein leiser, ein lauter, ein stummer Protest usw. „The

74 „A CULPA É MINHA / OU / A HORA DA ESTRELA / OU / ELA QUE SE ARRANJE / OU / O DIREITO AO GRITO [...]““ (Lispector 2002a [1977]: 11). 
right to scream“ hingegen weckt ein Bild von Dringlichkeit, von Schmerz und Lautstärke, ein physisches Bild.

Ein anderes Beispiel: Macabea erzählt am Ende des Buches - und ihres jungen Lebens - einer Wahrsagerin von sich selbst:

- Eu era pobre, comia mal, não tinha roupas boas. Então caí na vida. E gostei porque sou uma pessoa muito carinhosa, tinha carinho por todos os homens. Além do mais, na zona era divertido porque havia muita conversa entre as coleguinhas. Nós éramos muito unidas e só de vez em quando eu me atracava com uma. Mas isso também era bom, porque eu era muito forte e gostava de bater, de puxar cabelos e morder. Por falar em morder, você não pode imaginar que dentes lindos eu tinha, todos branquinhos e brilhantes. Mas se estragaram tanto que hoje uso dentadura postiça. Você acha que se nota que são postiços?

(Lispector 2002a [1977]: 80)

\section{Bei Pontiero heißt es:}

I was poor, I had nothing to eat, no decent clothes to wear. So I became a prostitute. I quite enjoyed the work for I'm a very affectionate woman, and I became very fond of all my clients. Besides, life was good in the red-light district. There was a great deal of friendship among the prostitutes. We were a closely-knit community, and only very rarely did I fight with any of the other girls. The quarrels were enjoyable, too, for I was a sturdy lass and I enjoyed punching, biting, and pulling the hair of anyone who crossed me. Speaking of biting, you can't imagine what lovely teeth I once had, all white and sparkling. Alas, they rotted so badly that I'm left with dentures. Can you tell that my teeth are false?

(Lispector 1992b: 73)

Moser macht den Schmerz spürbarer, der in diesen Zeilen steckt, ohne auf die Naivität der Sprecherin zu verzichten:

I was poor, I hardly had anything to eat, I didn't have nice clothes. So I ended up working [stärker impliziert ist hier das Ausweglose: Arbeiten war in ihrer Situation gleich Prostitution. Nur eine Prostituierte würde diese Worte wählen, während „I became a prostitute“ sachlicher klingt und mehr an der Perspektive des Zuhörers orientiert ist, Anm. LMK]. And I liked it because I'm a very sweet person, I was sweet to all the men [Hier wird eine besondere Tragik dieser Figur angespielt - das Thema durchzieht das ganze Buch - die Tragik, die darin liegt, dass Macabea sich ihrer Misere nicht bewusst ist. Dass der Umkehrschluss „,all men were sweet to me" sicher nicht gilt, wird an anderer Stelle deutlich, und schwingt hier bereits mit, Anm. $L M K]$. Besides, it was fun in the zone because the girls all hung out together. We had each other's backs and only every once in a while did I get into a fight with any of them. But that was good, too, because I was really strong and liked to throw punches, pull hair and bite. Speaking of biting, you can't imagine how gorgeous my teeth were, all white and sparkling. But they got ruined and now I have false teeth. You think people can tell they are false?

(Lispector 2011: 64-65)

Aus all dem spricht ein großes Ringen um Würde, ein Bedürfnis, schön und anziehend gefunden zu werden, dafür anerkannt zu sein, dass sie ihre Arbeit gut mache. Macabéa beklagt sich nicht, sondern bleibt auch in den demütigendsten Momenten auf die anderen, auf deren Urteil bedacht - der Text ist gerade 
deshalb so beklemmend, weil sie sich der Unerträglichkeit der Situation nicht bewusst wird. Das Entsetzen über Macabeas Lebensbedingungen bleibt ganz den Leser/innen überlassen, und Moser rückt es ihnen, so könnte man sagen, über einen direkteren, emotionaleren, physischeren Zugang zu dieser Figur näher als es bei Pontiero der Fall ist. In dem mit der Sonderausgabe 2020 erschienenen Nachwort von Paulo Gurgel Valente, tituliert „My mother, between Reality and Fiction“ wird diese Übersetzungsstrategie flankiert von der persönlichen Sicht des Sohnes auf die lebenslange Suche Clarice Lispectors nach literarischen Ausdrucksformen für ihr Bestreben, soziale Veränderungen in der brasilianischen Gesellschaft $\mathrm{zu}$ befördern, nach einer Integration ihrer Haltung zu sozialen Fragen in ihre Literatur. Er stellt dabei eine Verbindung her zu früheren Episoden ihrer Biographie und auch zu früheren Texten, unter anderem A paixão segundo G.H.

\subsubsection{Nach 2009: Rezeptionswelle in den USA}

Zur Zeit der Publikation der Neuübersetzung The Hour of The Star 2011 in den USA nahm gerade eine neue Rezeptionswelle im englischsprachigen Raum und insbesondere in den USA Fahrt auf, die 2009 mit der Publikation der ersten englischsprachigen Biographie langsam angestiegen war und 2015 auf ihrem Höhepunkt ankam. 2009 war Benjamin Mosers viel beachtete Lispector-Biographie in den USA erschienen, darauf folgten eine Reihe von Romanen und 2015 erstmals auch die gesammelten Erzählungen. Im Interview kommentierte Moser einmal, wie wichtig es für ihn gewesen sei, dieses Werk in so wenigen Jahren herauszugeben, weil er dadurch die Zusammenhänge unter den verschiedenen Texten (,the echoes“, vgl. Esposito 2011) besser habe im Blick behalten können. The Complete Stories erschien 2015 in der Übersetzung von Katrina Dodson, ebenfalls von Benjamin Moser herausgegeben. Der Literatur- und Filmkritiker Scott Esposito (The Paris Review) kommentiert den für eine so lange verstorbene Autorin bemerkenswerten Wiederentdeckungseffekt, der so maßgeblich von Moser angestoßen ist, im Sommer 2015 wie folgt:

I've gotten accustomed to talking about the ,Clarice Lispector tidal wave'. For weeks on end, I've scarcely been able to go online without seeing Lispector, who died in 1977, raved about, serialized, reviewed, discussed, or marveled at.

(Esposito 2015)

Bemerkenswert an dieser neuen Aufmerksamkeit für Clarice Lispector ist, wie stark ihre Rezeption von der Figur Benjamin Moser beeinflusst und - ja, man möchte schon sagen: hervorgebracht ist. Er hat die entscheidende Biographie geschrieben, die das Leben und Schaffen der Autorin für den westlichen europäischen/US-amerikanischen Literaturbetrieb überhaupt zugänglich macht, er 
überzeugte den US-amerikanischen Verlag New Directions von dem Neu-Übersetzungsprojekt und lieferte die Übersetzung des ersten Romans innerhalb kürzester Zeit selbst, er ist mit Kommentaren, Interviews und Lispector-Schwerpunkten in den Literaturzeitschriften ${ }^{75}$ verschiedener Länder vertreten.

Sieht man sich einmal die Kommentare in der US-amerikanischen Presse an, die die „Clarice Lispector tidal wave“ begleiten, fällt auf, dass bestimmte Elemente oder Narrative - vergleichbar mit der Literaturkritik in Deutschland, nur mit etwas anderen Themen - in den verschiedenen Kommentaren immer wieder aufgegriffen und in besonderer Weise herausgehoben werden. In den USA ist eines der bestimmenden Themen die Schönheit der Autorin, manchmal in Kombination mit anderen Persönlichkeitsaspekten oder Gewohnheiten, die etwas Dramatisches an sich haben bzw. offenbar Aufmerksamkeit erregen sollen für diese längst verstorbene Autorin. Oftmals sind es Kommentare zu ihrer ,schwierigen', ,mysteriösen“ Persönlichkeit oder zu ihrer Tablettensucht in den letzten Lebensjahren. Man beachte einmal den Einstieg von Ian Thomson (2014) zu einer Rezension der Moser-Biographie in The Spectator:

The brazilian novelist Clarice Lispector was a riddlesome and strange personality. Strikingly beautiful, with catlike green eyes, she died in Rio de Janeiro in 1977 at the age of only 57. Some said she wrote like Virginia Woolf (not necessarily a recommendation) and resembled Marlene Dietrich. She was, very, very sexy', remembered a friend. Yet she needed a great many cigarettes, pain-killers, anti-depressants, as well as anti-psychotics and sleeping pills to get through her final years.

The New York Times titelte 2005 in Anspielung auf die Sogwirkung, die Lispectors Literatur immer wieder auf Rezipientinnen und Rezipienten ausgeübt hat: „An Enigmatic Author who can be addictive“. Ein Times-Artikel, der im März 2005 eine Veranstaltung über Lispector mit Gregory Rabassa und Earl Fitz im Center for Jewish History in New York ankündigt, beginnt mit einem Verweis auf die verführerische Kraft der Autorin: „When Gregory Rabassa talks about Clarice Lispector, it is evident that his infatuation with her isn't purely literary., Those blue eyes, right out of Thomas Mann, ,The Magic Mountain', he sighed, during a recent interview. ,She was so beautiful““ (Salamon 2005).

75 Vgl. die entsprechenden Ausgaben von The Paris Review in New York, Schreibheft in Deutschland, für den französischsprachigen Raum vgl. das Appendix in Peixoto Cherem (2013). 


\subsubsection{Eine Neubewertung des Werkes}

Neben dem Versuch, für eine lange verstorbene Autorin Aufmerksamkeit durch das Aufrufen exzentrischer Eigenschaften und betörender Schönheit zu erzielen und gleichzeitig die ,mysteriöse' Clarice Lispector doch noch ein wenig auf bestimmte Eigenschaften festzuschreiben, durchzieht die US-amerikanische Presse der Jahre nach der Jahrtausendwende auch eine Neubewertung des Werks. Während die US-amerikanische Literaturkritik zunächst positiver auf The Hour of the Star reagiert hatte als auf das in Brasilien und in einigen anderen Kontexten von vielen Kritikern als wichtigstes Werk erachtete The Passion According to G.H., übernehmen mehrere einflussreiche US-amerikanische Kommentator/innen nun letztere Einschätzung. Vermutlich geschieht dies auf der Grundlage von Mosers Urteil, das viele Rezensent/innen in den USA entweder zitieren oder gleich übernehmen: Er hatte den Text als „masterpiece“ und „one of the greatest novels of the 20th century“ bezeichnet. ${ }^{76}$ Auch weitere Einschätzungen von Moser prägen die US-amerikanische Literaturkritik: Lispector sei die wichtigste weibliche Autorin des 20. Jahrhunderts aus Brasilien, Lispector sei darüber hinaus „The most important Jewish writer since Kafka“ (vgl Ian Thomson 2014). Das ebenfalls auf Mosers Darstellung zurückgehende Narrativ um die Schwangerschaft von Lispectors syphiliskranker Mutter, die nach einem russischen Volksglauben eine Frau von der Krankheit hätte heilen können, das in Deutschland immer wieder eingebracht worden ist, spielt in den USA kaum eine Rolle. Die Interpretation um die ,doppelte Tragik' in Lispectors Biographie durch den Verlust der Mutter in der Kindheit und die schwere Krankheit ihres Sohnes Pedro, denen sie beiden nicht helfen konnte, bietet allerdings einen schnell skizzierten, sehr plakativen und eindringlichen Zugang zu der schwierigen, unzugänglichen, von manchen als tragisch dargestellten Seite Clarice Lispectors. Offensichtlich ist diese psychologisierende Variante in Deutschland verbreiteter als in den USA. Zu finden ist sie vereinzelt und in leicht veränderter Form aber auch in der US-amerikanischen Literaturkritik: So tritt dieses Narrativ bei Nicholas Shakespeare (2014) wieder zuTage. Er spitzt es folgendermaßen zu: „Lispector was created to save her mother, but for her first nine years she was forced to watch her exiled parent dying painfully before her eyes.“ Er spielt auf den besagten Volksglauben an, dass eine Schwangerschaft von der Syphilis heilen könne - aber daraus zu machen „Lispector was created to save her mother“ ist noch einmal eine Inszenierungsstufe über der Aussage „For her first nine years she was forced to watch her

76 Vgl. dazu beispielsweise Shakespeare 2014: „In 1964, she wrote what many regard as her masterpiece.“ 
exiled parent dying painfully before her eyes“, die eine fragile psychische Disposition erklären soll. Die Sensation, die Lust am Erzählen besonders drastischer und einleuchtender Dramatik haben die Berichterstattung über Lispector zweifellos sehr geprägt, wenn auch in den USA auf etwas andere Weise als in Deutschland.

Ein Thema, auf das in den USA immer wieder besonders Bezug genommen wird, ist die Überraschung der Kritiker darüber, wie bekannt und hoch verehrt Lispector in Brasilien selbst sei, während man sie in den USA noch gar nicht kenne. Sehr deutlich wird darüber hinaus, sieht man die US-amerikanische Presse zur Rezeptionswelle um Lispector seit 2005 durch - gerade auch in den kritischen Beiträgen wird dies transparent - wie stark einzelne Figuren für den ,plötzlichen Hype` um Clarice Lispector in den USA eine tragende Rolle spielen: An erster Stelle Moser, aber auch die Übersetzerin Elisabeth Bishop wird immer wieder genannt, dann Rabassa, der als Übersetzer einiger zentraler Romane des lateinamerikanischen Boom in den USA Berühmtheit erlangt hat, auch jemand wie Earl Fitz, der zudem mit Vanderbuilt eine in den USA sehr renommierte Institution vertritt.

Deutlich wird im Kontext der Rezeptionswelle in den USA auch, wie sehr Lispectors Literatur noch heute polarisiert. Worum es in dieser Debatte in der US-amerikanischen Literaturkritik um die Qualität von Lispectors Literatur im Kern geht, lässt sich gut erschließen, indem man zwei der markantesten und einflussreichsten Stimmen einmal zusammen betrachtet. Interessanterweise beziehen sich Nicholas Shakespeare (The Telegraph) und J.D. Daniels (The Paris Review), beide selbst erfolgreiche Autoren, in dieser Frage auf den gleichen Punkt, auch wenn sie konträre Auffassungen vertreten.

Nicholas Shakespeare kritisiert die große Anerkennung für Lispectors Werk in den USA recht scharf, er kritisiert den häufig unternommenen Vergleich mit Autoren wie Kafka, Woolf und Joyce, und disqualifiziert Lispectors Schaffen, indem er schreibt: „To read Lispector is to watch a sleepwalker with eyes open groping towards an unknown destination, or a woman at a seance practicing automatic writing in order to discover what she actually thinks." Er schließt sich nach einer Lektüre des Romans The Passion According to G.H. und offenbar auch weiterer Lispector-Romane einer Rezeptionskultur an, die er auf Lispectors ersten amerikanischen Verleger zurückführt: „Alfred Knopf, though, spoke for a majority of more mature readers when he declared, after finishing Lispector's novel The Apple in the Dark, that he ,didn't understand a word of it‘." (Shakespeare 2014).

Er fährt folgendermaßen fort:

It grieves me to find myself tilting with some reluctance in Knopf's direction. After approaching Lispector with a delicious sense of anticipation and then feasting at her for a fort- 
night, I have to report that the result is wildly hit and miss, producing a lot of what Evelyn Waugh called "gibberish", and morbidly insensitive to readers who thirst for plot, character development, lucidity, precision, irony, excitement and humour [...].

Um dies noch einmal zusammenzufassen: Ihm fehle Handlung, Charakterentwicklung, Genauigkeit, Aufregung/Spannung, Humor, Lispector lesen sei in etwa so, wie dabei zusehen, wie jemand ungeordnete Gedanken, automatisches Schreiben produziere.

Wenn man sich nun einmal den Essay von J.D. Daniels ansieht, den dieser 2017 als Einstieg in eine Lispector-Veranstaltung geschrieben und dann im Mai desselben Jahres bei The Paris Review publiziert hat, fällt auf, dass er sich auf einen ähnlichen Punkt wie Shakespeare bezieht, nur mit einem gänzlich anderen Urteil dazu. Er zitiert Lispector: „, Coherence‘, says Lispector, ,I don’t want it any more.' Coherence is mutilation. I want disorder. I can only guess at it through a vehement incoherence.““ Daniels kommentiert: „Let's talk about this single aspect of Lispector. I'm going to tell you not just why her work is so important, why I think she is so important, but how I think it, the way in which I think that thought. " Was dann folgt, ist eine hoch interessante Auseinandersetzung mit einer Kontextualisierung des Inkohärenten mit der vorbewusstlichen Erfahrung bzw. mit verschiedenen Ebenen und Aspekten des ,unknown' (z. B. in Bezug auf Beckett, mit Bion: „What matters is the unknown“). Letztlich verortet Daniels Lispector nicht mehr bei Kafka und Joyce, sondern bei Beckett und Lacan. Und hier kommt auch wieder die Genderfrage zum Tragen: „I think the work of Lispector, as a whole, is the Moby-Dick of a certain kind of feminity: the female relationship to the female body. The mother's body is the origin, the great original mystery. Maybe only a woman could write this well, in this way." Es schließt sich der Kreis zum eingangs skizzierten Thema des „Addictive“: „I am not an intellectual“, Lispector says, „I write with my body“. I read this sentence of hers, and she changed my life“ (Daniels 2017). Hier ist wohl etwas angesprochen, was Clarice Lispector selbst immer wieder hervorgehoben hat, wenn sie sich darum bemühte, die Dinge hinter den Worten' zu finden. Ihr Sohn Paulo Gurgel Valente hebt diesen Aspekt in seinem 2020 erschienenen Nachwort zu einer Sonderausgabe von The Hour of the Star bei New Directions in New York hervor, indem er eine Antwort seiner Mutter auf die Frage, warum sie schreibe, aus dem Jahr 1975 zitiert:

My books are not much concerned with facts themselves because, for me, the important thing isn't facts in and of themselves, but the impact of those facts on the individual. That's what really matters. That's what I do. And I think that, in this sense, I also make books that are engaged with man and his reality, because reality is not a purely external phenomenon.“

(Gurgel Valente 2020) 
Sie bewegt sich mit diesem Anspruch sehr weit jenseits von Rezeptionserwartungen wie Plot, kohärenter Handlungsführung, ironischer Distanz, auch einer bestimmten Art von Humor. Darin liegt nicht zuletzt auch der Umstand begründet, dass ihr Werk einerseits nur so zögerlich auch im Ausland anerkannt wurde, und andererseits so passionierte wie einflussreiche Befürworter auf den Plan gerufen hat. Dieser Widerspruch von Ablehnung und höchster Anerkennung für ihre Literatur hat die internationale Zirkulation und Rezeption von Clarice Lispectors Werk immens geprägt, ohne in seiner großen Wirkungsmacht bisher ins Bewusstsein gerückt worden zu sein. Daher ist es wertvoll, dass diese Zusammenhänge in der US-amerikanischen Literaturkritik inzwischen offensichtlicher geworden sind - wenngleich auch nach wie vor nur in der $\mathrm{Zu}$ sammenschau extrem kontroverser Positionen. 